\title{
RESRAD Benchmarking Against Six Radiation Exposure Pathway Models
}

by E.R. Faillace, J.-J. Cheng, and C. Yu

Environmental Assessment Division,

Argonne National Laboratory, 9700 South Cass Avenue, Argonne, Illinois 60439

Work sponsored by United States Department of Energy,

Assistant Secretary for Environment, Safety and Health,

Office of Environmental Guidance, and

Assistant Secretary for Environmental Management,

Office of Environmental Restoration 


\section{DISCLAIMER}

Portions of this document may be illegible electronic image products. Images are produced from the best available original document. 


\section{CONTENTS}

ACKNOWLEDGMENTS $\ldots \ldots \ldots \ldots \ldots \ldots \ldots \ldots \ldots \ldots \ldots \ldots \ldots$ vii

NOTATION $\ldots \ldots \ldots \ldots \ldots \ldots \ldots \ldots \ldots \ldots \ldots \ldots \ldots \ldots \ldots$ viii

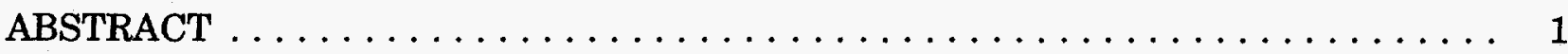

$1 \quad$ INTRODUCTION $\ldots \ldots \ldots \ldots \ldots \ldots \ldots \ldots \ldots \ldots \ldots \ldots \ldots \ldots$

2 BENCHMARKING AGAINST GENII-S, DECOM, PRESTO-EPA-CPG,

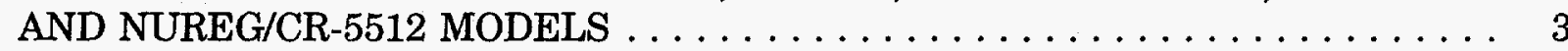

2.1 Model Descriptions . . . . . . . . . . . . . . . . . . . . 3

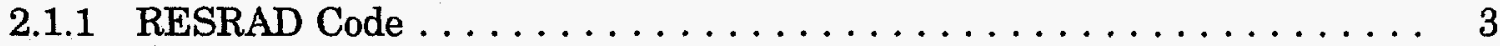

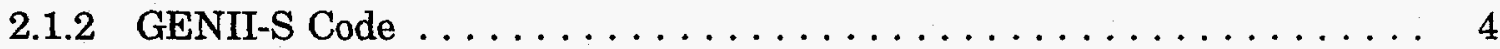

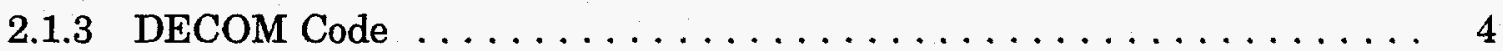

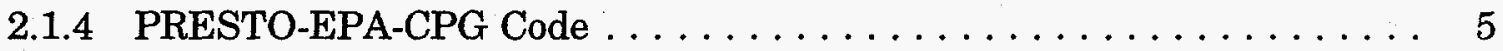

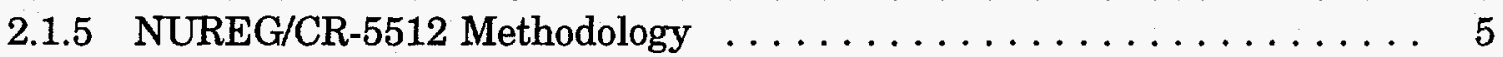

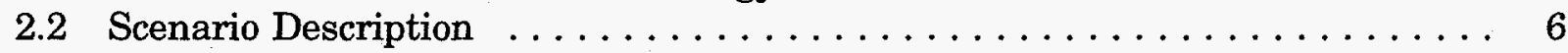

2.3 Benchmarking Results - Time Zero $\ldots \ldots \ldots \ldots \ldots \ldots$

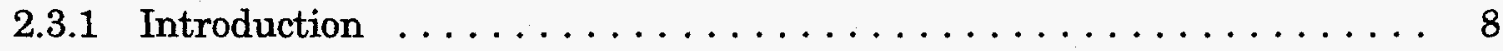

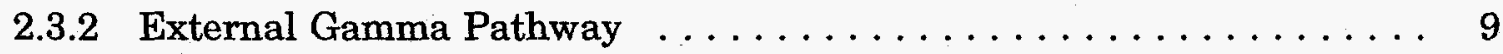

2.3.2.1 RESRAD vs. GENII-S .................... 9

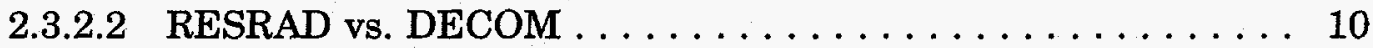

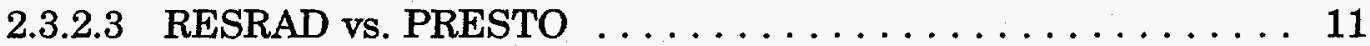

2.3.2.4 RESRAD vs. NUREG/CR-5512 . . . . . . . . . . . . . 13

2.3.2.5 Summary of the External Gamma Pathway . . . . . . . . 13

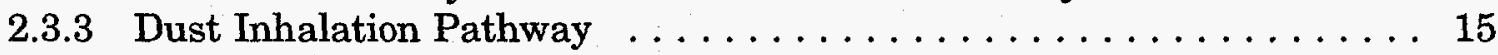

2.3.3.1 RESRAD vs. GENII-S . . . . . . . . . . . . . 15

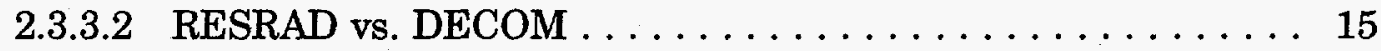

2.3.3.3 RESRAD vs. PRESTO . . . . . . . . . . . . . 16

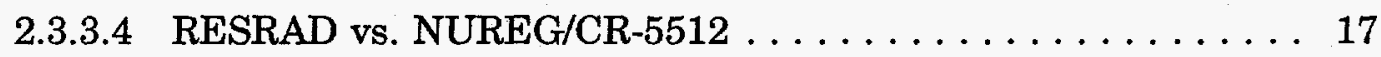

2.3.3.5 Summary of the Inhalation Pathway . . . . . . . . . 17

2.3.4 Soil Ingestion Pathway $\ldots \ldots \ldots \ldots \ldots \ldots \ldots \ldots \ldots \ldots \ldots \ldots$

2.3.4.1 RESRAD vs. GENII-S . . . . . . . . . . . . . . . . 19

2.3.4.2 RESRAD vs. NUREG/CR-5512 . . . . . . . . . . . . . . 19

2.3.4.3 Summary of the Soil Ingestion Pathway . . . . . . . . . . . 19

2.3 .5 Food Ingestion Pathways . . . . . . . . . . . . . . . 20

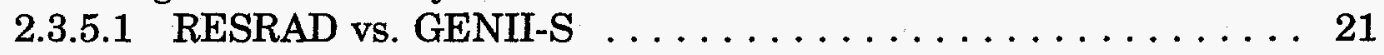

2.3 .5 .2 RESRAD vs. DECOM . . . . . . . . . . . . . 23

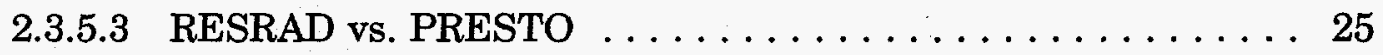

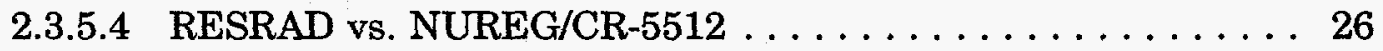

2.3.5.5 Summary of the Food Ingestion Pathways . . . . . . . . 28

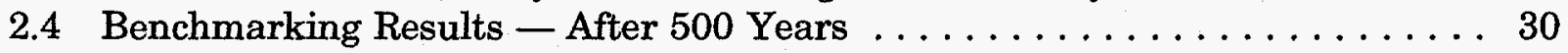

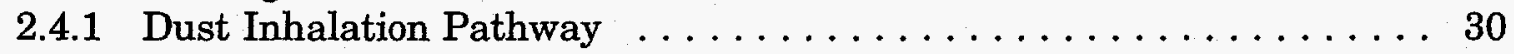

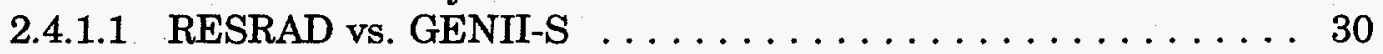

2.4.1.2 RESRAD vs. DECOM . . . . . . . . . . . . . 31

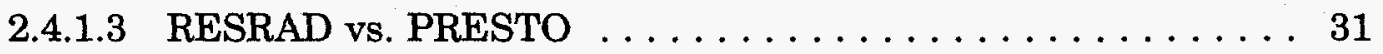


2.4.1.4 RESRAD vs. NUREG/CR-5512 . . . . . . . . . . . . . . 31

2.4.1.5 Summary of the Inhalation Pathway after 500 Years . . . . . 33

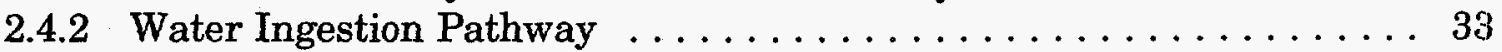

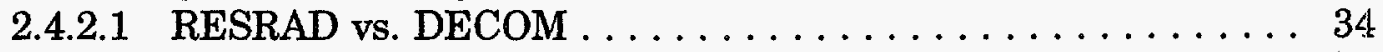

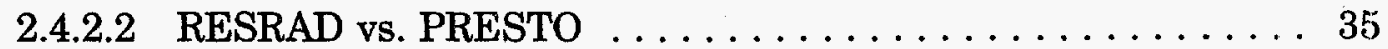

2.5 Radionuclide Decay and Ingrowth - RESRAD vs. GENII-S . . . . . . . . . 35

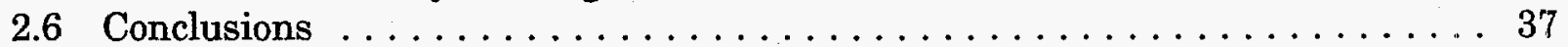

3 BENCHMARKING AGAINST GENII AND PATHRAE $\ldots \ldots \ldots \ldots \ldots$

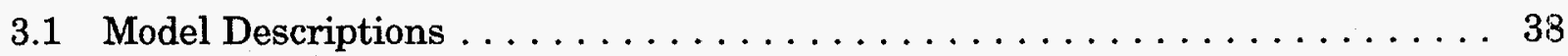

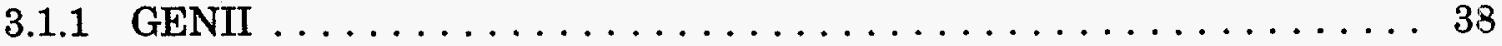

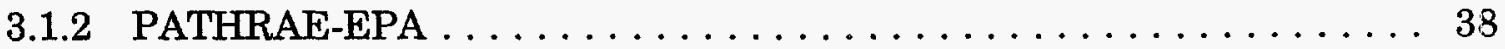

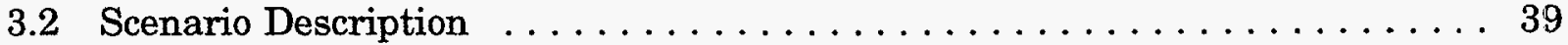

3.3 Comparison of Input Parameters $\ldots \ldots \ldots \ldots \ldots \ldots \ldots \ldots \ldots \ldots$

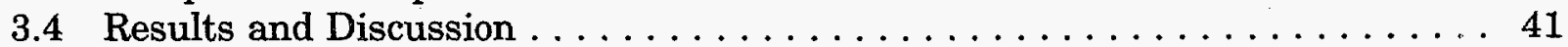

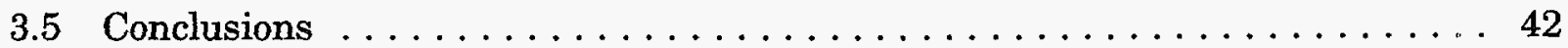

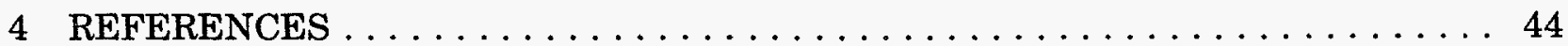

APPENDIX: Benchmarking RESRAD Radiation Dose Results against Data from DOE/LLW-188 . . . . . . . . . . . . . . . . . A A-1

\section{TABLES}

1 Comparison of External Dose Calculations, RESRAD vs. GENII-S $\ldots \ldots \ldots \ldots$

2 Comparison of External Dose Calculations, RESRAD vs. DECOM . . . . . . 11

3 Comparison of External Dose Calculations, RESRAD vs. PRESTO . . . . . . . 12

4 Comparison of External Dose Calculations, RESRAD vs. NUREG/CR-5512 . . . . 13

5 Comparison of External Dose Calculations, All Models . . . . . . . . . . . . 14

6 Comparison of Dust Inhalation Dose Calculations, RESRAD vs. GENII-S . . . . . 16

7 Comparison of Dust Inhalation Dose Calculations, RESRAD vs. DECOM _. . . . 16

8 Comparison of Dust Inhalation Dose Calculations, RESRAD vs. PRESTO . . . . . 17

9 Comparison of Dust Inhalation Dose Calculations,

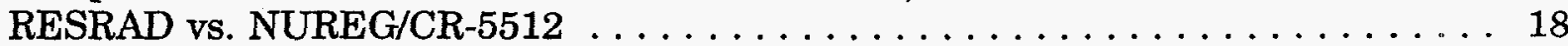

10 Comparison of Dust Inhalation Dose Calculations, All Models . . . . . . . . 18 


\section{TABLES (Cont.)}

11 Comparison of Soil Ingestion Dose Calculations, RESRAD vs. GENII-S $\ldots \ldots \ldots 19$

12 Comparison of Soil Ingestion Dose Calculations,

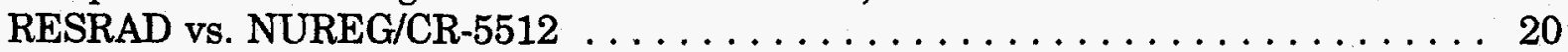

13 Comparison of Soil Ingestion Dose Calculations, All Models $\ldots \ldots \ldots \ldots \ldots$

14 Comparison of Food Ingestion Dose Calculations, RESRAD vs. GENII-S . . . . . . 22

15 Comparison of Food Ingestion Dose Calculations, RESRAD vs. DECOM . . . . . 24

16 Comparison of Food Ingestion Dose Calculations, RESRAD vs. PRESTO . . . . . 25

17 Comparison of Food Ingestion Dose Calculations,

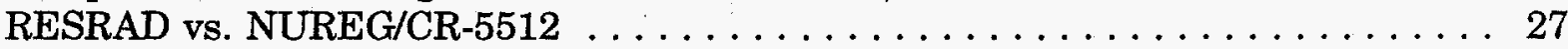

18 Comparison of Food Ingestion Dose Calculations, All Models . . . . . . . . . . 29

19 Comparison of Dust Inhalation Dose Calculations, RESRAD vs. GENII-S . . . . . 31

20 Comparison of Dust Inhalation Dose Calculations, RESRAD vs. DECOM . . . . . 32

21 Comparison of Dust Inhalation Dose Calculations, RESRAD vs. PRESTO . . . . . 32

22 Comparison of Dust Inhalation Dose Calculations, RESRAD vs. NUREG/CR-5512 . . . . . . . . . . . . . . . . 32

23 Comparison of Dust Inhalation Dose Calculations, All Models $\ldots \ldots \ldots \ldots \ldots 33$

24 Comparison of Water Ingestion Dose Calculations, RESRAD vs. DECOM . . . . . 34

25 Comparison of Inhalation Doses due to Ingrowth of Am-241 from Pu-241, RESRAD vs. GENII-S . . . . . . . . . . . . . . . . . . . 36

26 Parameter Values Used in the GENII and PATHRAE Codes $\ldots \ldots \ldots \ldots \ldots 39$

27 Parameter Values Used in the RESRAD Code $\ldots \ldots \ldots \ldots \ldots \ldots \ldots \ldots$

28 Comparison of RESRAD Results with GENII

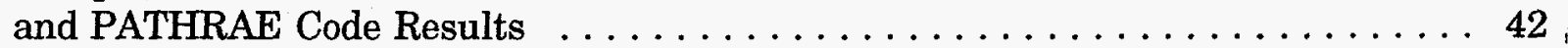

29 Comparison of RESRAD, GENII, and PATHRAE Relative Radiation Doses . . . . . . . . . . . . . . . . . . . . . . 43

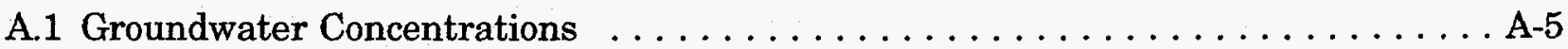

A.2 Input Parameters Used in Seitz et al. 1994 Benchmarking Report . . . . . . . . A-6 


\section{TABLES (Cont.)}

A.3 Input Parameters Used in BENCH1.DAT for RESRAD $\ldots \ldots \ldots \ldots \ldots \ldots$ A-7

A.4 Comparison of External Radiation Doses from a Unit Soil Concentration . . . . A A-8

A.5 Comparison of Inhalation Radiation Doses from a Unit Soil Concentration $\ldots \ldots \ldots \ldots \ldots \ldots \ldots \ldots \ldots \ldots \ldots \ldots \ldots \ldots \ldots \ldots$

A.6 Comparison of Drinking Water Ingestion Doses from a Unit Water Concentration $\ldots \ldots \ldots \ldots \ldots \ldots \ldots \ldots \ldots \ldots \ldots \ldots \ldots$

A.7 Comparison of Plant Ingestion Doses from a Unit Soil Concentration . . . . . . A A-9

A.8 Comparison of Plant Ingestion Doses from a Unit Water Concentration . . . . . A A-10

A.9 Comparison of Meat Ingestion Doses from a Unit Water Concentration . . . . . A-10

A.10 Comparison of Milk Ingestion Doses from a Unit Water Concentration . . . . A A-11 


\section{ACKNOWLEDGMENTS}

The authors would like to thank Eric Martell for compiling preliminary results, W. Alexander Williams, Hal Peterson, and Andy Wallo for reviewing the draft report, Bruce Napier for providing comments on GENII and GENII-S results, and Roger Seitz for providing copies of the DOE/LLW-188 report. 


\section{NOTATION}

The following is a list of acronyms, initialisms, and abbreviations (including units of measure) used in this document. Some acronyms used in tables only are defined in the respective tables.

\section{ACRONYMS, INITIALISMS, AND ABBREVIATIONS}

$\begin{array}{ll}\mathrm{Ac} & \text { actinium } \\ \mathrm{Am} & \text { americium } \\ \mathrm{C} & \text { carbon } \\ \mathrm{Co} & \text { cobalt } \\ \mathrm{Cs} & \text { cesium } \\ \mathrm{DOE} & \text { U.S. Department of Energy } \\ \mathrm{EPA} & \text { U.S. Environmental Protection Agency } \\ \mathrm{H} & \text { hydrogen } \\ \mathrm{I} & \text { iodine } \\ \mathrm{Ni} & \text { nickel } \\ \mathrm{Np} & \text { neptunium } \\ \mathrm{NUREG} / \mathrm{CR} & \text { U.S. Nuclear Regulatory Commission reports category } \\ \mathrm{Pa} & \text { protactinium } \\ \mathrm{Pb} & \text { lead } \\ \mathrm{Pu} & \text { plutonium } \\ \mathrm{Ra} & \text { radium } \\ \mathrm{Sr} & \text { strontium } \\ \mathrm{Tc} & \text { technetium } \\ \mathrm{Th} & \text { thorium } \\ \mathrm{U} & \text { uranium } \\ \mathrm{Y} & \text { yttrium }\end{array}$

\section{UNITS OF MEASURE}

$\begin{array}{llll}\mathrm{Bq} & \text { becquerel(s) } & \mathrm{m}^{3} & \text { cubic meter(s) } \\ \mathrm{Ci} & \text { curie(s) } & \mathrm{mrem} & \begin{array}{l}\text { millirem(s) } \\ \text { second(s) }\end{array} \\ \mathrm{pCi} & \text { picocurie(s) } & \mathrm{s} & \text { sievert(s) } \\ \mu \mathrm{Ci} & \text { microcurie(s) } & \mathrm{Sv} & \text { year(s) } \\ \mathrm{cm} & \text { centimeter(s) } & \mathrm{yr} & \\ \mathrm{cm}^{3} & \text { cubic centimeter(s) } & & \\ \mathrm{d} & \text { day(s) } & & \\ \mathrm{g} & \text { gram(s) } & & \\ \mathrm{mg} & \text { milligram(s) } & & \\ \mathrm{h} & \text { hour(s) } & & \\ \mathrm{kg} & \text { kilogram(s) } & & \\ \mathrm{L} & \text { liter(s) } & & \\ \mathrm{mL} & \text { milliliter(s) } & & \\ \mathrm{m} & \text { meter(s) } & & \\ \mathrm{m}^{2} & \text { square meter(s) } & & \end{array}$




\title{
RESRAD BENCHMARKING AGAINST SIX RADIATION EXPOSURE PATHWAY MODELS
}

\author{
by
}

E.R. Faillace, J.-J. Cheng, and C. Yu

\begin{abstract}
A series of benchmarking runs were conducted so that results obtained with the RESRAD code could be compared against those obtained with six pathway analysis models used to determine the radiation dose to an individual living on a radiologically contaminated site. The RESRAD computer code was benchmarked against five other computer codes - GENII-S, GENII, DECOM, PRESTO-EPA-CPG, and PATHRAE-EPA - and the uncodified methodology presented in the NUREG/CR-5512 report. Estimated doses for the external gamma pathway; the dust inhalation pathway; and the soil, food, and water ingestion pathways were calculated for each methodology by matching, to the extent possible, input parameters such as occupancy, shielding, and consumption factors.
\end{abstract}

\section{INTRODUCTION}

U.S. Department of Energy (DOE) Order 5400.5 (DOE 1990) requires that the methodology incorporated in the RESRAD computer code (Gilbert et al. 1989; Yu et al. 1993) be used to establish soil cleanup guidelines for radionuclide contamination at DOE sites. RESRAD is a pathway analysis code that calculates radiation doses to a hypothetical individual living on a contaminated site. Several other existing models can be used to perform similar tasks. Six of these models were selected for benchmark analyses of the RESRAD code: GENII-S, Version 1.485 (Leigh et al. 1992); GENII (Napier et al. 1988); DECOM, Version 2.2 (Till and Moore 1988); PRESTO-EPA-CPG (Hung 1989); PATHRAE-EPA (Rogers and Hung 1987); and NUREG/CR-5512 (Kennedy and Strenge 1992). The first five models have been codified for use on personal computers; the last model has not.

Two types of benchmark analyses were performed. In the first, as detailed in Section 2, the default residential-farmer scenario in RESRAD was used as a starting point, and the parameter values in the other computer codes were changed to match the RESRAD default scenario to the extent possible. Results obtained from the different methodologies were then compared with results from RESRAD for external gamma dose, dust inhalation dose, soil ingestion dose, food (plant, meat, and milk) ingestion dose, and drinking water 
ingestion dose. Comparisons between RESRAD and GENII-S, DECOM, PRESTO-EPA-CPG, and NUREG/CR-5512 were tabulated.

The second type of benchmark analysis, as described in Section 3, involved comparison of RESRAD results with published results for the GENII and PATHRAE-EPA codes (Seitz et al. 1992, 1994). The parameter values used in RESRAD were adapted according to the published descriptions for GENII and PATHRAE-EPA so that a similar scenario was simulated by the three different computer codes. Results are presented in Section 3 and the Appendix. 


\section{BENCHMARKING AGAINST GENII-S, DECOM, PRESTO-EPA-CPG, AND NUREG/CR-5512 MODELS}

\subsection{MODEL DESCRIPTIONS}

The RESRAD code and the four models against which it is benchmarked in this section are briefly described below. The four models are GENII-S, DECOM, PRESTO-EPA-CPG, and NUREG/CR-5512.

\subsubsection{RESRAD Code}

Version 4.6 of RESRAD (Gilbert et al. 1989) allows the user to define up to nine pathways and three exposure routes: external gamma radiation from radionuclides in soil; inhalation of contaminated dust and radon gas; and ingestion of contaminated plants, meat, milk, aquatic foods, water, and soil. ${ }^{1}$ Several scenarios, including residential, industrial, and recreational, can be modeled by adding or suppressing pathways and entering appropriate values for occupancy and consumption rates.

Data input is carried out through an interactive menu system that is divided into several site- and pathway-specific parameter submenus. The code also includes useraccessible dose-factor and transfer-factor libraries. Conservative but realistic defaults, based on a residential scenario, are provided for all parameter values. Other features of the code include time-dependent dose calculations, graphical and text output, and parameter sensitivity analysis. The text output consists of dose estimates (in mrem/yr) for each radionuclide and pathway at the user-specified times. The maximum dose and the time at which it occurs are also calculated. In addition, guidelines are calculated for each radionuclide entered by the user. These guidelines are soil concentration values at which the receptor will not receive a radiation dose in excess of a user-specified limit.

Leaching of radionuclides from the contaminated layer may be calculated by directly inputting the leach rate, by entering the contaminated zone distribution coefficients, by entering the groundwater concentrations and time since disposal, or by having the code calculate the leach rate by using the plant transfer factors. A one-dimensional (nondispersion) groundwater transport model incorporated into the RESRAD code is used to model the transport of radionuclides through a maximum of five unsaturated layers down to the saturated zone and into a residential well or pond. In calculating the groundwater concentrations, the code takes into account the retardation of radionuclide transport and ingrowth and decay during transport, as well as any change in the contaminated zone concentration from leaching and radioactive ingrowth and decay. The code takes progeny radionuclides into account and considers them to be transported independently of their parents.

1 Note: The calculations reported here were performed prior to the release of Version 5.0 of RESRAD (Yu et al. 1993). 


\subsubsection{GENII-S Code}

The GENII-S code (Leigh et al. 1992) is a comprehensive package of models that address routine and accidental releases of radionuclides to air or water, as well as residual contamination from spills or decommissioning operations. Both population and individual doses can be calculated. The addition of a sensitivity and uncertainty analysis shell enables the user to perform stochastic as well as deterministic runs. For this report, only that portion of the code involving deterministic calculation of chronic individual doses from residual contamination in soil was considered.

The code allows the user to model up to two layers of contaminated soil: surface and deep soil. Surface contamination is contained in the first $15 \mathrm{~cm}$ of soil. Deep soil contamination may be located at any depth below the first $15 \mathrm{~cm}$. The code calculates doses to a hypothetical receptor from the following pathways and exposure routes: external gamma dose from radionuclides in soil and air; inhalation dose from contaminated dust; and ingestion dose from intake of contaminated soil, plants, meat, milk, fish, and water. The code output options include printing tabulations of doses by radionuclide, pathway, and organ.

The GENII-S code includes a surface-water flow model for calculating radionuclide concentrations in surface water, but it does not include a groundwater model. The user can still assess the water ingestion dose, however, by explicitly entering the radionuclide concentrations in water.

\subsubsection{DECOM Code}

The DECOM code (Till and Moore 1988) allows the user to calculate doses from radionuclides with different concentrations in multiple soil layers (in 15-cm increments). The code calculates doses to a hypothetical receptor from the following pathways and exposure routes: external gamma dose from radionuclides in soil; inhalation dose from contaminated dust; and ingestion dose from intake of contaminated plants, meat, milk, and water. The code output is presented as total dose from all pathways; contributions by individual radionuclides and pathways are expressed as percentages of the total dose.

The code can be operated in one of two modes. In mode 1 , the user enters the relative mix of radionuclides at the site and specifies an allowable dose limit. The code calculates the maximum total concentration allowable in each contaminated soil layer so that the dose limit will not be exceeded. In mode 2 , the user specifies the radionuclide concentrations in each layer. The code then calculates the total dose and the percent contribution from each radionuclide and pathway. In mode 2 , the user can also specify a soil removal option; the code will then calculate the amount of soil that needs to be removed so that the receptor dose will remain below the allowable limit.

Dose and soil concentration limits can be calculated only for one user-determined point in time each time the code is run. The code performs leaching and decay calculations to estimate the depletion of radionuclides from the contaminated zone at times other than 
time zero, except when calculating the groundwater transport pathway. The groundwater transport model used in DECOM considers dispersion but does not take into account the depletion of radionuclides in the contaminated zone over time from leaching and radioactive decay. Thus, the model will overestimate the radionuclide concentrations in groundwater, particularly for short-lived radionuclides. The code does not take into account progeny ingrowth and transport.

\subsubsection{PRESTO-EPA-CPG Code}

The PRESTO-EPA-CPG (or simply PRESTO) code (Hung 1989) is designed to estimate radiation doses to individuals and critical population groups over a 1,000-year period from disposal of low-level radioactive waste. On-site doses resulting from farming and intrusion and off-site doses from exposure to contaminated air, surface water, and groundwater are considered. The code calculates doses to hypothetical individual receptors, both on-site and off-site, for the following pathways and exposure routes: external gamma dose from radionuclides in soil, water, and air; inhalation dose from contaminated dust; and ingestion dose from intake of contaminated plants, meat, milk, and water.

Data are input to PRESTO by creation or modification of two FORTRAN input files. Dose factors for external gamma radiation, inhalation, and ingestion are contained in another file that can be modified by the user. The default dose factors used by PRESTO are relatively old (1980) and are different from those used in RESRAD.

Code output options include printing doses by radionuclide, pathway, and organ. Doses summed by radionuclide and organ are provided for each user-specified time period. Dose contributions are itemized by pathway, radionuclide, and organ only for the time at which the maximum dose occurs. Separate doses are itemized for water ingestion and food ingestion; however, the separate contributions from the various food ingestion pathways are not itemized.

The PRESTO groundwater model considers dispersion of the contaminants during transport through the unsaturated zone and the aquifer. The user can select either a point source model or an area model. The area model, which divides the contaminated zone into nine point sources for calculational purposes, is recommended for the on-site well scenario (Section 2.2). The code does not take into account the ingrowth and transport of progeny radionuclides.

\subsubsection{NUREG/CR-5512 Methodology}

The methodology described in NUREG/CR-5512 (Kennedy and Strenge 1992) incorporates a set of generic screening models to calculate radiation doses received by an individual from residual contamination in buildings and soil, as well as from potential groundwater contamination. The methodology encompasses building occupancy and renovation scenarios and a residential scenario. 
For the residential scenario, the contaminants are limited to the top $15 \mathrm{~cm}$ of soil. The potential pathways and exposure routes considered in NUREG/CR-5512 are external gamma dose from radionuclides in soil; inhalation dose from contaminated dust; and ingestion dose from intake of contaminated soil, plants, meat, milk, fish, and water.

Equations for each pathway and default parameter values are provided in the NUREG/CR-5512 document. Because the methodology has not been codified, the user must perform the calculations by hand. For these benchmarking efforts, the results of the NUREG/CR-5512 methodology were obtained by setting up the equations for each pathway on an electronic spreadsheet. Some of the equations are quite complex and require the user to calculate the time-integrated decay factor for each radionuclide over the exposure year. For the agricultural pathways, parameters such as growing times, harvest times, and holdup times are also required as input to the calculations. For long-lived radionuclides, these details add very little to the accuracy of the calculations. In such cases, the user can conservatively assume that no loss due to radioactive decay occurs during the year of exposure.

In the NUREG/CR-5512 methodology, a three-box model is used to calculate the transport of radionuclides in groundwater. The first box represents the contaminated zone, the second box the unsaturated zone, and the third box the aquifer. A leaching model is used to calculate contaminant movement from the first box to the second and then to the third. Contaminant removal and accumulation mechanisms include decay and ingrowth in all three boxes and water extraction in the third. To simplify calculations, the following conservative assumptions were made: groundwater flow in the unsaturated and saturated zones is not considered, no contaminant retardation occurs in the aquifer, and no dilution occurs with inflowing uncontaminated aquifer water.

\subsection{SCENARIO DESCRIPTION}

The default residential-farmer scenario in RESRAD was used as the starting point for the benchmark analysis. The pathways considered in that scenario are external gamma radiation from contaminated soil; inhalation of contaminated dust; and ingestion of contaminated water, soil, and food products. The radon (and progeny) inhalation pathway was not included because of all the models compared, RESRAD is the only one that considers the radon pathway. The assumptions made for this scenario were as follows:

- The contaminated zone covers an area of $10,000 \mathrm{~m}^{2}$.

- The contaminated zone is $15 \mathrm{~cm}$ thick and has no cover (a special case was run, for the external pathway only, with a 1-m-thick contaminated zone and a 15-cm-thick cover).

- External gamma indoor exposure rates are $70 \%$ of outdoor levels.

- Mass loading of dust for the inhalation pathway is $0.2 \mathrm{mg} / \mathrm{m}^{3}$. 
- The inhalation rate is $8,520 \mathrm{~m}^{3} / \mathrm{yr}$.

- The soil ingestion rate is $36.5 \mathrm{~g} / \mathrm{yr}$.

- Indoor levels of dust are $40 \%$ of the outdoor levels.

- The fraction of soil ingested indoors that originates from outdoor soil is $40 \%$.

- The resident spends $25 \%$ of the time outdoors on-site, $50 \%$ indoors on-site, and $25 \%$ off-site.

- The resident consumes $160 \mathrm{~kg} / \mathrm{yr}$ of fruits, vegetables, and grains; $14 \mathrm{~kg} / \mathrm{yr}$ of leafy vegetables; $63 \mathrm{~kg} / \mathrm{yr}$ of meat; $92 \mathrm{~L} / \mathrm{yr}$ of milk; and $510 \mathrm{~L} / \mathrm{yr}$ of water.

- Fifty percent of the vegetables and all of the meat and milk consumed by the resident are produced on-site. (RESRAD uses an area factor to account for the fraction of grazing area that is contaminated; for a $10,000-\mathrm{m}^{2}$ area, a factor of 0.5 is applied by RESRAD to reduce the ingestion doses for meat and milk.)

- All the water consumed by the resident is drawn from an on-site well screened $10 \mathrm{~m}$ into the aquifer ( $10 \mathrm{~m}$ is also assumed to be the thickness of the aquifer in the other models that require this parameter).

- The unsaturated zone is $4 \mathrm{~m}$ thick.

- The exponential "b" parameter used by RESRAD to calculate the saturation ratio is assumed to be 5.3, resulting in an average moisture content in the contaminated and unsaturated zones of $0.3 \mathrm{~mL} / \mathrm{cm}^{3}$.

- Soil density, total porosity, and effective porosity in all soil layers are $1.6 \mathrm{~g} / \mathrm{cm}^{3}, 0.4$, and 0.2 , respectively.

- The saturated hydraulic conductivity is $10 \mathrm{~m} / \mathrm{yr}$ in the contaminated zone and $100 \mathrm{~m} / \mathrm{yr}$ in both the unsaturated zone and the aquifer.

- The hydraulic gradient in the aquifer is 0.02 , resulting in a groundwater velocity of $2 \mathrm{~m} / \mathrm{yr}$.

- Rainfall and irrigation rates are 1 and $0.2 \mathrm{~m} / \mathrm{yr}$, respectively, while the runoff and evapotranspiration coefficients are 0.2 and 0.6 , respectively, resulting in a net infiltration rate of $0.4 \mathrm{~m} / \mathrm{yr}$.

- The distribution coefficients and biotic-transfer factors used are the RESRAD default values for each radionuclide. 
- Seven representative radionuclides (including alpha, beta, and gamma emitters) were selected for the benchmark analyses. Soil concentrations of $1 \mathrm{pCi} / \mathrm{g}$ each of Co-60, Sr-90, I-129, Cs-137, U-234, U-238, and Pu-239 were assumed for all five models. When applicable, the short-lived progeny (half-life $<6$ months) were entered either explicitly or implicitly. The resulting doses take into account the contributions of progeny radionuclides. In DECOM, the dose from I-129 was not calculated because this radionuclide is not included in its database.

- To investigate the effects of radionuclide ingrowth, a special case was run entering a unit concentration of Pu-241, which decays to Am-241. Because of limitations in the other models, a comparison was only possible between RESRAD and GENII-S.

To the extent possible, the parameter values in the default file RESRAD.DEF were not altered (with the exception of the contaminated zone and cover thicknesses), and the parameter values in the other models were modified to reflect the RESRAD default values. However, in some cases, the model against which RESRAD was being benchmarked did not allow the user to match the parameter value used by RESRAD. Such was the case for the erosion rate in PRESTO and the inhalation rate in GENII-S. In those instances, the default parameter values in RESRAD and the remaining models were changed to match these fixed values. In some cases, a particular model incorporated a parameter not used by RESRAD. In those cases, the default value of that parameter was not changed.

In the NUREG/CR-5512 methodology, the activity initially present in soil must be integrated to account for decay, thus producing a time-averaged activity over the assessment year. To simplify calculations, the time-integrated activity factor over the assessment year was assumed to be $365 \mathrm{pCi}-\mathrm{d} / \mathrm{g}$ per $\mathrm{pCi} / \mathrm{g}$ of activity initially present in soil for all radionuclides (i.e., no decay). For even the shortest-lived radionuclide, Co-60, the activity present after one year of decay is $88 \%$ of the activity present at the beginning of the year. Thus, this simplification changes the results by less than $10 \%$ for all radionuclides.

\subsection{BENCHMARKING RESULTS - TIME ZERO}

\subsubsection{Introduction}

In the following sections, each pathway selected for analysis is discussed separately, and the results from RESRAD are compared with those from each of the other models. The results are presented as the ratio of the dose calculated by RESRAD to the dose calculated using one of the other four models. In this section, doses are compared at time zero for all pathways except the water ingestion pathway. To compare how each model treats radionuclide decay, leaching, and groundwater transport, the doses from the dust inhalation (a representative water-independent pathway) and water ingestion pathways are compared for an elapsed time of 500 years in Section 2.4 . 
Annual dose contributions from water-independent external gamma, dust inhalation, soil ingestion, and food ingestion pathways were calculated for the first year. The water ingestion pathway is not a contributor to this initial dose because groundwater transport is assumed to start at time zero, with no prior groundwater contamination.

For the PRESTO code, the dose comparison is made for the second year because the external gamma pathway (referred to as the basement residence model in that code) cannot be activated during the first year. Because of the additional year of radioactive decay and leaching, the dose contributions calculated by PRESTO are slightly reduced from those calculated by RESRAD. However, the radionuclides considered have half-lives that are long compared to one year, so this limitation of the PRESTO code does not significantly affect the results.

\subsubsection{External Gamma Pathway}

The first series of benchmarking runs was performed for the external dose pathway. One case was run for radionuclides present in the top $15 \mathrm{~cm}$ of soil. To account for the effects of a cover material, a second case was run with a 1-m-thick contaminated zone covered by $15 \mathrm{~cm}$ of uncontaminated soil. The NUREG/CR-5512 model considers only contamination in the top $15 \mathrm{~cm}$ of soil; therefore, only results for the first case were calculated with that model.

The RESRAD default values for area of contamination and soil density $\left(10,000 \mathrm{~m}^{2}\right.$ and $1.6 \mathrm{~g} / \mathrm{cm}^{3}$, respectively) were input in the first four models. The NUREG/CR-5512 methodology does not permit the user to adjust for area and density factors; instead, they are included by default in the dose factors used. Occupancy and shielding factors were adjusted to the RESRAD default value of 0.6 , which was derived by assuming $25 \%$ outdoor occupancy, $50 \%$ indoor occupancy with $70 \%$ of outside gamma levels, and $25 \%$ off-site occupancy.

\subsubsection{RESRAD vs. GENII-S}

In GENII-S, the user has the option of considering a surface or a deep contaminated zone. In the first case, the surface zone (top $15 \mathrm{~cm}$ ) was activated and the radionuclide concentrations were entered in units of $\mathrm{pCi} / \mathrm{kg}$. The soil density of this surface zone was changed from the default 225 to $240 \mathrm{~kg} / \mathrm{m}^{2}$, which is equivalent to a density of $1.6 \mathrm{~g} / \mathrm{cm}^{3}$ over a thickness of $15 \mathrm{~cm}$. GENII-S does not have a provision for shielding during indoor occupancy. To obtain a value equivalent to the shielding and occupancy factor used by RESRAD, the exposure time to ground contamination in GENII-S was changed from the default value of 8,760 to $5,256 \mathrm{~h} / \mathrm{yr}$, or $60 \%$ of a full year.

The two codes were then compared by calculating the external dose in the presence of an uncontaminated cover. In GENII-S, a concentration of $1.6 \times 10^{6} \mathrm{pCi} / \mathrm{m}^{3}$ was entered for each radionuclide in the deep contaminated zone. This value is equivalent to a concentration of $1.0 \mathrm{pCi} / \mathrm{g}$ in soil with a density of $1.6 \mathrm{~g} / \mathrm{cm}^{3}$. The presence of a $15-\mathrm{cm}$ uncontaminated surface layer was assumed. 
As shown in Table 1, the results in the first case (surface soil contamination) indicate that the external doses calculated by RESRAD tend to be higher (by factors in the range of 1.5 to 4.4) than those for GENII-S. Exceptions are I-129, a factor of 2.6 lower, and U-238, for which RESRAD calculates a dose that is 94 times lower. In the case of deep soil contamination, RESRAD calculates doses ranging from 1.9 to 49,000 times higher than those calculated by GENII-S (except for the U-238 dose, which is 50 times smaller).

\subsubsection{RESRAD vs. DECOM}

In the RESRAD code, the depth of the contaminated zone was set to $15 \mathrm{~cm}$, and all pathways except the external radiation pathway were suppressed. In DECOM, the surface soil depth was set to $15 \mathrm{~cm}$, and the soil density was set to $240 \mathrm{~kg} / \mathrm{m}^{2}\left(1.6 \mathrm{~g} / \mathrm{cm}^{3}\right)$ for a surface area of $10,000 \mathrm{~m}^{2}$. In DECOM, the percentage of time spent on-site was changed from $100 \%$ to $60 \%$ to simulate the RESRAD default value of 0.6 for the shielding and occupancy factor.

The two codes were then compared by considering the external dose in the presence of an uncontaminated cover. All of the above parameters were kept the same, except that a 15-cm cover was added on top of a 1-m-thick contaminated zone. The DECOM code only

TABLE 1 Comparison of External Dose Calculations, RESRAD vs. GENII-S (time zero)

\begin{tabular}{llll}
\hline & \multicolumn{2}{c}{ Doses (mrem/yr) } & \\
\cline { 2 - 3 } Radionuclide & GENII-S & RESRAD & $\begin{array}{c}\text { Dose Ratio, } \\
\text { RESRAD/GENII-S }\end{array}$ \\
\hline Surface soil & & & \\
Co-60 & 7.5 & $1.1 \times 10^{1}$ & 1.5 \\
Sr-90 & $1.9 \times 10^{-2}$ & 0.0 & NC \\
I-129 & $5.3 \times 10^{-3}$ & $2.0 \times 10^{-3}$ & $3.8 \times 10^{-1}$ \\
Cs-137 & 1.8 & 2.7 & 1.5 \\
U-234 & $1.8 \times 10^{-4}$ & $8.0 \times 10^{-4}$ & 4.4 \\
U-238 & 6.2 & $6.6 \times 10^{-2}$ & $1.1 \times 10^{-2}$ \\
Pu-239 & $1.3 \times 10^{-4}$ & $4.3 \times 10^{-4}$ & 3.3 \\
& & & \\
Deep soil & & & \\
Co-60 & 1.4 & 2.6 & 1.9 \\
Sr-90 & $1.4 \times 10^{-3}$ & 0.0 & NC \\
I-129 & $2.0 \times 10^{-9}$ & $9.8 \times 10^{-5}$ & $4.9 \times 10^{4}$ \\
Cs-137 & $1.9 \times 10^{-1}$ & $4.2 \times 10^{-1}$ & 2.2 \\
U-234 & $9.9 \times 10^{-7}$ & $2.1 \times 10^{-5}$ & $2.1 \times 10^{1}$ \\
U-238 & $5.5 \times 10^{-1}$ & $1.1 \times 10^{-2}$ & $2.0 \times 10^{-2}$ \\
Pu-239 & $1.2 \times 10^{-6}$ & $8.8 \times 10^{-6}$ & 7.3 \\
\hline
\end{tabular}

a $\mathrm{NC}=$ not calculated. 
allows for the input of concentrations in 15-cm layers. Thus, the doses calculated by DECOM were based on one uncontaminated 15-cm layer plus seven contaminated soil layers between 15 and $120 \mathrm{~cm}$. Table 2 compares the results for surface soil and deep soil doses.

Because Sr-90 and its decay product Y-90 are pure beta-emitters, no external gamma dose conversion factors are available for Sr-90. DECOM does not include a Pu-239 gamma dose conversion factor in its database.

In both cases, RESRAD calculates a dose for Co-60 and Cs-137 that is within a factor of 2 higher than the dose calculated by DECOM. For the uranium isotopes, a much greater discrepancy occurs; DECOM calculates significantly higher doses than RESRAD. In fact, the $\mathrm{U}-234$ dose calculated by DECOM is three to four times higher than the Cs-137 dose. These large discrepancies may result from erroneous dose-factor values used by DECOM to calculate external doses from the uranium isotopes. Also, RESRAD uses a volumetric dose conversion factor for a contaminated slab of infinite thickness; this factor is corrected for the actual thickness of the contaminated layer and shielding by an uncontaminated layer. DECOM uses surface dose factors distributed over $5-\mathrm{cm}$ intervals to simulate a volume source.

\subsubsection{RESRAD vs. PRESTO}

With PRESTO, the user can consider a surface and/or a deep contaminated zone by changing the thickness of the trench overburden and the depth of the trench. For the surface contamination case, a 15-cm-deep trench with no overburden and a total inventory of

\section{TABLE 2 Comparison of External Dose Calculations, RESRAD vs. DECOM (time zero)}

\begin{tabular}{llll}
\hline & \multicolumn{2}{c}{ Doses (mrem/yr) } & \\
\cline { 2 - 3 } Radionuclide & DECOM & RESRAD & $\begin{array}{c}\text { Dose Ratio, } \\
\text { RESRAD/DECOM }\end{array}$ \\
\hline Surface soil & & & \\
Co-60 & 7.3 & $1.1 \times 10^{1}$ & 1.5 \\
Sr-90 & 0.0 & 0.0 & $\mathrm{NC}^{\mathrm{a}}$ \\
Cs-137 & 1.8 & 2.7 & 1.5 \\
U-234 & 4.7 & $8.0 \times 10^{-4}$ & $1.7 \times 10^{-4}$ \\
U-238 & $2.1 \times 10^{1}$ & $6.6 \times 10^{-2}$ & $3.1 \times 10^{-3}$ \\
Pu-239 & 0.0 & $4.3 \times 10^{-4}$ & $\mathrm{NC}$ \\
& & & \\
Deep soil & & & \\
Co-60 & 1.6 & 2.6 & 1.6 \\
Sr-90 & 0.0 & 0.0 & $\mathrm{NC}$ \\
Cs-137 & $2.4 \times 10^{-1}$ & $4.2 \times 10^{-1}$ & 1.8 \\
U-234 & $9.7 \times 10^{-1}$ & $2.1 \times 10^{-5}$ & $2.2 \times 10^{-5}$ \\
U-238 & 4.2 & $1.1 \times 10^{-2}$ & $2.6 \times 10^{-3}$ \\
Pu-239 & 0.0 & $8.8 \times 10^{-6}$ & $\mathrm{NC}$ \\
\hline a NC = not calculated. & & \\
\hline
\end{tabular}


$2.4 \times 10^{-3} \mathrm{Ci}$ for each radionuclide were entered. The external gamma pathway can only be activated by assuming that the resident lives in a basement for part of the year. As mentioned earlier, this pathway can be activated only at one year after time zero. To obtain a value equivalent to the shielding and occupancy factor used by RESRAD, the factor in PRESTO characterizing the intensity and duration of gamma exposure from the basement scenario was set to 0.6 . For the deep contaminated soil case, a trench depth of $1.15 \mathrm{~m}$ with a 15-cm overburden thickness and an inventory of $1.6 \times 10^{-2} \mathrm{Ci}$ per radionuclide were entered. Table 3 compares the results for the two codes.

In both cases, PRESTO calculates a dose from U-238 that is significantly lower than the dose calculated by RESRAD; this may be due in part to failure of PRESTO to account for the ingrowth of short-lived U-238 progeny. The Co-60 and Cs-137 doses are also somewhat lower in the PRESTO calculations for the surface soil case (and deep soil case for Co-60). For all other radionuclides, the doses calculated by PRESTO are higher than those from RESRAD by up to a factor of 190 . The doses calculated by PRESTO are not significantly lower in the deep soil case when compared with the surface soil case. In addition, it is not clear why the I-129 dose is zero for the surface soil case but non-zero in the deep soil case.

TABLE 3 Comparison of External Dose Calculations, RESRAD vs. PRESTO (time zero)

\begin{tabular}{llll} 
& \multicolumn{2}{c}{ Doses (mrem/yr) } & \\
\cline { 2 - 3 } Radionuclide & PRESTO & RESRAD & $\begin{array}{c}\text { Dose Ratio, } \\
\text { RESRAD/PRESTO }\end{array}$ \\
\cline { 2 - 3 } Surface soil & & & \\
Co-60 & 2.7 & $1.1 \times 10^{1}$ & 4.1 \\
Sr-90 & 0.0 & 0.0 & NC \\
I-129 & 0.0 & $2.0 \times 10^{-3}$ & NC \\
Cs-137 & $8.0 \times 10^{-1}$ & 2.7 & 3.4 \\
U-234 & $8.4 \times 10^{-4}$ & $8.0 \times 10^{-4}$ & $9.5 \times 10^{-1}$ \\
U-238 & $6.7 \times 10^{-4}$ & $6.6 \times 10^{-2}$ & $9.9 \times 10^{1}$ \\
Pu-239 & $4.4 \times 10^{-4}$ & $4.3 \times 10^{-4}$ & $9.8 \times 10^{-1}$ \\
& & & \\
Deep soil & & & \\
Co-60 & 2.3 & 2.6 & 1.1 \\
Sr-90 & 0.0 & 0.0 & $\mathrm{NC}$ \\
I-129 & $1.9 \times 10^{-2}$ & $9.8 \times 10^{-5}$ & $5.2 \times 10^{-3}$ \\
Cs-137 & $6.8 \times 10^{-1}$ & $4.2 \times 10^{-1}$ & $6.2 \times 10^{-1}$ \\
U-234 & $8.1 \times 10^{-4}$ & $2.1 \times 10^{-5}$ & $2.6 \times 10^{-2}$ \\
U-238 & $6.4 \times 10^{-4}$ & $1.1 \times 10^{-2}$ & $1.7 \times 10^{1}$ \\
Pu-239 & $3.8 \times 10^{-4}$ & $8.8 \times 10^{-6}$ & $2.3 \times 10^{-2}$ \\
\hline
\end{tabular}

a $\mathrm{NC}=$ not calculated. 


\subsubsection{RESRAD vs. NUREG/CR-5512}

The equation in NUREG/CR-5512 that is used to calculate external exposure (Equation 5.69) requires the user to input the number of days during the assessment year spent gardening, outdoors on-site, and indoors on-site. The NUREG/CR-5512 default values of 4.17 days gardening, 71.83 days outdoors, and 200 days indoors were changed to $0,91.25$, and 182.5 days, respectively, to obtain the same occupancy factors used by RESRAD. The shielding factor for indoor occupancy was changed from the NUREG/CR-5512 default of 0.33 to the RESRAD default of 0.7 . The dose factors for external radiation exposure were obtained from Table E.2 of the report after converting from units of Sv/d per Bq/m to units of $\mathrm{mrem} / \mathrm{h}$ per pCi/g. Table 4 shows the results for the surface soil case. The deep soil case is not compared because the NUREG/CR-5512 methodology only simulates a $15-\mathrm{cm}$ soil layer.

With the exception of I-129 and U-238, the doses calculated by RESRAD are higher than those from NUREG/CR-5512 by factors ranging from 1.3 to 3.3. The I-129 and U-238 doses calculated by RESRAD are approximately 0.25 and 0.5 , respectively, of the dose calculated with the NUREG/CR-5512 methodology.

\subsubsection{Summary of the External Gamma Pathway}

Table 5 summarizes the external gamma pathway doses at time zero that were calculated by using each of the five models.

For high energy gamma emitters in soil (Co-60 and Cs-137), the calculated doses are within a factor of 5 for all models; RESRAD calculated the highest doses in all cases except the deep soil dose from Cs-137 calculated by PRESTO.

TABLE 4 Comparison of External Dose Calculations (surface soil only), RESRAD vs. NUREG/CR-5512 (time zero)

\begin{tabular}{llll} 
& \multicolumn{2}{c}{ Doses (mrem/yr) } & \\
\cline { 2 - 3 } Radionuclide & NUREG & RESRAD & $\begin{array}{c}\text { Dose Ratio, } \\
\text { RESRAD/NUREG }\end{array}$ \\
\hline Co-60 & 8.7 & $1.1 \times 10^{1}$ & 1.3 \\
Sr-90 & 0.0 & 0.0 & $\mathrm{NC}^{\mathrm{a}}$ \\
I-129 & $7.9 \times 10^{-3}$ & $2.0 \times 10^{-3}$ & $2.5 \times 10^{-1}$ \\
Cs-137 & 1.9 & 2.7 & 1.4 \\
U-234 & $2.4 \times 10^{-4}$ & $8.0 \times 10^{-4}$ & 3.3 \\
U-238 & $1.3 \times 10^{-1}$ & $6.6 \times 10^{-2}$ & $5.3 \times 10^{-1}$ \\
Pu-239 & $1.7 \times 10^{-4}$ & $4.3 \times 10^{-4}$ & 2.5 \\
\hline
\end{tabular}

a $\mathrm{NC}=$ not calculated. 
TABLE 5 Comparison of External Dose Calculations, All Models (time zero)

\begin{tabular}{llllll}
\hline & \multicolumn{5}{c}{ Doses (mrem/yr) } \\
\cline { 2 - 6 } Radionuclide & RESRAD & GENII-S & DECOM & PRESTO & NUREG \\
\hline Surface soil & & & & \\
Co-60 & $1.1 \times 10^{1}$ & 7.5 & 7.3 & 2.7 & 8.7 \\
Sr-90 & 0.0 & $1.9 \times 10^{-2}$ & 0.0 & 0.0 & 0.0 \\
I-129 & $2.0 \times 10^{-3}$ & $5.3 \times 10^{-3}$ & NC & 0.0 & $7.9 \times 10^{-3}$ \\
Cs-137 & 2.7 & 1.8 & 1.8 & $8.0 \times 10^{-1}$ & 1.9 \\
U-234 & $8.0 \times 10^{-4}$ & $1.8 \times 10^{-4}$ & 4.7 & $8.4 \times 10^{-4}$ & $2.4 \times 10^{-4}$ \\
U-238 & $6.6 \times 10^{-2}$ & 6.2 & $2.1 \times 10^{1}$ & $6.7 \times 10^{-4}$ & $1.3 \times 10^{-1}$ \\
Pu-239 & $4.3 \times 10^{-4}$ & $1.3 \times 10^{-4}$ & 0.0 & $4.4 \times 10^{-4}$ & $1.7 \times 10^{-4}$ \\
& & & & & \\
Deep soil & & & & & \\
Co-60 & 2.6 & 1.4 & 1.6 & 2.3 & NC \\
Sr-90 & 0.0 & $1.4 \times 10^{-3}$ & 0.0 & 0.0 & NC \\
I-129 & $9.8 \times 10^{-5}$ & $2.0 \times 10^{-9}$ & NC & $1.9 \times 10^{-2}$ & NC \\
Cs-137 & $4.2 \times 10^{-1}$ & $1.9 \times 10^{-1}$ & $2.4 \times 10^{-1}$ & $6.8 \times 10^{-1}$ & NC \\
U-234 & $2.1 \times 10^{-5}$ & $9.9 \times 10^{-7}$ & $9.7 \times 10^{-1}$ & $8.1 \times 10^{-4}$ & NC \\
U-238 & $1.1 \times 10^{-2}$ & $5.5 \times 10^{-1}$ & 4.2 & $6.4 \times 10^{-4}$ & NC \\
Pu-239 & $8.8 \times 10^{-6}$ & $1.2 \times 10^{-6}$ & 0.0 & $3.8 \times 10^{-4}$ & NC \\
\hline
\end{tabular}

a $\mathrm{NC}=$ not calculated.

Only GENII-S calculated an external gamma dose from Sr-90. External dose calculations for I-129 varied significantly between models when surface soil and deep soil cases were compared. It is not clear why PRESTO calculated a zero dose from I-129 for the surface soil case but calculated a non-zero dose for the deep soil case; this is physically impossible. Also, GENII-S calculated an I-129 dose for the deep soil case that is more than six orders of magnitude lower than the surface soil case. This appears to be inconsistent with the calculations for U-234 and Pu-239, both of which had lower doses than I-129 in the surface soil case but higher doses in the deep soil case.

The doses calculated by DECOM for U-234 and U-238 were significantly higher than the doses calculated by all other models because of the high dose conversion factors assumed by DECOM for these two radionuclides. The PRESTO calculations for U-238 underestimated the external dose since they do not include the contributions from the short-lived progeny of U-238.

With the exception of DECOM, which assumes a zero external dose from $\mathrm{Pu}-239$, all other models calculated Pu-239 doses within a factor of four in the surface soil case. In the deep soil case, however, PRESTO calculated a dose that is significantly higher than the dose calculated by RESRAD or GENII-S. 
All models appear to account for the shielding properties of a clean surface soil layer (except PRESTO with I-129 and NUREG/CR-5512, which considers only surface soil) since the calculated doses are lower for the deep soil case than for the surface soil case. However, the relative attenuation factors vary (in some cases, significantly) between models.

\subsubsection{Dust Inhalation Pathway}

The second series of benchmarking runs was performed for the dust inhalation dose pathway from radionuclides present in the top $15 \mathrm{~cm}$ of soil. In the RESRAD, GENII-S, DECOM, and PRESTO models, all pathways except the dust inhalation pathway were suppressed. Equation 5.70 in NUREG/CR-5512 was used to calculate the dose from the inhalation pathway.

The RESRAD default value for mass loading of dust in air $\left(2 \times 10^{-4} \mathrm{~g} / \mathrm{m}^{3}\right)$ was entered in the four other models. The RESRAD code is the only model that considers the size of the contaminated area when adjusting doses; however, the area factor for inhalation calculated by RESRAD is very close to one (0.97) for an area of $10,000 \mathrm{~m}^{2}$ and will not significantly affect the results. Because the inhalation rate in GENII-S is fixed at $270 \mathrm{~mL} / \mathrm{s}$ $\left(8,520 \mathrm{~m}^{3} / \mathrm{yr}\right)$, the inhalation rates in RESRAD, DECOM, PRESTO, and NUREG/CR-5512 were adjusted to this value. Occupancy and shielding factors were adjusted to the RESRAD default value of 0.45 , which was derived by assuming $25 \%$ outdoor occupancy, $50 \%$ indoor occupancy with $40 \%$ of dust originating from contaminated soil, and $25 \%$ off-site occupancy.

\subsubsection{RESRAD vs. GENII-S}

To adjust for the occupancy and shielding factor used by RESRAD, the inhalation exposure time in GENII-S was reduced from the default value of 8,760 to $3,942 \mathrm{~h} / \mathrm{yr}$. As mentioned previously, the inhalation rate in RESRAD was adjusted from the default value of 8,400 to $8,520 \mathrm{~m}^{3} / \mathrm{yr}$. Table 6 compares the inhalation doses obtained by using the two codes.

RESRAD calculated a higher inhalation dose for all radionuclides except $\mathrm{Co}-60$. The doses calculated by GENII-S and RESRAD agree within a factor of two, with the exception of Sr-90 (RESRAD calculated a dose that is seven times higher). These discrepancies may be attributed to differences in the dose factor method used by GENII-S to calculate the committed effective dose equivalent.

\subsubsection{RESRAD vs. DECOM}

The DECOM default mass loading factor for dust $\left(7 \times 10^{-5} \mathrm{~g} / \mathrm{m}^{3}\right)$ was changed to $2 \times 10^{-4} \mathrm{~g} / \mathrm{m}^{3}$. To account for the RESRAD default occupancy and shielding factor of 0.45 , the parameter in DECOM for percentage of time on-site was changed from the default value of $100 \%$ to $45 \%$. The DECOM default inhalation rate of $8,300 \mathrm{~m}^{3} / \mathrm{yr}$ was increased to $8,520 \mathrm{~m}^{3} / \mathrm{yr}$. Table 7 lists the inhalation doses obtained by using the two codes. 
TABLE 6 Comparison of Dust Inhalation Dose Calculations, RESRAD vs. GENII-S (time zero)

\begin{tabular}{llll}
\hline & \multicolumn{2}{c}{ Doses (mrem/yr) } & \\
\cline { 2 - 3 } Radionuclide & GENII-S & RESRAD & $\begin{array}{c}\text { Dose Ratio, } \\
\text { RESRAD/GENII-S }\end{array}$ \\
\hline Co-60 & $1.4 \times 10^{-4}$ & $1.1 \times 10^{-4}$ & $7.9 \times 10^{-1}$ \\
Sr-90 & $1.4 \times 10^{-4}$ & $9.7 \times 10^{-4}$ & 6.9 \\
I-129 & $1.1 \times 10^{-4}$ & $1.3 \times 10^{-4}$ & 1.2 \\
Cs-137 & $2.1 \times 10^{-5}$ & $2.4 \times 10^{-5}$ & 1.1 \\
U-234 & $9.3 \times 10^{-2}$ & $9.7 \times 10^{-2}$ & 1.0 \\
U-238 & $8.3 \times 10^{-2}$ & $8.9 \times 10^{-2}$ & 1.1 \\
Pu-239 & $2.1 \times 10^{-1}$ & $3.8 \times 10^{-1}$ & 1.8 \\
\hline
\end{tabular}

TABLE 7 Comparison of Dust Inhalation Dose Calculations, RESRAD vs. DECOM (time zero)

\begin{tabular}{llll}
\hline & \multicolumn{2}{c}{ Doses (mrem/yr) } & \\
\cline { 2 - 3 } Radionuclide & DECOM & RESRAD & $\begin{array}{c}\text { Dose Ratio, } \\
\text { RESRAD/DECOM }\end{array}$ \\
\hline Co-60 & $1.1 \times 10^{-4}$ & $1.1 \times 10^{-4}$ & 1.0 \\
Sr-90 & $1.0 \times 10^{-3}$ & $9.7 \times 10^{-4}$ & $9.7 \times 10^{-1}$ \\
Cs-137 & $2.5 \times 10^{-5}$ & $2.4 \times 10^{-5}$ & $9.6 \times 10^{-1}$ \\
U-234 & $8.5 \times 10^{-2}$ & $9.7 \times 10^{-2}$ & 1.1 \\
U-238 & $9.2 \times 10^{-2}$ & $8.9 \times 10^{-2}$ & $9.7 \times 10^{-1}$ \\
Pu-239 & $3.9 \times 10^{-1}$ & $3.8 \times 10^{-1}$ & $9.7 \times 10^{-1}$ \\
\hline
\end{tabular}

The RESRAD and DECOM results for the dust inhalation pathway were in excellent agreement. The area factor used accounts for the slightly lower doses calculated by RESRAD.

\subsubsection{RESRAD vs. PRESTO}

The default PRESTO scenario does not consider the on-site inhalation pathway. To activate this pathway, the mass loading for dust inhalation was changed in the PRESTO default file from 0.0 to $2 \times 10^{-4} \mathrm{~g} / \mathrm{m}^{3}$, and the fraction of year that the on-site resident is exposed to dust was changed from 0.0 to 0.45 . The PRESTO inhalation rate was changed from the default value of 8,035 to $8,520 \mathrm{~m}^{3} / \mathrm{yr}$. Table 8 lists the inhalation doses obtained by using the two codes.

The inhalation doses for Co-60, I-129, and the uranium isotopes calculated with the PRESTO code were higher than those calculated with RESRAD by factors ranging from 1.5 to 3.3. The Sr-90 and Pu-239 doses calculated by RESRAD were 1.3 and 6.5 times higher, respectively. The use of different dose factors may account for this variability. 
TABLE 8 Comparison of Dust Inhalation Dose

Calculations, RESRAD vs. PRESTO (time zero)

\begin{tabular}{llll}
\hline & \multicolumn{2}{c}{ Doses (mrem/yr) } & \\
\cline { 2 - 3 } Radionuclide & PRESTO & RESRAD & $\begin{array}{c}\text { Dose Ratio, } \\
\text { RESRAD/PRESTO }\end{array}$ \\
\hline Co-60 & $2.9 \times 10^{-4}$ & $1.1 \times 10^{-4}$ & $3.8 \times 10^{-1}$ \\
Sr-90 & $1.5 \times 10^{-4}$ & $9.7 \times 10^{-4}$ & 6.5 \\
I-129 & $4.4 \times 10^{-4}$ & $1.3 \times 10^{-4}$ & $3.0 \times 10^{-1}$ \\
Cs-137 & $2.3 \times 10^{-5}$ & $2.4 \times 10^{-5}$ & 1.0 \\
U-234 & $1.5 \times 10^{-1}$ & $9.7 \times 10^{-2}$ & $6.5 \times 10^{-1}$ \\
U-238 & $1.3 \times 10^{-1}$ & $8.9 \times 10^{-2}$ & $6.8 \times 10^{-1}$ \\
Pu-239 & $2.9 \times 10^{-1}$ & $3.8 \times 10^{-1}$ & 1.3 \\
\hline
\end{tabular}

\subsubsection{RESRAD vs. NUREG/CR-5512}

As in the case for external exposure, the equation used in NUREG/CR-5512 to calculate inhalation doses (Equation 5.70) requires the user to input the number of days during the assessment year spent gardening and the number of days spent on-site, both indoors and outdoors. The NUREG/CR-5512 default values of 4.17 days gardening, 71.83 days outdoors, and 200 days indoors were changed to $0,91.25$, and 182.5 days, respectively, to obtain the same occupancy factors used by RESRAD. In Equation 5.70, different mass loading factors are used for outdoor and indoor occupancy. For outdoor occupancy, this factor was changed from the default $1 \times 10^{-4} \mathrm{~g} / \mathrm{m}^{3}$ to $2 \times 10^{-4} \mathrm{~g} / \mathrm{m}^{3}$. The default indoor mass loading factor is calculated as $5 \times 10^{-5} \mathrm{~g} / \mathrm{m}^{3}$, plus a resuspension factor of $0.4 / \mathrm{m}$ times a surface dust loading of $5 \times 10^{-5} \mathrm{~g} / \mathrm{m}^{2}$, totaling $7 \times 10^{-5} \mathrm{~g} / \mathrm{m}^{3}$. This indoor default was changed to $8 \times 10^{-5} \mathrm{~g} / \mathrm{m}^{3}$, which is equal to the RESRAD assumption that indoor dust levels are $40 \%$ of outdoor levels. The dose factors for inhalation were obtained from Table E.2 of the NUREG/CR-5512 report after converting from units of Sv/Bq to units of $\mathrm{mrem} / \mathrm{pCi}$.

Table 9 lists the inhalation doses obtained by using the two codes. For all radionuclides, the doses calculated by the two codes were equal within a factor of 1.5 .

\subsubsection{Summary of the Inhalation Pathway}

Table 10 summarizes the inhalation pathway doses at time zero calculated by using each of the five models.

With few exceptions, dust inhalation doses calculated by all models were within a factor of 2 for all radionuclides. Both GENII-S and PRESTO calculated Sr-90 doses that were an order of magnitude lower than Sr-90 doses calculated by the other models. The I-129 dose calculated by PRESTO was a factor of 3 higher than the dose calculated by the other models. These discrepancies are due in large part to differences in the dose factors used by each code. 
TABLE 9 Comparison of Dust Inhalation Dose Calculations, RESRAD vs. NUREG/CR-5512 (time zero)

\begin{tabular}{llll}
\hline & \multicolumn{2}{c}{ Doses (mrem/yr) } & \\
\cline { 2 - 3 } Radionuclide & NUREG & RESRAD & $\begin{array}{c}\text { Dose Ratio, } \\
\text { RESRAD/NUREG }\end{array}$ \\
\hline Co-60 & $1.7 \times 10^{-4}$ & $1.1 \times 10^{-4}$ & $6.6 \times 10^{-1}$ \\
Sr-90 & $1.0 \times 10^{-3}$ & $9.7 \times 10^{-4}$ & $9.7 \times 10^{-1}$ \\
I-129 & $1.3 \times 10^{-4}$ & $1.3 \times 10^{-4}$ & 1.0 \\
Cs-137 & $2.4 \times 10^{-5}$ & $2.4 \times 10^{-5}$ & 1.0 \\
U-234 & $1.0 \times 10^{-1}$ & $9.7 \times 10^{-2}$ & $9.6 \times 10^{-1}$ \\
U-238 & $9.1 \times 10^{-2}$ & $8.9 \times 10^{-2}$ & $9.8 \times 10^{-1}$ \\
Pu-239 & $3.3 \times 10^{-1}$ & $3.8 \times 10^{-1}$ & 1.2 \\
\hline
\end{tabular}

\begin{abstract}
TABLE 10 Comparison of Dust Inhalation Dose Calculations, All Models (time zero)
\end{abstract}

\begin{tabular}{llllll}
\hline & \multicolumn{5}{c}{ Doses (mrem/yr) } \\
\cline { 2 - 6 } Radionuclide & RESRAD & GENII-S & DECOM & PRESTO & NUREG \\
\hline Co-60 & $1.1 \times 10^{-4}$ & $1.4 \times 10^{-4}$ & $1.1 \times 10^{-4}$ & $2.9 \times 10^{-4}$ & $1.7 \times 10^{-4}$ \\
Sr-90 & $9.7 \times 10^{-4}$ & $1.4 \times 10^{-4}$ & $1.0 \times 10^{-3}$ & $1.5 \times 10^{-4}$ & $1.0 \times 10^{-3}$ \\
I-129 & $1.3 \times 10^{-4}$ & $1.1 \times 10^{-4}$ & NC $^{\mathrm{a}}$ & $4.4 \times 10^{-4}$ & $1.3 \times 10^{-4}$ \\
Cs-137 & $2.4 \times 10^{-5}$ & $2.1 \times 10^{-5}$ & $2.5 \times 10^{-5}$ & $2.3 \times 10^{-5}$ & $2.4 \times 10^{-5}$ \\
U-234 & $9.7 \times 10^{-2}$ & $9.3 \times 10^{-2}$ & $8.5 \times 10^{-2}$ & $1.5 \times 10^{-1}$ & $1.0 \times 10^{-1}$ \\
U-238 & $8.9 \times 10^{-2}$ & $8.3 \times 10^{-2}$ & $9.2 \times 10^{-2}$ & $1.3 \times 10^{-1}$ & $9.1 \times 10^{-2}$ \\
Pu-239 & $3.8 \times 10^{-1}$ & $2.1 \times 10^{-1}$ & $3.9 \times 10^{-1}$ & $2.9 \times 10^{-1}$ & $3.3 \times 10^{-1}$ \\
\hline
\end{tabular}

a $\mathrm{NC}=$ not calculated.

\title{
2.3.4 Soil Ingestion Pathway
}

The third series of benchmarking runs was performed for the soil ingestion dose pathway for radionuclides present in the top $15 \mathrm{~cm}$ of soil. Because the DECOM and PRESTO codes do not consider the soil ingestion pathway, RESRAD could not be compared with those codes.

The RESRAD default value for the annual ingestion rate of soil ( $36.5 \mathrm{~g} / \mathrm{yr}$ ) was used as the baseline ingestion rate in the other models. This baseline ingestion rate was adjusted to account for occupancy factors and dilution with uncontaminated materials. The RESRAD default adjustment value is 0.45 , which was derived by assuming $25 \%$ outdoor occupancy, $50 \%$ indoor occupancy with $40 \%$ of ingested material originating from contaminated soill, and $25 \%$ off-site occupancy. 


\subsubsection{RESRAD vs. GENII-S}

To adjust for the soil ingestion rate and the occupancy and dilution factors used by RESRAD, the soil ingestion rate in GENII-S was reduced from the default value of 410 to $45 \mathrm{mg} / \mathrm{d}$. Table 11 compares the soil ingestion doses obtained with the two codes.

RESRAD calculated a higher ingestion dose for all cases. The doses calculated by GENII-S and RESRAD agreed within a factor of 1.2 to 2.9, with the exception of the uranium isotopes and Pu-239 (RESRAD calculated doses that were more than 10 times higher). These discrepancies may be attributed to differences in the dose factor method used by GENII-S to calculate the committed effective dose equivalent, as well as the less conservative dose factors for uranium and plutonium used by GENII-S.

\subsubsection{RESRAD vs. NUREG/CR-5512}

Equation 5.73 in NUREG/CR-5512 was used to calculate the soil ingestion dose. This equation does not account for the fraction of soil or dust ingested that originates from uncontaminated sources. Therefore, the effective transfer rate for ingestion of soil was reduced from the default value of $5 \times 10^{-2}$ to $4.5 \times 10^{-2} \mathrm{~g} / \mathrm{d}$ to be consistent with the occupancy and dilution factor used in RESRAD. The dose factors for ingestion were obtained from Table E.2 of the NUREG report after converting from units of Sv/Bq to units of $\mathrm{mrem} / \mathrm{pCi}$. Table 12 lists the soil ingestion doses obtained with the two codes. For all radionuclides, the doses calculated by the two models were the same within a factor of 1.2.

\subsubsection{Summary of the Soil Ingestion Pathway}

Table 13 summarizes the soil ingestion pathway doses at time zero calculated by using three of the five models.

TABLE 11 Comparison of Soil Ingestion Dose Calculations, RESRAD vs. GENII-S (time zero)

\begin{tabular}{llll}
\hline & \multicolumn{2}{c}{ Doses (mrem/yr) } & \\
\cline { 2 - 3 } Radionuclide & GENII-S & RESRAD & $\begin{array}{c}\text { Dose Ratio, } \\
\text { RESRAD/GENII-S }\end{array}$ \\
\hline Co-60 & $1.5 \times 10^{-4}$ & $4.3 \times 10^{-4}$ & 2.9 \\
Sr-90 & $1.8 \times 10^{-3}$ & $2.3 \times 10^{-3}$ & 1.3 \\
I-129 & $3.7 \times 10^{-3}$ & $4.6 \times 10^{-3}$ & 1.2 \\
Cs-137 & $7.1 \times 10^{-4}$ & $8.2 \times 10^{-4}$ & 1.2 \\
U-234 & $3.9 \times 10^{-4}$ & $4.3 \times 10^{-3}$ & $1.1 \times 10^{1}$ \\
U-238 & $3.5 \times 10^{-4}$ & $4.1 \times 10^{-3}$ & $1.2 \times 10^{1}$ \\
Pu-239 & $7.5 \times 10^{-4}$ & $7.1 \times 10^{-2}$ & $9.5 \times 10^{1}$ \\
\hline
\end{tabular}


TABLE 12 Comparison of Soil Ingestion Dose Calculations, RESRAD vs. NUREG/CR-5512 (time zero)

\begin{tabular}{lccc}
\hline & \multicolumn{2}{c}{ Doses (mrem/yr) } & \\
\cline { 2 - 3 } Radionuclide & NUREG & RESRAD & $\begin{array}{c}\text { Dose Ratio, } \\
\text { RESRAD/NUREG }\end{array}$ \\
\hline Co-60 & $4.4 \times 10^{-4}$ & $4.3 \times 10^{-4}$ & $9.7 \times 10^{-1}$ \\
Sr-90 & $2.5 \times 10^{-3}$ & $2.3 \times 10^{-3}$ & $9.1 \times 10^{-1}$ \\
I-129 & $4.5 \times 10^{-3}$ & $4.6 \times 10^{-3}$ & 1.0 \\
Cs-137 & $8.2 \times 10^{-4}$ & $8.2 \times 10^{-4}$ & 1.0 \\
U-234 & $4.7 \times 10^{-3}$ & $4.3 \times 10^{-3}$ & $9.2 \times 10^{-1}$ \\
U-238 & $4.4 \times 10^{-3}$ & $4.1 \times 10^{-3}$ & $9.3 \times 10^{-1}$ \\
Pu-239 & $5.8 \times 10^{-2}$ & $7.1 \times 10^{-2}$ & 1.2 \\
\hline
\end{tabular}

TABLE 13 Comparison of Soil Ingestion Dose Calculations, All Models (time zero)

\begin{tabular}{llllll}
\hline & \multicolumn{5}{c}{ Doses (mrem/yr) } \\
\cline { 2 - 6 } Radionuclide & RESRAD & GENII-S & DECOM & PRESTO & NUREG \\
\hline & & & & \\
Co-60 & $4.3 \times 10^{-4}$ & $1.5 \times 10^{-4}$ & NC & NC & $4.4 \times 10^{-4}$ \\
Sr-90 & $2.3 \times 10^{-3}$ & $1.8 \times 10^{-3}$ & NC & NC & $2.5 \times 10^{-3}$ \\
I-129 & $4.6 \times 10^{-3}$ & $3.7 \times 10^{-3}$ & NC & NC & $4.5 \times 10^{-3}$ \\
Cs-137 & $8.2 \times 10^{-4}$ & $7.1 \times 10^{-4}$ & NC & NC & $8.2 \times 10^{-4}$ \\
U-234 & $4.3 \times 10^{-3}$ & $3.9 \times 10^{-4}$ & NC & NC & $4.7 \times 10^{-3}$ \\
U-238 & $4.1 \times 10^{-3}$ & $3.5 \times 10^{-4}$ & NC & NC & $4.4 \times 10^{-3}$ \\
Pu-239 & $7.1 \times 10^{-2}$ & $7.5 \times 10^{-4}$ & NC & NC & $5.8 \times 10^{-2}$ \\
\hline
\end{tabular}

a $\mathrm{NC}=$ not calculated.

A dose comparison for the soil ingestion pathway was possible for only three of the five models: RESRAD, GENII-S, and NUREG/CR-5512. Excellent agreement was obtained between RESRAD and NUREG/CR-5512, where doses from all radionuclides were within a factor of 1.2. The doses from U-234 and U-238 calculated by GENII-S were one order of magnitude lower, while the Pu-239 dose was two orders of magnitude lower. The doses calculated by GENII-S for the other radionuclide were in much better agreement with doses calculated by RESRAD and NUREG/CR-5512. The dose conversion factors used by GENII-S probably account for these differences.

\subsubsection{Food Ingestion Pathways}

The fourth series of benchmarking runs was performed for the food ingestion. pathway for radionuclides present in the top $15 \mathrm{~cm}$ of soil. Ingestion doses were calculated. 
for the consumption of plants, meat, and milk produced on a contaminated site. In the RESRAD model, all pathways except the plant, meat, and milk pathway were suppressed. In GENII-S, these pathways are identified as terrestrial food and animal food ingestion pathways. In DECOM, the plant, meat, and milk pathways are all included within the food ingestion pathway. In PRESTO, the doses from the food ingestion pathways are summed. Several equations in Chapter 5.0 of NUREG/CR-5512 were used to calculate the dose from the food ingestion pathways.

The RESRAD default values for the annual ingestion rates of leafy vegetables (14 kg/yr); other vegetables, fruits, and grains (160 kg/yr); meat (63 kg/yr); and milk (92 L/yr) were used as the baseline consumption rates in the other models. The baseline rates are adjusted automatically in the RESRAD code to account for the fraction obtained off-site (50\% of plant products) or the fraction raised on uncontaminated soil (50\% of meat and milk products). In the other models, the fraction of contaminated food was adjusted either explicitly or by dividing the doses obtained by a factor of two.

The method for treatment of the food ingestion pathways by the various models ranges from use of relatively few parameters (DECOM) to use of a large number of parameters (GENII-S, PRESTO, and NUREG/CR-5512); RESRAD is between the two extremes. DECOM accounts for root uptake but not foliar deposition in the plant ingestion pathway, and fodder ingestion rates by cattle are incorporated directly into the transfer factors. GENII-S, PRESTO, and NUREG/CR-5512, however, include such parameters as plant growing times, food storage times before consumption, and fraction of animal feed that is fresh pasture. For long-lived radionuclides, the parameters that will have a more significant impact on the ingestion doses are the transfer factors, consumption rates, and dose factors.

\subsubsection{RESRAD vS. GENII-S}

Table 14 compares doses calculated by RESRAD and GENII-S for ingestion pathways. For calculation of the dose from ingestion of plants grown on contaminated soil, the default consumption rates in GENII-S were changed from 15 to $14 \mathrm{~kg} / \mathrm{yr}$ for leafy vegetables. The GENII-S code allows the user to specify the consumption of other vegetables, fruits, and grains separately, with defaults of 140,64 , and $72 \mathrm{~kg} / \mathrm{yr}$, respectively. Because RESRAD uses a single consumption rate, the RESRAD default value of $160 \mathrm{~kg} / \mathrm{yr}$ was allocated equally among these three plant types ( $53.3 \mathrm{~kg} / \mathrm{yr}$ each). Also, because the RESRAD code assumes that $50 \%$ of plant products consumed are imported, the results obtained with the GENII-S code (which considers all products to be grown on-site) had to be divided by 2 . The transfer factors for leafy vegetables, other vegetables, fruits, and grains included in GENII-S were changed to the single default value used by RESRAD for soil-to-plant transfer for each radionuclide. By dividing the RESRAD transfer factors by the moisture content in each plant type (from NUREG/CR-5512, Table 6.17), these transfer factors were converted from a wet-weight basis to the dry-weight basis used in GENII-S. In GENII-S, the fraction of roots in contaminated surface soil was set to 0.167 by taking the ratio of contaminated soil thickness $(15 \mathrm{~cm})$ to the RESRAD default root depth $(90 \mathrm{~cm})$. 
TABLE 14 Comparison of Food Ingestion Dose Calculations, RESRAD vs. GENII-S (time zero)

\begin{tabular}{llll}
\hline & \multicolumn{2}{c}{ Doses (mrem/yr) } & \\
\cline { 2 - 3 } Radionuclide & GENII-S & RESRAD & $\begin{array}{c}\text { Dose Ratio, } \\
\text { RESRAD/GENII-S }\end{array}$ \\
\cline { 2 - 3 } Plant ingestion & & & \\
Co-60 & $1.9 \times 10^{-3}$ & $3.6 \times 10^{-3}$ & 1.9 \\
Sr-90 & $2.4 \times 10^{-1}$ & $4.1 \times 10^{-1}$ & 1.7 \\
I-129 & $4.7 \times 10^{-2}$ & $8.3 \times 10^{-2}$ & 1.8 \\
Cs-137 & $4.4 \times 10^{-3}$ & $1.5 \times 10^{-3}$ & $3.4 \times 10^{-1}$ \\
U-234 & $6.5 \times 10^{-4}$ & $9.6 \times 10^{-3}$ & $1.5 \times 10^{1}$ \\
U-238 & $6.8 \times 10^{-4}$ & $9.2 \times 10^{-3}$ & $1.4 \times 10^{1}$ \\
Pu-239 & $2.1 \times 10^{-4}$ & $1.8 \times 10^{-2}$ & $8.9 \times 10^{1}$ \\
& & & \\
Meat ingestion & & & \\
Co-60 & $4.7 \times 10^{-5}$ & $8.9 \times 10^{-5}$ & 1.9 \\
Sr-90 & $2.7 \times 10^{-3}$ & $3.0 \times 10^{-3}$ & 1.1 \\
I-129 & $3.6 \times 10^{-2}$ & $4.3 \times 10^{-2}$ & 1.2 \\
Cs-137 & $1.5 \times 10^{-3}$ & $1.2 \times 10^{-3}$ & $8.0 \times 10^{-1}$ \\
U-234 & $1.6 \times 10^{-4}$ & $1.2 \times 10^{-3}$ & 8.0 \\
U-238 & $2.2 \times 10^{-4}$ & $1.2 \times 10^{-3}$ & 5.4 \\
Pu-239 & $1.1 \times 10^{-4}$ & $3.2 \times 10^{-3}$ & $3.0 \times 10^{1}$ \\
& & & \\
Milk ingestion & & & \\
Co-60 & $2.8 \times 10^{-5}$ & $5.2 \times 10^{-5}$ & 1.9 \\
Sr-90 & $1.5 \times 10^{-2}$ & $1.8 \times 10^{-2}$ & 1.2 \\
I-129 & $2.1 \times 10^{-2}$ & $2.6 \times 10^{-2}$ & 1.2 \\
Cs-137 & $2.6 \times 10^{-4}$ & $2.3 \times 10^{-4}$ & $8.8 \times 10^{-1}$ \\
U-234 & $2.1 \times 10^{-5}$ & $1.8 \times 10^{-4}$ & 8.6 \\
U-238 & $1.9 \times 10^{-5}$ & $1.7 \times 10^{-4}$ & 8.7 \\
Pu-239 & $5.0 \times 10^{-10}$ & $1.9 \times 10^{-8}$ & $3.8 \times 10^{1}$ \\
\hline
\end{tabular}

As shown in Table 14, for all radionuclides except Cs-137, doses calculated by RESRAD were higher by factors ranging from 1.8 to 89 . The Cs-137 dose was three times lower. The ratios calculated for the plant pathway for each radionuclide were very close to the ratios calculated for the soil ingestion pathway for the same radionuclides. This similarity indicates that dose factor differences account for most of the discrepancies between the two models.

To calculate the dose from ingestion of meat, the default value for beef consumption in GENII-S was changed from 70 to $63 \mathrm{~kg} / \mathrm{yr}$. The consumption rate for poultry and eggs in GENII-S was set to 0. The fraction of feed from fresh pasture was set to 1.0 (i.e., no stored feed). In GENII-S, the code's default values for plant-to-meat transfer factors were replaced with RESRAD default values. The GENII-S code does not allow the user to specify the cattle's intake rate of fodder; it is not clear how this value differs from the RESRAD default value. Because RESRAD assumes that an area of at least $20,000 \mathrm{~m}^{2}$ is needed to raise cattle, 
an area factor of 0.5 is automatically calculated by the code. Therefore, the meat ingestion doses calculated by GENII-S were divided by 2 to obtain the doses listed in Table 14 .

For all radionuclides except Cs-137, the doses calculated by RESRAD were higher by factors of 1.1 to 30 . The Cs-137 dose was $20 \%$ lower. As was the case for the plant ingestion pathway, much of the discrepancy between the two models can be attributed to dose factor differences.

To calculate the dose from ingestion of milk, the default value for milk consumption in GENII-S was changed from 230 to $92 \mathrm{~L} / \mathrm{yr}$. The fraction of feed from fresh pasture was set at 1.0. Because RESRAD assumes an area factor of 0.5 , the milk ingestion doses calculated by GENII-S were divided by 2 to obtain the doses listed in Table 14 . For all radionuclides except $\mathrm{Cs}-137$, the doses calculated by RESRAD were higher than the GENII-S doses by factors ranging from 1.2 to 38 . The Cs-137 dose was slightly lower.

\subsubsection{RESRAD vs. DECOM}

Table 15 compares ingestion dose results computed by RESRAD and DECOM. To calculate the dose from ingestion of plants grown on contaminated soil, the default consumption rates in DECOM were changed from 18 to $14 \mathrm{~kg} / \mathrm{yr}$ for leafy vegetables and from 176 to $160 \mathrm{~kg} / \mathrm{yr}$ for other vegetables, fruits, and grains. The soil-to-plant transfer factors were changed to the RESRAD defaults. Because the RESRAD code assumes that $50 \%$ of the plant products consumed are imported, the percentage of leafy vegetables and produce grown on-site was changed from the DECOM default of $100 \%$ to $50 \%$.

In all cases, except for U-234 and Pu-239, the plant ingestion doses obtained with RESRAD were about 5 times lower than the DECOM doses. The RESRAD-calculated U-234 and Pu-239 doses were approximately 2 times higher than those calculated by DECOM (Table 15).

To calculate the dose from ingestion of meat, the default value for meat consumption in DECOM was changed from 94 to $63 \mathrm{~kg} / \mathrm{yr}$. For DECOM, the percentage of meat produced on-site was changed from the default value of $100 \%$ to $50 \%$ to account for the area factor applied by RESRAD. The transfer factor used by DECOM for pasture feed was converted to the required dry-weight basis by dividing the RESRAD default soil-to-plant transfer factor (wet-weight basis) by 0.22 to account for the moisture content in pasture grass. This value is the same one recommended in NUREG/CR-5512 to convert from dry-weight to wet-weight transfer factors. The DECOM code also uses soil-to-meat transfer factors that account for the ingestion of soil by animals, a subpathway not considered by RESRAD Version 4.6. The DECOM code also includes another parameter not used by RESRAD Version 4.6 - the quantity of soil ingested by a cow. ${ }^{2}$ The DECOM default value for this parameter

2 Ingestion of soil by animals is considered in Version 5.0 of RESRAD (Yu et al. 1993). 
TABLE 15 Comparison of Food Ingestion Dose Calculations, RESRAD vs. DECOM (time zero)

\begin{tabular}{llll}
\hline & \multicolumn{2}{c}{ Doses (mrem/yr) } & \\
\cline { 2 - 3 } Radionuclide & DECOM & RESRAD & $\begin{array}{c}\text { Dose Ratio, } \\
\text { RESRAD/DECOM }\end{array}$ \\
\cline { 2 - 3 } Plant ingestion & & & \\
Co-60 & $2.0 \times 10^{-2}$ & $3.6 \times 10^{-3}$ & $1.8 \times 10^{-1}$ \\
Sr-90 & 2.1 & $4.1 \times 10^{-1}$ & $1.9 \times 10^{-1}$ \\
Cs-137 & $8.2 \times 10^{-3}$ & $1.5 \times 10^{-3}$ & $1.8 \times 10^{-1}$ \\
U-234 & $5.2 \times 10^{-3}$ & $9.6 \times 10^{-3}$ & 1.9 \\
U-238 & $4.7 \times 10^{-2}$ & $9.2 \times 10^{-3}$ & $2.0 \times 10^{-1}$ \\
Pu-239 & $8.8 \times 10^{-3}$ & $1.8 \times 10^{-2}$ & 2.1 \\
& & & \\
Meat ingestion & & & \\
Co-60 & $8.9 \times 10^{-3}$ & $8.9 \times 10^{-5}$ & $1.0 \times 10^{-2}$ \\
Sr-90 & $5.0 \times 10^{-2}$ & $3.0 \times 10^{-3}$ & $6.0 \times 10^{-2}$ \\
Cs-137 & $1.8 \times 10^{-1}$ & $1.2 \times 10^{-3}$ & $6.6 \times 10^{-3}$ \\
U-234 & $8.2 \times 10^{-5}$ & $1.2 \times 10^{-3}$ & $1.5 \times 10^{1}$ \\
U-238 & $7.5 \times 10^{-4}$ & $1.2 \times 10^{-3}$ & 1.5 \\
Pu-239 & $1.4 \times 10^{-6}$ & $3.2 \times 10^{-3}$ & $2.2 \times 10^{3}$ \\
Milk ingestion & & & \\
Co-60 & & & \\
Sr-90 & $1.3 \times 10^{-3}$ & $5.2 \times 10^{-5}$ & $4.0 \times 10^{-2}$ \\
Cs-137 & $3.6 \times 10^{-1}$ & $1.8 \times 10^{-2}$ & $4.9 \times 10^{-2}$ \\
U-234 & $9.0 \times 10^{-2}$ & $2.3 \times 10^{-4}$ & $2.5 \times 10^{-3}$ \\
U-238 & $3.6 \times 10^{-4}$ & $1.8 \times 10^{-4}$ & $4.9 \times 10^{-1}$ \\
Pu-239 & $3.3 \times 10^{-3}$ & $1.7 \times 10^{-4}$ & $5.1 \times 10^{-2}$ \\
\hline
\end{tabular}

$(500 \mathrm{~g} / \mathrm{d})$ and the soil-to-meat transfer factors were left unchanged. The DECOM code does not allow the user to specify the cattle's intake rate of fodder; it is not clear how this value differs from the RESRAD default value.

As shown in Table 15, for Co-60, Sr-90, and Cs-137, the doses obtained with RESRAD were lower than the DECOM doses by factors ranging from 16 to 150 . For the uranium isotopes and Pu-239, the doses calculated by RESRAD were 1.5 to 2,200 times higher than the DECOM doses. Differences in the transfer factor methods used, rather than dose factor differences, account for most of the differences in the results.

To calculate the dose from ingestion of milk, the default value for milk consumption in DECOM was changed from 112 to $92 \mathrm{~L} / \mathrm{yr}$. The percentage of milk produced on-site was changed from the default value of $100 \%$ to $50 \%$ to account for the area factor applied by RESRAD. Similar issues regarding parameters used by DECOM to calculate the meat ingestion dose were encountered with the milk ingestion pathway; as with the meat ingestion pathway, DECOM default soil-to-meat transfer factors and soil ingestion rates were not 
changed. For all radionuclides, the doses obtained by using RESRAD were lower than the DECOM doses by factors ranging from 2 to 400 (Table 15).

\subsubsection{RESRAD vs. PRESTO}

Table 16 compares ingestion doses calculated by RESRAD and PRESTO. To calculate the dose from ingestion of plants grown on contaminated soil, the default consumption rates in PRESTO were changed from 88.5 to $160 \mathrm{~kg} / \mathrm{yr}$ for other vegetables, fruits, and grains (in both RESRAD and PRESTO, the default for leafy vegetable consumption is $14 \mathrm{~kg} / \mathrm{yr}$ ). Because the RESRAD code assumes that $50 \%$ of plant products consumed are imported, the results obtained with the PRESTO code were divided by 2 . The soil-to-plant transfer factors for leafy vegetables and for other vegetables, fruits, and grains included in PRESTO were changed to the single default value used by RESRAD.

TABLE 16 Comparison of Food Ingestion Dose Calculations, RESRAD vs. PRESTO (time zero)

\begin{tabular}{llll}
\hline & \multicolumn{2}{c}{ Doses (mrem/yr) } & \\
\cline { 2 - 3 } Radionuclide & PRESTO & RESRAD & $\begin{array}{c}\text { Dose Ratio, } \\
\text { RESRAD/PRESTO }\end{array}$ \\
\hline Plant ingestion & & & \\
Co-60 & $1.9 \times 10^{-4}$ & $3.6 \times 10^{-3}$ & $1.8 \times 10^{1}$ \\
Sr-90 & $3.1 \times 10^{-3}$ & $4.1 \times 10^{-1}$ & $1.3 \times 10^{2}$ \\
I-129 & $4.2 \times 10^{-3}$ & $8.3 \times 10^{-2}$ & $2.0 \times 10^{-1}$ \\
Cs-137 & $5.1 \times 10^{-4}$ & $1.5 \times 10^{-3}$ & 2.9 \\
U-234 & $1.1 \times 10^{-4}$ & $9.6 \times 10^{-3}$ & $9.1 \times 10^{1}$ \\
U-238 & $9.9 \times 10^{-5}$ & $9.2 \times 10^{-3}$ & $9.3 \times 10^{1}$ \\
Pu-239 & $1.7 \times 10^{-3}$ & $1.8 \times 10^{-2}$ & $1.1 \times 10^{1}$ \\
& & & \\
Meat ingestion & & & $1.0 \times 10^{1}$ \\
Co-60 & $8.7 \times 10^{-6}$ & $8.9 \times 10^{-5}$ & $9.1 \times 10^{1}$ \\
Sr-90 & $3.3 \times 10^{-5}$ & $3.0 \times 10^{-3}$ & 4.6 \\
I-129 & $9.4 \times 10^{-3}$ & $4.3 \times 10^{-2}$ & 1.1 \\
Cs-137 & $1.0 \times 10^{-3}$ & $1.2 \times 10^{-3}$ & $3.6 \times 10^{1}$ \\
U-234 & $3.4 \times 10^{-5}$ & $1.2 \times 10^{-3}$ & $3.7 \times 10^{1}$ \\
U-238 & $3.2 \times 10^{-5}$ & $1.2 \times 10^{-3}$ & \\
Pu-239 & $9.9 \times 10^{-4}$ & $3.2 \times 10^{-3}$ & 3.2 \\
& & & \\
Milk ingestion & & & \\
Co-60 & $7.3 \times 10^{-6}$ & $5.2 \times 10^{-5}$ & 7.2 \\
Sr-90 & $3.1 \times 10^{-4}$ & $1.8 \times 10^{-2}$ & $5.7 \times 10^{1}$ \\
I-129 & $5.8 \times 10^{-3}$ & $2.6 \times 10^{-2}$ & 4.4 \\
Cs-137 & $2.4 \times 10^{-4}$ & $2.3 \times 10^{-4}$ & $9.4 \times 10^{-1}$ \\
U-234 & $5.9 \times 10^{-6}$ & $1.8 \times 10^{-4}$ & $3.0 \times 10^{1}$ \\
U-238 & $5.6 \times 10^{-6}$ & $1.7 \times 10^{-4}$ & $3.0 \times 10^{1}$ \\
Pu-239 & $6.2 \times 10^{-9}$ & $1.9 \times 10^{-8}$ & 3.0 \\
\hline
\end{tabular}


As shown in Table 16, for all radionuclides, RESRAD calculated higher plant ingestion doses than PRESTO by factors ranging from 2.9 to 130 .

To calculate the meat ingestion dose, the default value for beef consumption in PRESTO was changed from 62.8 to $63 \mathrm{~kg} / \mathrm{yr}$, and the fraction of feed from fresh pasture was set to 1.0 (i.e., no stored feed). RESRAD default values for plant-to-meat transfer factors were used. The cattle's intake rate of fodder was changed from the PRESTO default of $50 \mathrm{~kg} / \mathrm{d}$ to the RESRAD default of $68 \mathrm{~kg} / \mathrm{d}$. As with the other codes, the meat ingestion doses calculated by PRESTO were divided by 2 to account for the area factor calculated by RESRAD. As with the plant ingestion pathway, RESRAD calculated higher doses than PRESTO by factors of 1.1 to 91 (Table 16).

Milk ingestion doses were calculated by changing the PRESTO default value for consumption of cow's milk from 89.4 to $92 \mathrm{~L} / \mathrm{yr}$. The ingestion rate of goat's milk was set to 0 . The fraction of feed from fresh pasture was set to 1.0. Because RESRAD assumes an area factor of 0.5 , the milk ingestion doses calculated by PRESTO were divided by 2 to obtain the doses listed in Table 16. RESRAD calculated higher doses for all radionuclides except Cs-137 (1.1 times lower). In all three ingestion pathways, the best agreement was obtained for Cs-137 doses, while the largest differences were for the Sr-90 doses.

\subsubsection{RESRAD vs. NUREG/CR-5512}

Table 17 compares ingestion doses from RESRAD and NUREG/CR-5512. Equation 5.5 in NUREG/CR-5512 was used to calculate the radionuclide concentrations in edible parts of plants. The results were entered in Equations 5.9, 5.10, 5.67, 5.71, and 5.72 of NUREG/CR-5512 to calculate the produce ingestion dose. The transfer factors for root uptake used in NUREG/CR-5512 require conversion from a dry-weight to a wet-weight basis. This conversion was not required when entering the RESRAD default transfer factors because they are already based on wet weight. The mass loading transfer factor (referred to as the foliar deposition model in RESRAD) used by NUREG/CR-5512 was set to 0.1 for leafy vegetables and 0.01 for all other vegetables, fruits, and grains after reviewing the values reported in Table 6.9 of NUREG/CR-5512. Because of the long half-life of all radionuclides used in this report, all factors involving radiological decay functions were set to 0 decay over one year to simplify the calculations. The annual ingestion rate of leafy vegetables listed in Table 6.15 of NUREG/CR-5512 (11 kg/yr) was replaced with the RESRAD default of $14 \mathrm{~kg} / \mathrm{yr}$. The values reported in the same table for other vegetables, fruits, and grains are 51,46 , and $69 \mathrm{~kg} / \mathrm{yr}$, respectively; the total of $166 \mathrm{~kg} / \mathrm{yr}$ was replaced with the RESRAD default of $160 \mathrm{~kg} / \mathrm{yr}$ (apportioned equally among the three produce categories). The dose factors for ingestion were obtained from Table E.2 of the NUREG report after converting from units of $\mathrm{Sv} / \mathrm{Bq}$ to units of $\mathrm{mrem} / \mathrm{pCi}$. The diet fraction parameter was set to 0.5 to account for the fraction of produce grown on-site.

The doses calculated by NUREG/CR-5512 were 6.3 to 100 times higher than those calculated by RESRAD (Table 17). Differences in the foliar deposition model may account for these discrepancies. 
TABLE 17 Comparison of Food Ingestion Dose Calculations, RESRAD vs. NUREG/CR-5512 (time zero)

\begin{tabular}{llll} 
& \multicolumn{2}{c}{ Doses (mrem/yr) } & \\
\cline { 2 - 3 } Radionuclide & NUREG & RESRAD & $\begin{array}{c}\text { Dose Ratio, } \\
\text { RESRAD/NUREG }\end{array}$ \\
\cline { 2 - 3 } Plant ingestion & & & \\
Co-60 & $3.5 \times 10^{-2}$ & $3.6 \times 10^{-3}$ & $1.0 \times 10^{-1}$ \\
Sr-90 & 2.6 & $4.1 \times 10^{-1}$ & $1.6 \times 10^{-1}$ \\
I-129 & $6.2 \times 10^{-1}$ & $8.3 \times 10^{-2}$ & $1.3 \times 10^{-1}$ \\
Cs-137 & $3.4 \times 10^{-2}$ & $1.5 \times 10^{-3}$ & $4.4 \times 10^{-2}$ \\
U-234 & $2.0 \times 10^{-1}$ & $9.6 \times 10^{-3}$ & $4.7 \times 10^{-2}$ \\
U-238 & $1.9 \times 10^{-1}$ & $9.2 \times 10^{-3}$ & $4.8 \times 10^{-2}$ \\
Pu-239 & 1.8 & $1.8 \times 10^{-2}$ & $9.9 \times 10^{-3}$ \\
& & & \\
Meat ingestion & & & \\
Co-60 & $1.7 \times 10^{-3}$ & $8.9 \times 10^{-5}$ & $5.3 \times 10^{-2}$ \\
Sr-90 & $2.3 \times 10^{-2}$ & $3.0 \times 10^{-3}$ & $1.3 \times 10^{-1}$ \\
I-129 & $4.7 \times 10^{-1}$ & $4.3 \times 10^{-2}$ & $9.2 \times 10^{-2}$ \\
Cs-137 & $7.0 \times 10^{-2}$ & $1.2 \times 10^{-3}$ & $1.7 \times 10^{-2}$ \\
U-234 & $6.8 \times 10^{-2}$ & $1.2 \times 10^{-3}$ & $1.8 \times 10^{-2}$ \\
U-238 & $6.4 \times 10^{-2}$ & $1.2 \times 10^{-3}$ & $1.9 \times 10^{-2}$ \\
Pu-239 & $7.6 \times 10^{-1}$ & $3.2 \times 10^{-3}$ & $4.2 \times 10^{-3}$ \\
Milk ingestion & & & \\
Co-60 & & & \\
Sr-90 & $1.0 \times 10^{-3}$ & $5.2 \times 10^{-5}$ & $5.1 \times 10^{-2}$ \\
I-129 & $1.2 \times 10^{-1}$ & $1.8 \times 10^{-2}$ & $1.5 \times 10^{-1}$ \\
Cs-137 & $2.9 \times 10^{-1}$ & $2.6 \times 10^{-2}$ & $9.0 \times 10^{-2}$ \\
U-234 & $1.4 \times 10^{-2}$ & $2.3 \times 10^{-4}$ & $1.6 \times 10^{-2}$ \\
U-238 & $1.0 \times 10^{-2}$ & $1.8 \times 10^{-4}$ & $1.7 \times 10^{-2}$ \\
Pu-239 & $9.0 \times 10^{-3}$ & $1.7 \times 10^{-4}$ & $1.9 \times 10^{-2}$ \\
\hline & $4.7 \times 10^{-6}$ & $1.9 \times 10^{-8}$ & $4.0 \times 10^{-3}$ \\
\hline
\end{tabular}

Equations 5.15, 5.18, 5.19, 5.20, 5.67, 5.71, and 5.72 in NUREG/CR-5512 were used to calculate the concentrations in meat and the meat ingestion dose. As with the plant ingestion pathway, transfer factors for root uptake used in NUREG/CR-5512 for fodder require conversion from a dry-weight basis to a wet-weight basis. No conversion was required when entering the RESRAD default transfer factors. The mass loading transfer factor used by NUREG/CR-5512 was set to 0.07 for pasture grasses after reviewing the values reported in Table 6.9. The consumption rate of fresh forage listed in Table 6.23 of NUREG/CR-5512 for beef cattle was changed from $27 \mathrm{~kg} / \mathrm{d}$ to the RESRAD default of $68 \mathrm{~kg} / \mathrm{d}$. As in the DECOM code, the NUREG/CR-5512 methodology includes the transfer of contaminants from soil to meat as the result of ingestion of soil by cattle during foraging. The parameter in NUREG/CR-5512 for this process is the fraction of forage intake that is made up of contaminated soil. The default value for this parameter is listed as 0.02 in Table 6.23 of NUREG/CR-5512. The fraction of pasture forage eaten by a cow that is grown on uncontaminated soil was set to 0.5 . All factors involving radiological decay functions were 
set to 0 decay over one year to simplify the calculations. The annual ingestion rates of beef and poultry listed in Table 6.15 of NUREG/CR-5512 total $68 \mathrm{~kg} / \mathrm{yr}$; this was replaced with the RESRAD default of $63 \mathrm{~kg} / \mathrm{yr}$. The dose factors for ingestion were obtained from Table E.2 of the report after converting from units of $\mathrm{Sv} / \mathrm{Bq}$ to units of $\mathrm{mrem} / \mathrm{pCi}$.

As shown in Table 17, the doses calculated with NUREG/CR-5512 are 7.6 to 240 times higher than those calculated by RESRAD. These differences may result in large part from model differences, including the foliar deposition transfer model and the direct soil-to-cow transfer model.

The equations used to calculate the milk ingestion dose in NUREG/CR-5512 are the same as those used for the meat ingestion pathway. The only differences are the plant-to-milk transfer factors and the fodder and milk consumption rates. RESRAD default values were used for the transfer factors. The fodder ingestion rate for milk cattle was changed from $36 \mathrm{~kg} / \mathrm{d}$ (Table 6.23 in NUREG/CR-5512) to the RESRAD default value of $55 \mathrm{~kg} / \mathrm{d}$. The milk consumption rate was changed from $100 \mathrm{~L} / \mathrm{yr}$ (Table 6.15 in NUREG/ $\mathrm{CR}-5512$ ) to the RESRAD default value of $92 \mathrm{~L} / \mathrm{yr}$. All other parameters were the same as for the meat ingestion pathway.

The doses calculated with NUREG/CR-5512 were 6.7 to 250 times higher than doses calculated by RESRAD (Table 17). These differences are similar in magnitude when compared to ratios calculated for the meat ingestion doses.

\subsubsection{Summary of the Food Ingestion Pathways}

Table 18 summarizes the inhalation pathway doses at time zero calculated by using each of the five models.

For all radionuclides in the plant ingestion pathway, the doses calculated by using the NUREG/CR-5512 methodology were consistently higher than the doses calculated by all other models. The PRESTO code calculated the lowest plant ingestion doses for all radionuclides except $\mathrm{Pu}-239$ (GENII-S calculated a lower dose). The difference between the highest and lowest calculated dose exceeded two orders of magnitude for most radionuclides but approached four orders of magnitude for Pu-239.

For the meat ingestion pathway, the highest doses calculated by using the NUREG/CR-5512 methodology were the highest doses calculated from the actinides; DECOM calculated the highest dose from the fission and activation products. As with the plant ingestion pathway, PRESTO calculated the lowest doses for all radionuclides except Pu-239 (in this case, DECOM calculated a lower dose). A large range of variability occurred between high and low doses, ranging from less than two orders of magnitude for I-129 to greater than five orders of magnitude for Pu-239. 
TABLE 18 Comparison of Food Ingestion Dose Calculations, All Models (time zero)

\begin{tabular}{|c|c|c|c|c|c|}
\hline \multirow[b]{2}{*}{ Radionuclide } & \multicolumn{5}{|c|}{ Doses (mrem/yr) } \\
\hline & RESRAD & GENII-S & DECOM & PRESTO & NUREG \\
\hline \multicolumn{6}{|l|}{ Plant ingestion } \\
\hline $\mathrm{Co}-60$ & $3.6 \times 10^{-3}$ & $1.9 \times 10^{-3}$ & $2.0 \times 10^{-2}$ & $1.9 \times 10^{-4}$ & $3.5 \times 10^{-2}$ \\
\hline Sr-90 & $4.1 \times 10^{-1}$ & $2.4 \times 10^{-1}$ & 2.1 & $3.1 \times 10^{-3}$ & 2.6 \\
\hline $\mathrm{I}-129$ & $8.3 \times 10^{-2}$ & $4.7 \times 10^{-2}$ & $\mathrm{NC}^{\mathrm{a}}$ & $4.2 \times 10^{-3}$ & $6.2 \times 10^{-1}$ \\
\hline Cs-137 & $1.5 \times 10^{-3}$ & $4.4 \times 10^{-3}$ & $8.2 \times 10^{-3}$ & $5.1 \times 10^{-4}$ & $3.4 \times 10^{-2}$ \\
\hline $\mathrm{U}-234$ & $9.6 \times 10^{-3}$ & $6.5 \times 10^{-4}$ & $5.2 \times 10^{-3}$ & $1.1 \times 10^{-4}$ & $2.0 \times 10^{-1}$ \\
\hline $\mathrm{U}-238$ & $9.2 \times 10^{-3}$ & $6.8 \times 10^{-4}$ & $4.7 \times 10^{-2}$ & $9.9 \times 10^{-5}$ & $1.9 \times 10^{-1}$ \\
\hline $\mathrm{Pu}-239$ & $1.8 \times 10^{-2}$ & $2.1 \times 10^{-4}$ & $8.8 \times 10^{-3}$ & $1.7 \times 10^{-3}$ & 1.8 \\
\hline \multicolumn{6}{|l|}{ Meat ingestion } \\
\hline $\mathrm{Co}-60$ & $8.9 \times 10^{-5}$ & $4.7 \times 10^{-5}$ & $8.9 \times 10^{-3}$ & $8.7 \times 10^{-6}$ & $1.7 \times 10^{-3}$ \\
\hline $\mathrm{Sr}-90$ & $3.0 \times 10^{-3}$ & $2.7 \times 10^{-3}$ & $5.0 \times 10^{-2}$ & $3.3 \times 10^{-5}$ & $2.3 \times 10^{-2}$ \\
\hline $\mathrm{I}-129$ & $4.3 \times 10^{-2}$ & $3.6 \times 10^{-2}$ & $\mathrm{NC}$ & $9.4 \times 10^{-3}$ & $4.7 \times 10^{-1}$ \\
\hline Cs-137 & $1.2 \times 10^{-3}$ & $1.5 \times 10^{-3}$ & $1.8 \times 10^{-1}$ & $1.0 \times 10^{-3}$ & $7.0 \times 10^{-2}$ \\
\hline $\mathrm{U}-234$ & $1.2 \times 10^{-3}$ & $1.6 \times 10^{-4}$ & $8.2 \times 10^{-5}$ & $3.4 \times 10^{-5}$ & $6.8 \times 10^{-2}$ \\
\hline $\mathrm{U}-238$ & $1.2 \times 10^{-3}$ & $2.2 \times 10^{-4}$ & $7.5 \times 10^{-4}$ & $3.2 \times 10^{-5}$ & $6.4 \times 10^{-2}$ \\
\hline $\mathrm{Pu}-239$ & $3.2 \times 10^{-3}$ & $1.1 \times 10^{-4}$ & $1.4 \times 10^{-6}$ & $9.9 \times 10^{-4}$ & $7.6 \times 10^{-1}$ \\
\hline \multicolumn{6}{|l|}{ Milk ingestion } \\
\hline $\mathrm{Co}-60$ & $5.2 \times 10^{-5}$ & $2.8 \times 10^{-5}$ & $1.3 \times 10^{-3}$ & $7.3 \times 10^{-6}$ & $1.0 \times 10^{-3}$ \\
\hline Sr-90 & $1.8 \times 10^{-2}$ & $1.5 \times 10^{-2}$ & $3.6 \times 10^{-1}$ & $3.1 \times 10^{-4}$ & $1.2 \times 10^{-1}$ \\
\hline I-129 & $2.6 \times 10^{-2}$ & $2.1 \times 10^{-2}$ & $\mathrm{NC}$ & $5.8 \times 10^{-3}$ & $2.9 \times 10^{-1}$ \\
\hline Cs-137 & $2.3 \times 10^{-4}$ & $2.6 \times 10^{-4}$ & $9.0 \times 10^{-2}$ & $2.4 \times 10^{-4}$ & $1.4 \times 10^{-2}$ \\
\hline U-234 & $1.8 \times 10^{-4}$ & $2.1 \times 10^{-5}$ & $3.6 \times 10^{-4}$ & $5.9 \times 10^{-6}$ & $1.0 \times 10^{-2}$ \\
\hline U-238 & $1.7 \times 10^{-4}$ & $1.9 \times 10^{-5}$ & $3.3 \times 10^{-3}$ & $5.6 \times 10^{-6}$ & $9.0 \times 10^{-3}$ \\
\hline $\mathrm{Pu}-239$ & $1.9 \times 10^{-8}$ & $5.0 \times 10^{-10}$ & $4.2 \times 10^{-7}$ & $6.2 \times 10^{-9}$ & $4.7 \times 10^{-6}$ \\
\hline
\end{tabular}

a $\mathrm{NC}=$ not calculated.

For the milk ingestion pathway, use of the NUREG/CR-5512 methodology once again resulted in the highest doses from the actinides; DECOM calculated the highest dose from the fission and activation products. While PRESTO still calculated the lowest doses for most radionuclides, RESRAD calculated the lowest dose for Cs-137 and GENII-S calculated the lowest dose for $\mathrm{Pu}-239$. As in the previous two pathways, a large variability was found in the calculated doses, ranging from two to three orders of magnitude for all radionuclides except $\mathrm{Pu}-239$ (four orders of magnitude).

Such a large variability in the food ingestion doses can be attributed primarily to differences in the mathematical formulae used by each code to model these pathways. Some additional variability is due to differences in the dose factors, as was the case for the soil ingestion pathway. 


\subsection{BENCHMARKING RESULTS - AFTER 500 YEARS}

Additional runs were performed for the point in time 500 years after time zero to investigate the effect of time on the calculated doses. Of the five models being used, only RESRAD and PRESTO calculate doses at more than one time over a user-selected time interval. PRESTO limits the user to a 1,000-year interval; the RESRAD default is 10,000 years. In GENII-S and DECOM, only one time can be calculated per run. For water-independent pathways, NUREG/CR-5512 does not explicitly indicate how doses at future times are to be calculated; for the groundwater pathway, the user is instructed to iterate the model once per year until a maximum dose is reached. Because of these considerations, a complete set of comparisons between RESRAD and the other five models could not be performed.

\subsubsection{Dust Inhalation Pathway}

To determine the effects of time on dose, the dust inhalation pathway was selected as representative of the water-independent pathways. All parameters that affect the leach rate from the 15- $\mathrm{cm}$ contaminated zone (including soil properties, meteorological parameters, and distribution coefficients) were set to the RESRAD defaults. One exception was the erosion rate, which was calculated with the PRESTO default file as $0.0002 \mathrm{~m} / \mathrm{yr}$. This ralue was used in the RESRAD run (the other three models do not account for erosion over time). The infiltration rate calculated by RESRAD is $0.4 \mathrm{~m} / \mathrm{yr}$ (precipitation plus irrigation corrected for runoff and evapotranspiration). GENII-S requires the user to enter leach rates in the transfer factor library. Leach rates were obtained from the values calculated by RESRAD on the basis of default distribution coefficients, soil density and porosity, saturation ratio, and infiltration rate. All other parameters applicable to time zero calculations (inhalation rates, mass loading, area dimensions, and occupancy and shielding factors) were not changed.

\subsubsection{RESRAD vs. GENII-S}

Table 19 compares the dust inhalation doses calculated by GENII-S and RESRAD after 500 years. For both codes, the dose from Co-60 and I-129 is effectively 0, primarily because of the radioactive decay of $\mathrm{Co}-60$ and leaching of I-129. GENII-S calculated a Sr-90 dose that was five orders of magnitude higher than the RESRAD dose. However, RESRAD calculated doses from all other radionuclides that were five to nine orders of magnitude higher than GENII-S doses. The reason for such large differences is not clear. The much larger differences in the U-234 values could be due in part to the ingrowth of U-234 decay products. This ingrowth is accounted for by RESRAD but not by GENII-S. These U-234: progeny have much higher default distribution coefficients than uranium and are retained in the contaminated zone. 
TABLE 19 Comparison of Dust Inhalation Dose Calculations, RESRAD vs. GENII-S (500 years)

\begin{tabular}{llll}
\hline & \multicolumn{2}{c}{ Doses (mrem/yr) } & \\
\cline { 2 - 3 } Radionuclide & GENII-S & RESRAD & $\begin{array}{c}\text { Dose Ratio, } \\
\text { RESRAD/GENII-S }\end{array}$ \\
\cline { 2 - 3 } Co-60 & $1.3 \times 10^{-39}$ & 0.0 & NC \\
Sr-90 & $2.0 \times 10^{-16}$ & $2.0 \times 10^{-21}$ & $1.0 \times 10^{-5}$ \\
I-129 & 0.0 & 0.0 & NC \\
Cs-137 & $9.0 \times 10^{-17}$ & $3.5 \times 10^{-11}$ & $3.9 \times 10^{5}$ \\
U-234 & $6.4 \times 10^{-15}$ & $2.1 \times 10^{-5}$ & $3.4 \times 10^{9}$ \\
U-238 & $5.7 \times 10^{-15}$ & $3.6 \times 10^{-9}$ & $6.3 \times 10^{5}$ \\
Pu-239 & $1.4 \times 10^{-7}$ & $8.2 \times 10^{-2}$ & $5.9 \times 10^{5}$ \\
\hline
\end{tabular}

a $\mathrm{NC}=$ not calculated.

\subsubsection{RESRAD vs. DECOM}

Table 20 compares the dust inhalation doses calculated by DECOM after 500 years with those calculated by RESRAD.

In both cases, the Co-60 and Sr-90 doses were essentially 0 . DECOM calculated a higher dose for all other radionuclides except U-234. This difference is due in part to the erosion of $67 \%$ of the contaminated zone over 500 years, a factor not taken into account in the DECOM code. Once again, the U-234 dose calculated by RESRAD was higher because of decay product ingrowth.

\subsubsection{RESRAD vs. PRESTO}

Table 21 shows the dust inhalation doses calculated by PRESTO for after 500 years. The I-129 dose calculated by PRESTO was the same as the inhalation dose calculated at time zero, despite the very low distribution coefficient (resulting in a high leach rate) and the erosion of the contaminated zone, both factors accounted for in PRESTO. The reason for this situation is not clear, but it could be related to vertical migration assumptions incorporated into PRESTO for wastes buried in disposal trenches. PRESTO calculated a zero dose for Co-60, Sr-90, and the uranium isotopes. The doses calculated by the two codes for Cs-137 and Pu-239 were the same within a factor of 3.

\subsubsection{RESRAD vs. NUREG/CR-5512}

No explicit formula for the calculation of future dust inhalation doses is provided in NUREG/CR-5512. For sake of comparison, Table 22 shows the doses by NUREG/CR-5512 at time zero corrected only for radioactive decay. In all cases, the NUREG/CR-5512 doses 
TABLE 20 Comparison of Dust Inhalation Dose Calculations, RESRAD vs. DECOM (500 years)

\begin{tabular}{llll}
\hline & \multicolumn{2}{c}{ Doses (mrem/yr) } & \\
\cline { 2 - 3 } Radionuclide & DECOM & RESRAD & $\begin{array}{c}\text { Dose Ratio, } \\
\text { RESRAD/DECOM }\end{array}$ \\
\hline Co-60 & 0.0 & 0.0 & NC \\
Sr-90 & 0.0 & $2.0 \times 10^{-21}$ & NC \\
Cs-137 & $1.1 \times 10^{-10}$ & $3.5 \times 10^{-11}$ & $3.2 \times 10^{-1}$ \\
U-234 & $5.2 \times 10^{-9}$ & $2.1 \times 10^{-5}$ & $4.0 \times 10^{3}$ \\
U-238 & $5.7 \times 10^{-9}$ & $3.6 \times 10^{-9}$ & $6.3 \times 10^{-1}$ \\
Pu-239 & $2.5 \times 10^{-1}$ & $8.2 \times 10^{-2}$ & $3.3 \times 10^{-1}$ \\
\hline
\end{tabular}

a $\mathrm{NC}=$ not calculated

TABLE 21 Comparison of Dust Inhalation Dose Calculations, RESRAD vs. PRESTO (500 years)

\begin{tabular}{llll}
\hline & \multicolumn{2}{c}{ Doses (mrem/yr) } & \\
\cline { 2 - 3 } Radionuclide & PRESTO & RESRAD & $\begin{array}{c}\text { Dose Ratio, } \\
\text { RESRAD/PRESTO }\end{array}$ \\
\hline Co-60 & 0.0 & 0.0 & $\mathrm{NC}^{\mathrm{a}}$ \\
Sr-90 & 0.0 & $2.0 \times 10^{-21}$ & $\mathrm{NC}$ \\
$\mathrm{I}-129$ & $4.4 \times 10^{-4}$ & 0.0 & $\mathrm{NC}$ \\
Cs-137 & $1.1 \times 10^{-11}$ & $3.5 \times 10^{-11}$ & 3.2 \\
U-234 & 0.0 & $2.1 \times 10^{-5}$ & $\mathrm{NC}$ \\
U-238 & 0.0 & $3.6 \times 10^{-9}$ & $\mathrm{NC}$ \\
Pu-239 & $1.1 \times 10^{-1}$ & $8.2 \times 10^{-2}$ & $7.5 \times 10^{-1}$ \\
\hline
\end{tabular}

a $\mathrm{NC}=$ not calculated.

TABLE 22 Comparison of Dust Inhalation Dose Calculations, RESRAD vs. NUREG/CR-5512 (500 years)

\begin{tabular}{llll}
\hline & \multicolumn{2}{c}{ Doses (mrem/yr) } & \\
\cline { 2 - 3 } Radionuclide & NUREG & RESRAD & $\begin{array}{c}\text { Dose Ratio, } \\
\text { RESRAD/NUREG }\end{array}$ \\
\cline { 2 - 3 } Co-60 & $3.9 \times 10^{-33}$ & 0.0 & NC \\
Sr-90 & $6.5 \times 10^{-9}$ & $2.0 \times 10^{-21}$ & $3.1 \times 10^{-13}$ \\
I-129 & $1.3 \times 10^{-4}$ & 0.0 & $\mathrm{NC}$ \\
Cs-137 & $2.5 \times 10^{-10}$ & $3.5 \times 10^{-11}$ & $1.4 \times 10^{-1}$ \\
U-234 & $1.0 \times 10^{-1}$ & $2.1 \times 10^{-5}$ & $2.1 \times 10^{-4}$ \\
U-238 & $9.1 \times 10^{-2}$ & $3.6 \times 10^{-9}$ & $4.0 \times 10^{-8}$ \\
Pu-239 & $3.3 \times 10^{-1}$ & $8.2 \times 10^{-2}$ & $2.5 \times 10^{-1}$ \\
\hline
\end{tabular}

a $\mathrm{NC}=$ not calculated 
were higher. The best agreement was obtained for radionuclides with the lowest default leach rates (Cs-137 and Pu-239). For these nuclides, the differences are due to the erosion of the contaminated zone as calculated by RESRAD.

\subsubsection{Summary of the Inhalation Pathway after 500 Years}

Table 23 summarizes the inhalation pathway doses after 500 years calculated by using each of the five models.

While large differences were generally found between models, some agreement was obtained in a few cases. Of the non-zero doses, the best agreement was found between RESRAD, DECOM, PRESTO, and NUREG/CR-5512 for Cs-137 and Pu-239; the calculated doses fall within a factor of 20 . The Cs-137 and Pu-239 doses calculated by GENII-S were five orders of magnitude smaller.

\subsubsection{Water Ingestion Pathway}

The default scenario in RESRAD assumes that the on-site resident ingests $510 \mathrm{~L} / \mathrm{yr}$ of water drawn from a well located at the downgradient edge of the contaminated zone. The RESRAD water ingestion doses could be compared only with DECOM and PRESTO. GENII-S does not have a groundwater transport pathway; ingestion doses are calculated following direct user input of groundwater radionuclide concentrations. The NUREG/CR-5512 calculations for the groundwater pathway are not easily performed by hand because they require iterations representing many years to obtain the maximum dose. The methodology uses first order leaching and decay rate equations to calculate radionuclide movement between compartments, but no groundwater transport or dispersion model is used. Because no groundwater movement is considered, the aquifer is assumed to be contaminated in the

TABLE 23 Comparison of Dust Inhalation Dose Calculations, All Models (500 years)

\begin{tabular}{llllll}
\hline & \multicolumn{5}{c}{ Doses (mrem/yr) } \\
\cline { 2 - 6 } Radionuclide & RESRAD & GENII-S & DECOM & PRESTO & NUREG \\
\hline Co-60 & 0.0 & $1.3 \times 10^{-39}$ & 0.0 & 0.0 & $3.9 \times 10^{-33}$ \\
Sr-90 & $2.0 \times 10^{-21}$ & $2.0 \times 10^{-16}$ & 0.0 & 0.0 & $6.5 \times 10^{-9}$ \\
I-129 & 0.0 & 0.0 & NC & $4.4 \times 10^{-4}$ & $1.3 \times 10^{-4}$ \\
Cs-137 & $3.5 \times 10^{-11}$ & $9.0 \times 10^{-17}$ & $1.1 \times 10^{-10}$ & $1.1 \times 10^{-11}$ & $2.5 \times 10^{-10}$ \\
U-234 & $2.1 \times 10^{-5}$ & $6.4 \times 10^{-15}$ & $5.2 \times 10^{-9}$ & 0.0 & $1.0 \times 10^{-1}$ \\
U-238 & $3.6 \times 10^{-9}$ & $5.7 \times 10^{-15}$ & $5.7 \times 10^{-9}$ & 0.0 & $9.1 \times 10^{-2}$ \\
Pu-239 & $8.2 \times 10^{-2}$ & $1.4 \times 10^{-7}$ & $2.5 \times 10^{-1}$ & $1.1 \times 10^{-1}$ & $3.3 \times 10^{-1}$ \\
\hline
\end{tabular}

a $\mathrm{NC}=$ not calculated. 
first year following the release. The model also assumes that the dilution volume is the larger of the volume of water percolating through the contaminated zone or the household usage volume. Therefore, the NUREG/CR-5512 methodology is expected to produce more conservative groundwater concentrations than RESRAD, especially for large area sources.

\subsubsection{RESRAD vs. DECOM}

The groundwater model used in DECOM assumes a steady-state release from the contaminated zone because of leaching and does not consider radioactive decay over time. Therefore, the groundwater ingestion doses calculated by DECOM will be independent of time. Because RESRAD accounts for the time dependency of the source, the maximum concentrations in groundwater of radionuclides with different decay constants, leach rates, and retardation coefficients will be reached at different times. DECOM considers the dispersion of contaminants; RESRAD uses a nondispersion model. The DECOM defaults for the longitudinal and transverse dispersivities were not changed (10 and $1 \mathrm{~m}$, respectively). The infiltration rate was set to the value calculated by RESRAD (40 cm/yr). All distribution coefficients were set to the RESRAD defaults. The volumetric water fraction in the contaminated zone in DECOM was set to the average value (0.3) calculated by RESRAD for the contaminated and unsaturated zones. The groundwater seepage velocity was set to $6.3 \times 10^{-8} \mathrm{~m} / \mathrm{s}$, which corresponds to the groundwater velocity calculated by RESRAD for a hydraulic gradient of 0.02 and a hydraulic conductivity of $100 \mathrm{~m} / \mathrm{yr}$. The aquifer depth in DECOM was set to $10 \mathrm{~m}$, the RESRAD default depth of the well in the aquifer. The fraction of water consumed that is drawn from the well was set to $100 \%$ for both codes. Results of the two runs are compared in Table 24. As expected from the difference in the code approaches, the groundwater ingestion doses calculated by DECOM were one to six orders of magnitude higher than the doses calculated by RESRAD after 500 years.

TABLE 24 Comparison of Water Ingestion Dose Calculations, RESRAD vs. DECOM (500 years)

\begin{tabular}{llll}
\hline & \multicolumn{2}{c}{ Doses (mrem/yr) } & \\
\cline { 2 - 3 } Radionuclide & DECOM & RESRAD & $\begin{array}{c}\text { Dose Ratio, } \\
\text { RESRAD/DECOM }\end{array}$ \\
\hline Co-60 & $5.6 \times 10^{-5}$ & 0.0 & $\mathrm{NC}^{\mathrm{a}}$ \\
Sr-90 & $1.3 \times 10^{-1}$ & $1.5 \times 10^{-4}$ & $1.2 \times 10^{-3}$ \\
Cs-137 & $2.6 \times 10^{-4}$ & 0.0 & $\mathrm{NC}$ \\
U-234 & $4.9 \times 10^{-1}$ & $7.4 \times 10^{-2}$ & $1.5 \times 10^{-1}$ \\
U-238 & 4.7 & $7.2 \times 10^{-2}$ & $1.5 \times 10^{-2}$ \\
Pu-239 & $1.8 \times 10^{-2}$ & $4.3 \times 10^{-8}$ & $2.4 \times 10^{-6}$ \\
\hline
\end{tabular}

a $\mathrm{NC}=$ not calculated. 


\subsubsection{RESRAD vs. PRESTO}

The PRESTO groundwater model assumes that the contaminated zone is divided into nine equivalent point sources. The contaminant leach rate from these point sources is a function of the infiltration rate and distribution coefficients, both of which were set equal to the RESRAD defaults for this comparison. For the transport of contaminants in groundwater, all soil and hydrogeological parameters were set equal to the RESRAD defaults. Because PRESTO takes into consideration the dispersion of contaminants during groundwater transport, while RESRAD does not, PRESTO defaults for dispersivity were used $(0.3 \mathrm{~m}$ in both the unsaturated zone and the aquifer). To estimate dilution in the aquifer, the PRESTO default plume dispersion angle was used ( 0.3 radians). The aquifer was assumed to be 10-m thick, and the well was assumed to be located $50 \mathrm{~m}$ from the center of the site (assuming the site was $100 \mathrm{~m} \times 100 \mathrm{~m}$ ).

A zero dose was calculated by PRESTO for all radionuclides after 500 years. During the 1,000-year interval allowed in PRESTO, the only radionuclide contributing to a non-zero dose was Sr-90, which would reach a maximum concentration in water after 577 years. No clear explanation can be given for the zero groundwater dose from I-129 between time zero and 500 years; this situation is unusual since the I-129 dose should reach a peak before Sr-90 because of the lower distribution coefficient $(0.1 \mathrm{~mL} / \mathrm{g}$ for I-129 compared with $30 \mathrm{~mL} / \mathrm{g}$ for Sr-90). By trial-and-error, it was determined that a minimum distribution coefficient of $5 \mathrm{~mL} / \mathrm{g}$ was required for PRESTO to calculate a groundwater ingestion dose. However, inspection of the annual doses for the 1,000-year period indicated a uniform cycle of periods of elevated water ingestion doses with intervening periods of zero dose. Increasing the distribution coefficient has the effect of decreasing the number of cycles. The reason for this behavior could not be ascertained, but may be related to the method used by PRESTO to simulate an area source (i.e., nine equivalent point sources).

\subsection{RADIONUCLIDE DECAY AND INGROWTH — RESRAD vs. GENII-S}

The ingrowth of radioactive progeny from an initially present parent radionuclide can result in higher doses than would be contributed by the parent alone. To investigate how the other models account for ingrowth of progeny, a comparison was made using the $\mathrm{Pu}-241 / \mathrm{Am}-241$ decay chain. This pair was selected because the short half-life of Pu-241 (14.4 yr) relative to Am-241 (432.2 yr) results in a rapid decay of the parent, leaving only the progeny behind. This test was possible only between RESRAD and GENII-S. Neither DECOM or PRESTO consider progeny ingrowth, and NUREG/CR-5512 considers only the dose from ingrowth during the first year of exposure.

A relatively simple pathway, the inhalation of contaminated dust, was selected. With the exception of the inhalation rate, which is fixed in GENII-S (see Section 2.3.3), and the erosion rate (set to zero in RESRAD), the parameter values used by RESRAD were the defaults for the residential farmer scenario. With the exception of the inhalation dose factors, the parameter values used in GENII-S to calculate inhalation doses were the same as those used by RESRAD. A concentration of $1 \mathrm{pCi} / \mathrm{g}$ of Pu-241 (1,000 pCi/kg in GENII-S) was 
entered in the top $15 \mathrm{~cm}$ of soil. The leach rates for Pu-241 and Am-241 were calculated by RESRAD to be $8.3 \times 10^{-4}$ and $8.3 \times 10^{-2}$ per year, respectively. These values were entered in the FTRANS.DAT file in GENII-S. Because the default americium leach rate is two orders of magnitude higher than the plutonium leach rate, the americium is not retained in the surface soil as strongly as the plutonium. The calculated doses should reflect the competing effects of ingrowth and the leaching of Am-241.

Considering the radionuclide half-lives and leach rates, a 100-year time horizon was sufficient to encompass the peak dose from ingrowth of Am-241. In RESRAD, the year in which doses are calculated was set to 1, 2, 5, 10, 20, 50, and 100 years. Because GENII-S allows the user to calculate doses only at one user-specified year, multiple runs were executed by changing the inventory disposal time for each run.

Table 25 lists the time-dependent inhalation doses calculated by GENII-S and RESRAD and shows the contributions from parent (Pu-241) and progeny (Am-241) radionuclides.

The doses from Pu-241 calculated by RESRAD were approximately 2.2 times higher than the Pu-241 doses calculated by GENII-S. The doses from Am-241 calculated by RESRAD were approximately 1.3 times higher than the Am-241 doses calculated by GENII-S. For both radionuclides, this ratio remains constant over the time span considered. Despite the higher leach rate, the dose from Am-241 becomes the dominant contributor as the Pu-241 decays; when considering the total dose, the RESRAD/GENII-S ratio decreases from 2.2 at time zero to 1.3 after 100 years. In RESRAD, the peak inhalation dose occurs after 5 years; in GENII-S, the peak dose occurs after 10 years. This discrepancy is the result of differences in the dose ratios for each radionuclide as discussed previously. Because the dose ratios for the individual radionuclides remain constant over time, the discrepancy is primarily due to differences in the dose factors used in RESRAD and GENII-S. It appears that both models account for the effects of radionuclide decay, ingrowth, and leaching in a consistent manner.

TABLE 25 Comparison of Inhalation Doses due to Ingrowth of Am-241 from Pu-241, RESRAD vs. GENII-S

\begin{tabular}{ccccc}
\hline & \multicolumn{4}{c}{ Doses (mrem/yr) } \\
\cline { 2 - 5 } Year & $\begin{array}{c}\text { Pu-241 } \\
\text { GENII-S }\end{array}$ & $\begin{array}{c}\text { Am-241 } \\
\text { GENII-S }\end{array}$ & $\begin{array}{c}\text { Pu-241 } \\
\text { RESRAD }\end{array}$ & $\begin{array}{c}\text { Am-241 } \\
\text { RESRAD }\end{array}$ \\
\hline & & & & \\
0 & $3.4 \times 10^{-3}$ & 0.0 & $7.4 \times 10^{-3}$ & 0.0 \\
1 & $3.3 \times 10^{-3}$ & $4.4 \times 10^{-4}$ & $7.1 \times 10^{-3}$ & $5.8 \times 10^{-4}$ \\
2 & $3.1 \times 10^{-3}$ & $8.9 \times 10^{-4}$ & $6.8 \times 10^{-3}$ & $1.1 \times 10^{-3}$ \\
5 & $2.7 \times 10^{-3}$ & $1.8 \times 10^{-3}$ & $5.8 \times 10^{-3}$ & $2.2 \times 10^{-3}$ \\
10 & $2.1 \times 10^{-3}$ & $2.6 \times 10^{-3}$ & $4.6 \times 10^{-3}$ & $3.2 \times 10^{-3}$ \\
20 & $1.3 \times 10^{-3}$ & $2.7 \times 10^{-3}$ & $2.8 \times 10^{-3}$ & $3.3 \times 10^{-3}$ \\
50 & $3.0 \times 10^{-4}$ & $1.0 \times 10^{-3}$ & $6.4 \times 10^{-4}$ & $1.3 \times 10^{-3}$ \\
100 & $2.6 \times 10^{-5}$ & $1.0 \times 10^{-4}$ & $5.5 \times 10^{-5}$ & $1.3 \times 10^{-4}$ \\
\hline
\end{tabular}




\subsection{CONCLUSIONS}

Conclusions reached from the comparison of results presented in Tables 1 through 25 can be summarized as follows:

- For the external dose pathway, the best agreement with RESRAD results was obtained with the NUREG/CR-5512 methodology. The discrepancies with the other codes spanned several orders of magnitude for some radionuclides, particularly the low-energy gamma emitters.

- The results from the dust inhalation pathway agreed within less than a factor of 10 for all models; DECOM exhibited the closest agreement to RESRAD.

- Good agreement was found between the soil ingestion doses calculated by RESRAD and NUREG/CR-5512. The actinide ingestion doses calculated by RESRAD and GENII-S were in poor agreement.

- Results of the food ingestion pathway calculations indicated considerable variability among the various models, sometimes spanning two or more orders of magnitude.

- With the exception of U-234, the best agreement for the dust inhalation dose after 500 years was obtained between RESRAD and DECOM. Results from the other models spanned several orders of magnitude.

- Because of significantly different groundwater models, no agreement was found at 500 years among doses calculated by RESRAD, DECOM, and PRESTO.

- Other than modeling differences, some of the discrepancies were due to differences (and possible errors) in the dose factor libraries used. The possibility of errors in data entry or code errors and bugs cannot be excluded as potential causes for some of these discrepancies. 


\section{BENCHMARKING AGAINST GENII AND PATHRAE}

This section summarizes a benchmarking effort to compare results from RESRAD with those of the PATHRAE and GENII computer codes. The results of PATHRAE and GENII were taken directly from a paper presented at the 1992 Waste Management Symposium (Seitz et al. 1992) in which the authors compared the PATHRAE and GENII computer codes.

\subsection{MODEL DESCRIPTIONS}

\subsubsection{GENII}

The GENII code (Napier et al. 1988) was the predecessor of the GENII-S code developed by Pacific Northwest Laboratory. The function of the GENII code is similar to that of GENII-S except it does not have the capability to perform uncertainty analysis for the input parameters. Section 2.1.2 summarizes the applications of the GENII-S code.

\subsubsection{PATHRAE-EPA}

The PATHRAE-EPA code (Rogers and Hung 1987) was designed to calculate average annual and maximum annual effective doses and cancer risks to an on-site critical population group and an off-site population at risk. Cancer risks are calculated from the effective dose equivalent and a constant risk/dose conversion factor. This approach is different from that used in RESRAD, which uses EPA slope factors to obtain lifetime excess cancer risks.

The approach used in PATHRAE is similar to that used in PRESTO. The scenarios by which radioactivity can reach humans are as follows: groundwater migration with discharge to a river or to a well; surface erosion of the cover material and waste and subsequent contamination of surface water; saturation of waste with subsequent overflows to a stream; ingestion of food grown on the contaminated site either with or without associated disturbance of the waste material; direct gamma exposure; inhalation of radioactive dust on-site and off-site; and inhalation of radon while inside a structure built on the waste site. Annual doses are obtained by performing food chain analyses for ingestion of produce, meat, milk, fish, and drinking water. Inhalation doses are obtained directly with an inhalation rate and a time fraction input parameter. Dispersion is considered in the transport of nuclides in the groundwater system. However, the ingrowth of progeny nuclides is considered only for three-member decay chains. When a decay chain includes more than three members, some of the progeny nuclides are represented by using identical transport parameters and by assuming that the chain member is in equilibrium with its parent.

Five input files with specific names and input parameters are required to run the PATHRAE code. The code generates a text output file that tabulates input summary and 
calculational results, including concentrations in different environmental media and annual doses and risks at different time periods for individual radionuclides and pathways.

\subsection{SCENARIO DESCRIPTION}

In the paper by Seitz et al. (1992), an intruder scenario was assumed, and the calculational results for three exposure pathways - external gamma, dust inhalation, and plant food ingestion - were compared. Because the meat and milk pathways involve more complicated food chain analyses, the methodologies implemented in different computer codes to calculate annual doses vary considerably. Therefore, annual doses from these two pathways were not compared in the Seitz et al. (1992) paper. Because the intrusion scenario considered did not involve a groundwater contribution, leaching of contaminants from the waste site was not taken into account, and that feature of RESRAD was disabled for these comparisons. Table 26 lists the input parameters used for that comparison. An effort was made to maintain as much consistency as possible in the input data when using the RESRAD code. Table 27 lists the RESRAD input parameters (default values were used for the RESRAD parameters not listed in Table 27).

\subsection{COMPARISON OF INPUT PARAMETERS}

The soil concentration used in the RESRAD code was $1 \mathrm{pCi} / \mathrm{g}$, versus $1 \mathrm{Ci} / \mathrm{m}^{3}$ in the GENII and PATHRAE codes. With a soil density of $1.6 \mathrm{~g} / \mathrm{cm}^{3}$, the concentration of $1 \mathrm{Ci} / \mathrm{m}^{3}$ converts to $625,000 \mathrm{pCi} / \mathrm{g}$. Therefore, the doses calculated with the RESRAD code were

TABLE 26 Parameter Values Used in the GENII and PATHRAE Codes

\begin{tabular}{ll}
\hline \multicolumn{1}{c}{ Parameters } & \multicolumn{1}{c}{ Values } \\
\hline Soil concentration & $1 \mathrm{Ci} / \mathrm{m}^{3}$ \\
Soil density & $1.6 \mathrm{~g} / \mathrm{cm}^{3}$ \\
Exposure time & $8,760 \mathrm{~h} / \mathrm{yr}$ \\
Breathing rate & $8,400 \mathrm{~m}^{3} / \mathrm{yr}$ \\
Dust loading & $5.53 \times 10^{-8} \mathrm{~kg} / \mathrm{m}^{3}$ \\
Time of dose occurrence & 1 year after disposal \\
Leafy vegetable consumption & $18 \mathrm{~kg} / \mathrm{yr}$ \\
Produce consumption & $176 \mathrm{~kg} / \mathrm{yr}$ \\
Fraction of consumed food & \\
$\quad$ that is contaminated & $25 \%$ \\
Dry-to-wet ratios & \\
$\quad$ Leafy vegetable & 0.066 (PATHRAE) \\
$\quad$ Produce & 0.187 (PATHRAE) \\
Internal dose conversion & \\
$\quad$ factors & GENII default values \\
\hline
\end{tabular}


TABLE 27 Parameter Values Used in the RESRAD Code

\begin{tabular}{|c|c|}
\hline Parameters & Values \\
\hline Soil concentration & $1 \mathrm{pCi} / \mathrm{g}$ \\
\hline Soil density & $1.6 \mathrm{~g} / \mathrm{cm}^{3}$ \\
\hline Time fraction spent outdoors & 1 \\
\hline Inhalation rate & $8,400 \mathrm{~m}^{3} / \mathrm{yr}$ \\
\hline $\begin{array}{l}\text { Mass loading factor for dust } \\
\text { inhalation }\end{array}$ & $5.53 \times 10^{-5} \mathrm{~g} / \mathrm{m}^{3}$ \\
\hline $\begin{array}{l}\text { Mass loading factor for foliar } \\
\text { deposition }\end{array}$ & $5.53 \times 10^{-5} \mathrm{~g} / \mathrm{m}^{3}$ \\
\hline Time of dose occurrence & 1 year after disposal \\
\hline Leafy vegetable consumption & $18 \mathrm{~kg} / \mathrm{yr}$ \\
\hline $\begin{array}{l}\text { Vegetables, fruits, and grain } \\
\text { consumption }\end{array}$ & $176 \mathrm{~kg} / \mathrm{yr}$ \\
\hline Dose conversion factors & RESRAD default values \\
\hline Thickness of contaminated zone $\mathrm{e}^{\mathrm{a}}$ & $0.15 \mathrm{~m}$ \\
\hline Area of contaminated zone $e^{a}$ & $2,500 \mathrm{~m}^{2}$ \\
\hline Thickness of cover material & $0 \mathrm{~m}$ \\
\hline $\begin{array}{l}\text { Distribution coefficients, } \\
\text { all zones }\end{array}$ & $1 \times 10^{6} \mathrm{~cm}^{3} / \mathrm{g}$ \\
\hline Irrigation rate & $1 \times 10^{-4} \mathrm{~m} / \mathrm{yr}$ \\
\hline Precipitation rate & $1 \times 10^{-4} \mathrm{~m} / \mathrm{yr}$ \\
\hline Contaminated zone erosion rate & $0 \mathrm{~m} / \mathrm{yr}$ \\
\hline
\end{tabular}

a Data from Wood (1992).

multiplied by 625,000 so that they could be compared with those of PATHRAE and GENII. The exposure time of $8,760 \mathrm{~h} / \mathrm{yr}$ listed in Table 26 corresponds to a value of 1 for the "time fraction spent outdoors" parameter in the RESRAD code. The dust loading of $5.53 \times 10^{-8} \mathrm{~kg} / \mathrm{m}^{3}$ listed in Table 26 is equivalent to $5.53 \times 10^{-5} \mathrm{~g} / \mathrm{m}^{3}$, after a conversion factor is applied. This value was used in the RESRAD code for the mass loading factors for both dust inhalation and foliar deposition. The produce consumption rate listed in Table 26 can be represented by the fruits, vegetables, and grain consumption rate parameter in the RESRAD code. Seitz et al. (1992) assumed that $25 \%$ of the consumed food was contaminated, (i.e., was from the contaminated site). The version of the RESRAD code used in this study has a built-in capability to automatically estimate the fraction of consumed food grown. on-site. With a contaminated area of $2,500 \mathrm{~m}^{2}$ (Wood 1992), the fraction estimated by RESRAD was $50 \%$. Because that value was different from the $25 \%$ used in the other two codes, the RESRAD doses for the plant food ingestion pathway were divided by 2 .

The food/soil transfer factors used in the RESRAD code are on the weight basis of dry soil and wet plant; therefore, the results do not have to be converted to account for the dry-to-wet plant food ratio. The soil/water distribution coefficients used in the RESRAD code for all radionuclides were set to $1,000,000 \mathrm{~cm}^{3} / \mathrm{g}$. Such a large value will suppress the influence of leaching from the waste. Furthermore, both the irrigation and precipitation rate 
parameters were set to $0.0001 \mathrm{~m} / \mathrm{yr}$ to reduce the magnitude of the water infiltration rate. These two selections result in an estimated leaching of $3.0 \times 10^{-11}(1 / \mathrm{yr})$, which is negligible in the dose calculation, and provide consistency in the simulated conditions between the RESRAD code and the GENII and PATHRAE codes. The contaminated zone erosion rate used in the RESRAD code was set to 0 since this input parameter was not mentioned in the Seitz et al. (1992) paper. Delay times between harvest and consumption were not considered in the version of the RESRAD code used in this study; however, because all of the radionuclides in the comparison have much longer half-lives than the possible delay times between harvest and consumption, the influence of the delay on the calculated doses should be insignificant. The default soil-to-plant transfer factors and dose conversion factors were used in the RESRAD calculation.

\subsection{RESULTS AND DISCUSSION}

Table 28 lists the radiation doses calculated by the three computer codes. Table 29 lists the relative doses after normalization with the ingestion dose of Sr-90 from GENII, that is, $2.4 \times 10^{5} \mathrm{mrem} / \mathrm{yr}$. The relative doses predicted by GENII and PATHRAE are almost identical to those published by Seitz et al. (1992). In general, good agreement was obtained for the ingestion and inhalation pathways. The differences arise primarily from differences in the soil-to-plant transfer factors and the dose conversion factors. The excellent agreement between the GENII and PATHRAE codes may be explained by the intention to obtain results that agree within $10 \%$, as mentioned in the Seitz et al. (1992) paper. To attain this goal, the primary inputs of the GENII and PATHRAE codes were set to identical values, and a number of secondary inputs for the two codes were also made consistent.

In Table 28, the major differences lie in the direct gamma doses. Implementation of different dose conversion factors and methodologies may explain these large inconsistencies. Theoretically, Co-60 (a gamma emitter) should impart a larger external dose than Sr-90 (both Sr-90 and its decay product Y-90 are beta emitters); however, GENII predicts a Sr-90 dose greater than the Co-60 dose. PATHRAE predicts little difference in the external doses for Co-60 and Sr-90. Significant differences in the doses from these two radionuclides can only be observed from the RESRAD results. Another gamma emitter, Cs-137, was estimated to give external doses of $4.2 \times 10^{4}$ and $1.0 \times 10^{5} \mathrm{mrem} / \mathrm{yr}$ by GENII and PATHRAE, respectively. Both of the numbers are greater than the doses estimated by the two codes for Co-60. Cobalt-60 has a stronger penetration capability than Cs-137. This situation is consistent with the prediction by RESRAD, which yields a Co-60 dose that is approximately 4 times higher than the Cs-137 dose. The relatively closer magnitudes of $1.0 \times 10^{7}$ and $2.7 \times 10^{6}$ for Co-60 and Cs-137 reported by RESRAD versus differences of four to five orders in the GENII and PATHRAE results suggests that the Co-60 dose estimated by RESRAD is more reasonable. Furthermore, examination of the external doses discussed in Section 2.3.2 shows that the GENII-S results were close to the RESRAD results for both Co-60 and Cs-137. This suggests that the results presented in Seitz et al. (1992) for external 
TABLE 28 Comparison of RESRAD Results with GENI and PATHRAE Code Results ${ }^{\mathrm{a}}$

\begin{tabular}{|c|c|c|c|c|c|}
\hline \multirow[b]{3}{*}{ Radionuclide } & \multirow{2}{*}{\multicolumn{3}{|c|}{ Doses (mrem/yr) }} & \multicolumn{2}{|c|}{ Dose Ratios } \\
\hline & & & & \multirow{2}{*}{$\begin{array}{l}\text { RESRAD/ } \\
\text { GENII }\end{array}$} & \multirow{2}{*}{$\begin{array}{l}\text { RESRAD/ } \\
\text { PATHRAE }\end{array}$} \\
\hline & GENII & PATHRAE & RESRAD & & \\
\hline \multicolumn{6}{|l|}{ Plant ingestion ${ }^{b}$} \\
\hline Sr-90 & $2.4 \times 10^{5}$ & $2.2 \times 10^{5}$ & $1.4 \times 10^{5}$ & $5.8 \times 10^{-1}$ & $6.4 \times 10^{-1}$ \\
\hline Tc-99 & $2.1 \times 10^{4}$ & $2.1 \times 10^{4}$ & $1.6 \times 10^{3}$ & $7.6 \times 10^{-2}$ & $7.6 \times 10^{-1}$ \\
\hline I-129 & $6.9 \times 10^{4}$ & $7.2 \times 10^{4}$ & $2.9 \times 10^{4}$ & $4.2 \times 10^{-1}$ & $4.0 \times 10^{-1}$ \\
\hline $\mathrm{Cs}-137$ & $8.0 \times 10^{3}$ & $7.8 \times 10^{3}$ & $4.9 \times 10^{2}$ & $6.1 \times 10^{-2}$ & $6.3 \times 10^{-2}$ \\
\hline Pu-239 & $1.4 \times 10^{3}$ & $1.4 \times 10^{3}$ & $5.9 \times 10^{3}$ & 4.2 & 4.2 \\
\hline \multicolumn{6}{|l|}{ Dust inhalation } \\
\hline Sr-90 & $6.2 \times 10^{1}$ & $5.9 \times 10^{1}$ & $3.5 \times 10^{2}$ & 5.6 & 5.9 \\
\hline Tc-99 & 2.6 & 2.5 & 2.1 & $8.0 \times 10^{-1}$ & $8.0 \times 10^{-1}$ \\
\hline $\mathrm{I}-129$ & $4.5 \times 10^{1}$ & $4.4 \times 10^{1}$ & $4.9 \times 10^{1}$ & 1.1 & 1.1 \\
\hline Cs-137 & 8.6 & 8.7 & 8.6 & 1.0 & 1.0 \\
\hline Pu-239 & $1.5 \times 10^{5}$ & $1.5 \times 10^{5}$ & $1.4 \times 10^{5}$ & $9.3 \times 10^{-1}$ & $9.3 \times 10^{-1}$ \\
\hline \multicolumn{6}{|l|}{ External gamma } \\
\hline $\mathrm{Co}-60$ & 3.1 & 6.8 & $1.0 \times 10^{7}$ & $3.2 \times 10^{6}$ & $1.5 \times 10^{6}$ \\
\hline Sr-90 & 6.8 & 0.0 & 0.0 & $\mathrm{NC}^{\mathrm{c}}$ & \\
\hline $\mathrm{I}-129$ & $5.3 \times 10^{2}$ & $1.0 \times 10^{5}$ & $2.0 \times 10^{4}$ & $3.8 \times 10^{1}$ & $2.0 \times 10^{-1}$ \\
\hline Cs-137 & $4.2 \times 10^{4}$ & $1.0 \times 10^{5}$ & $2.7 \times 10^{6}$ & $6.4 \times 10^{1}$ & $2.7 \times 10^{1}$ \\
\hline Pu-239 & $3.1 \times 10^{1}$ & $1.4 \times 10^{3}$ & $4.5 \times 10^{2}$ & $1.5 \times 10^{1}$ & $3.2 \times 10^{-1}$ \\
\hline
\end{tabular}

a GENII and PATHRAE results were taken from Wood (1992); these results were subsequently published in Seitz et al. (1992) as relative doses and are presented in Table 29.

b From leafy vegetables and produce.

c $\mathrm{NC}=$ not calculated.

dose may be erroneous. (Recent communication with $R$. Seitz indicated that an error was made in the initial calculations; this error has been corrected. The corrected results have been published in a recent report [Seitz et al. 1994]. Benchmarking of RESRAD with the corrected results is presented in Appendix A.)

\subsection{CONCLUSIONS}

The doses predicted by the RESRAD, GENII, and PATHRAE codes for the inhalation and ingestion pathways were in relatively good agreement. Differences were caused primarily by the transfer factors and dose conversion factors used in the dose calculation.

Predicted effective doses for external radiation differed considerably among the three codes. The external doses for Co-60 estimated by the GENII and PATHRAE codes were much. 
TABLE 29 Comparison of RESRAD, GENII, and PATHRAE Relative Radiation Doses ${ }^{a}$

\begin{tabular}{|c|c|c|c|}
\hline \multirow[b]{2}{*}{ Radionuclide } & \multicolumn{3}{|c|}{ Relative Doses } \\
\hline & GENII $^{b}$ & PATHRAE & RESRAD \\
\hline \multicolumn{4}{|l|}{ Plant ingestion } \\
\hline Sr-90 & 1.0 & $9.2 \times 10^{-1}$ & $5.8 \times 10^{-1}$ \\
\hline Tc-99 & $8.7 \times 10^{-2}$ & $8.7 \times 10^{-2}$ & $6.7 \times 10^{-3}$ \\
\hline $\mathrm{I}-129$ & $2.9 \times 10^{-1}$ & $3.0 \times 10^{-1}$ & $1.2 \times 10^{-1}$ \\
\hline Cs-137 & $3.3 \times 10^{-2}$ & $3.2 \times 10^{-2}$ & $2.0 \times 10^{-3}$ \\
\hline $\mathrm{Pu}-239$ & $5.8 \times 10^{-3}$ & $5.8 \times 10^{-3}$ & $2.5 \times 10^{-2}$ \\
\hline \multicolumn{4}{|l|}{ Dust inhalation } \\
\hline Sr-90 & $2.6 \times 10^{-4}$ & $2.5 \times 10^{-4}$ & $1.5 \times 10^{-3}$ \\
\hline Tc-99 & $1.1 \times 10^{-5}$ & $1.0 \times 10^{-5}$ & $8.8 \times 10^{-6}$ \\
\hline I-129 & $1.9 \times 10^{-4}$ & $1.8 \times 10^{-4}$ & $2.0 \times 10^{-4}$ \\
\hline Cs-137 & $3.6 \times 10^{-5}$ & $3.6 \times 10^{-5}$ & $3.6 \times 10^{-5}$ \\
\hline $\mathrm{Pu}-239$ & $6.2 \times 10^{-1}$ & $6.2 \times 10^{-1}$ & $5.8 \times 10^{-1}$ \\
\hline \multicolumn{4}{|l|}{ External gamma } \\
\hline Co-60 & $1.3 \times 10^{-5}$ & $2.8 \times 10^{-5}$ & $4.2 \times 10^{1}$ \\
\hline Sr-90 & $2.8 \times 10^{-5}$ & 0.0 & 0.0 \\
\hline $\mathrm{I}-129$ & $2.2 \times 10^{-3}$ & $4.2 \times 10^{-1}$ & $8.3 \times 10^{-2}$ \\
\hline Cs-137 & $1.7 \times 10^{-1}$ & $4.2 \times 10^{-1}$ & $1.1 \times 10^{-1}$ \\
\hline Pu-239 & $1.3 \times 10^{-4}$ & $5.8 \times 10^{-3}$ & $1.9 \times 10^{-3}$ \\
\hline \multicolumn{4}{|c|}{$\begin{array}{l}\text { The relative doses were the radiation doses listed in Table } 28 \\
\text { and normalized by } 2.4 \times 10^{5}(\mathrm{mrem} / \mathrm{yr}) \text {. }\end{array}$} \\
\hline \multicolumn{4}{|c|}{$\begin{array}{l}\text { The relative doses for GENII were the same as those } \\
\text { published by Seitz et al. (1992). }\end{array}$} \\
\hline \multicolumn{4}{|c|}{$\begin{array}{l}\text { The relative doses for PATHRAE were the same as those } \\
\text { published by Seitz et al. (1992) except for the external gamma } \\
\text { dose for Sr-90, which was } 1.6 \times 10^{-3} \text { in the Seitz paper and } \\
\text { converted to a radiation dose of } 3.8 \times 10^{2}(\mathrm{mrem} / \mathrm{yr}) \text {. }\end{array}$} \\
\hline
\end{tabular}

closer to each other than they were to the RESRAD results. However, judging by the radiation properties of the other radionuclides, the results indicate that the RESRAD estimation of $\mathrm{Co}-60$ dose is more reasonable. This benchmarking exercise has demonstrated that in judging the validity of risk assessment models, comparison of the results from different models is not enough - professional judgment and the availability of the real data should play important roles in assessing the results. 


\section{REFERENCES}

Gilbert, T.L., et al., 1989, A Manual for Implementing Residual Radioactive Material Guidelines, ANL/ES-160, DOE/CH/8901, prepared by Argonne National Laboratory, Argonne, III., for U.S. Department of Energy, Washington, D.C.

Hung, C.Y., 1989, User's Guide for the SYSCPG Program-A PC Version of the PRESTO-EPA-CPG Operation System, EPA 520/1-89-017, U.S. Environmental Protection Agency, Washington, D.C.

Kennedy, W.E., and D.L. Strenge, 1992, Residual Radioactive Contamination from Decommissioning; Volume 1; Technical Basis for Translating Contamination Levels to Annual Total Effective Dose Equivalent, NUREG/CR-5512, prepared by Pacific Northwest Laboratory, Richland, Wash., for U.S. Nuclear Regulatory Commission, Washington, D.C.

Leigh, C.D., et al., 1992, User's Guide for GENII-S: A Code for Statistical and Deterministic Simulations for Radiation Doses to Humans from Radionuclides in the Environment, SAND91-0561A, Sandia National Laboratories, Albuquerque, N.M.

Napier, B.A., et al., 1988, GENII - The Hanford Environmental Radiation Dosimetry Software System, vols. 1 and 2, PNL-6584, Pacific Northwest Laboratory, Richland, Wash.

Rogers, V.C., and C. Hung, 1987, PATHRAE-EPA: A Low-Level Radioactive Waste Environmental Transport and Risk Assessment Code - Methodology and Users Manual, EPA 520/1-87-028, prepared by Rogers and Associates, Salt Lake City, Utah, for U.S. Environmental Protection Agency, Washington, D.C.

Seitz, R.R., et al., 1992, "Comparison of Computer Codes and Approaches Used at DOE Sites to Model Intrusion Scenarios," proceedings of the Symposium on Waste Management, Tueson, Ariz., March 1-5, vol. 1, p. 509.

Seitz, R.R., et al., 1994, Benchmarking of Computer Codes and Approaches for Modeling Exposure Scenarios, DOE/LLW-188, prepared by Idaho National Engineering Laboratory, EG\&G Idaho, Inc., Idaho Falls, Idaho, for U.S. Department of Energy, Washington, D.C.

Till, J.E., and R.E. Moore, 1988, "A Pathway Analysis Approach for Determining Acceptable Levels of Contamination of Radionuclides in Soil," Health Physics 55(3):541.

U.S. Department of Energy, 1990, "Radiation Protection of the Public and the Environment," DOE Order 5400.5, Washington, D.C.

Wood, M.I., 1992, personal communication from Wood (Westinghouse Hanford Company, Richland, Wash.) to C. Yu (Argonne National Laboratory, Argonne, nl.), July 22.

Yu, C., et al., 1993, Manual for Implementing Residual Radioactive Material Guidelines Using RESRAD, Version 5.0, Working Draft, ANL/EAD/LD-2, Argonne National Laboratory, Argonne, Ill. 
A-1

APPENDIX:

BENCHMARKING RESRAD RADIATION DOSE RESULTS AGAINST DATA FROM DOE/LLW-188 
A-2 


\section{APPENDIX:}

\section{BENCHMARKING RESRAD RADIATION DOSE RESULTS AGAINST DATA FROM DOE/LLW-188}

This appendix compares radiation dose results from RESRAD and those from DOE/LLW-188 (Seitz et al. 1994) for GENII and PATHRAE. As mentioned in Section 3, the external doses for Co-60 calculated by Seitz et al. (1992) with GENII and PATHRAE were much lower (approximately six orders less) than those calculated by RESRAD. Argonne National Laboratory (ANL) documented the rationale for the RESRAD results and forwarded this information to Seitz for review. Subsequently, Seitz issued a report (Seitz et al. 1994) that contains more extensive comparisons between the GENII and PATHRAE codes by including more radionuclides and pathways. This appendix presents benchmarking results using the latest version of the RESRAD code (Version 5.191) and the results from GENII and PATHRAE as presented in the recent report of Seitz et al. (1994).

\section{A.1 METHODOLOGY}

In the report by Seitz et al. (1994), the benchmarking was limited to comparisons of external, plant ingestion, and inhalation doses from a unit soil concentration $\left(1 \mathrm{Ci} / \mathrm{m}^{3}\right)$ and plant, meat, milk, and water ingestion doses from a unit water concentration $(1 \mu \mathrm{Ci} / \mathrm{L})$. Because radiation doses at a future time were not compared, discrepancies in environmental transport models (such as the air dispersion model and groundwater model) used by the different computer codes could not be identified. However, excluding the influence of the fate and transport models, a direct comparison of the food transfer models for radionuclides can easily be made.

Radionuclides in the soil phase constitute the original source of contamination considered in the RESRAD model. Theoretically, water contamination cannot be observed at time zero (when the radioactive material is placed in the soil phase) since it takes some time for the radionuclides to be transported through the vadose zone (unsaturated zone) and reach the groundwater table, unless the contaminated zone is located in the saturated zone. RESRAD allows for the input of groundwater concentrations only in cases in which the waste material was placed on-site a specific period of time prior to the radiological survey. During this time, the radionuclides would have already penetrated the unsaturated zone and reached the groundwater table. In this case, the input groundwater concentrations should be those measured at the same time as the soil concentrations. RESRAD will derive the soil/water distribution coefficients for the radionuclides on the basis of the input concentrations and soil property, meteorological, and hydrological parameters. This particular feature of RESRAD was used in this benchmarking effort to generate a unit water concentration $(1 \mu \mathrm{Ci} / \mathrm{L})$ and to calculate the food concentrations from the contaminated irrigation water. In Seitz et al. (1994), the leaching factor for the GENII code was set to zero. In order to make the leaching effect negligible, the time since material placement parameter and the unsaturated zone thickness parameter used in the RESRAD code were tuned so that the leaching constant was 
small enough to match the setting in the other comparison, yet still yield valid distribution coefficients.

In Seitz et al. (1994), different plant transfer factors were used for leafy and nonleafy vegetables. In RESRAD, both types of plant food have the same transfer factors. The same situation applies to livestock fodder. In Seitz et al. (1994), different storage times and root uptake factors were used for fresh and stored fodder. In RESRAD, only one type of fodder is considered in each calculation. To generate comparable results, multiple RESRAD runs were performed with different input values for food consumption rates and livestock fodder consumption rates by using the corresponding transfer factors and storage times. The results were then summed to give total doses for comparison. The root uptake transfer factors used in the RESRAD code are the plant/soil concentration ratios for wet plants and dry soil. The transfer factors used in the GENII and PATHRAE codes are based on the ratio of dry plants to dry soil. The values used by Seitz et al. (1994) must be adjusted by the dry-to-wet ratios to comply with RESRAD's definition of the transfer factor.

Because the purpose of the Seitz et al. report (1994) is to compare the food transfer models rather than the environmental fate models, the number of input parameters required is far less than the total number of parameters used in the RESRAD code. In the comparison reported here, the same input values were used as in Seitz et al. (1994) whenever possible. For those parameters that were not used or specified in the report, the RESRAD default values were selected.

\section{A.2 RESRAD INPUT PARAMETERS}

The soil concentration for each of the radionuclides considered in this comparison was $666,667 \mathrm{pCi} / \mathrm{g}$. This value is equivalent to a soil concentration of $1 \mathrm{Ci} / \mathrm{m}^{3}$, with a soil density of $1.5 \mathrm{~g} / \mathrm{cm}^{3}$. The groundwater concentration for each of the radionuclides was $1,000,000 \mathrm{pCi} / \mathrm{L}$, which is equivalent to $1 \mu \mathrm{Ci} / \mathrm{L}$ as specified in Seitz et al. (1994). The time since material placement parameter was set to 300 years. The cover thickness was set to $0 \mathrm{~m}$. Erosion was not considered. The irrigation rate was $0.914 \mathrm{~m} / \mathrm{yr}$, which converts to $36 \mathrm{in./yr}$, as mentioned in Seitz et al. (1994). The precipitation rate was $0.11 \mathrm{~m} / \mathrm{yr}$. The runoff coefficient and evapotranspiration coefficient were set to the default values. The values of these parameters were not mentioned in Seitz et al. (1994); however, they are needed in the RESRAD code to derive the soil/water distribution coefficients. The thickness of the unsaturated zone parameter was set to $0.1 \mathrm{~m}$ after several trials with the time since material placement parameter to reduce the leaching effect. The input distribation coefficients for parent radionuclides were ignored by RESRAD during dose calculations because of the nonzero input groundwater concentrations. The distribution coefficients for progeny radionuclides were all set to $1.0 \times 10^{9} \mathrm{~cm}^{3} / \mathrm{g}$ so that the progeny groundwater concentrations were much smaller than their parent concentrations, and their contributions to the total doses were negligible. The derived $K_{d}$ values for parent radionuclides were $213.6 \mathrm{~cm}^{3} / \mathrm{g}$, and the leaching constants were $8.3 \times 10^{-3}(1 / \mathrm{yr})$. Table A.1 lists the groundwater concentrations for all radionuclides at time zero. Principal decay progeny (with. 
half-lives greater than 0.5 year) were Ac-227, $\mathrm{Pa}-231, \mathrm{~Pb}-210$, Th-229, Th-230, U-233, U-234, and U-235. Lead-210 is the decay progeny of Ra-226 and U-238. Its groundwater concentration of $8.5 \times 10^{1} \mathrm{pCi} / \mathrm{L}$ comes primarily from Ra-226. Uranium-233 is the decay progeny of $\mathrm{Np}-237$; its groundwater concentration is $1.21 \mathrm{pCi} / \mathrm{L}$. The progeny concentrations were all small compared to their parent concentrations $-1,000,000 \mathrm{pCi} / \mathrm{L}$. Their contributions to the total doses, as confirmed by the dose/source ratios for the water-dependent components of the plant, meat, and milk pathways in the detailed report generated by RESRAD, were negligible.

\section{Several RESRAD runs were} performed to simulate the conditions in Seitz et al. (1994). To use different root uptake transfer factors for plants and fodder, the plant, meat, and milk pathways cannot be considered simultaneously in a single run. Even for the plant pathway, two separate calculations have to be performed by RESRAD to consider different root transfer factors for leafy and nonleafy vegetables. Six input data files with their own databases were created to duplicate the exposure scenarios assumed in Seitz et al. (1994) (Table A.2 lists the input parameters). The first input data file (BENCH1.DAT) considered the external, inhalation, plant, and drinking water pathways. The inhalation rate was $8,500 \mathrm{~m}^{3} / \mathrm{yr}$. Mass loading factors were $0.0001 \mathrm{~g} / \mathrm{m}^{3}$ for both inhalation and foliar deposition. The exposed individual spent $100 \%$ of the time outdoors onsite. The plant consumption rates were $172 \mathrm{~kg} / \mathrm{yr}$ for fruits, vegetables, and grain, and $0 \mathrm{~kg} / \mathrm{yr}$ for leafy vegetables. The contamination fraction for plant food was $25 \%$. The root uptake factors for nonleafy vegetables in Seitz et al. (1994) were multiplied by a dry-to-wet ratio of 0.187 and used with BENCH1.DAT in the RESRAD calculation. The inhalation and ingestion internal dose conversion factors used in the RESRAD calculation were also from Seitz et al. (1994).

Table A.3 lists the input parameters used in BENCH1.DAT. The results generated by using this input data file are listed in Table A.4 for external radiation doses, in Table A.5 for inhalation doses, and in Table A.6 for drinking water doses and can be compared directly with GENII and PATHRAE results. The second input data file (BENCH2.DAT) used by RESRAD considered only the plant pathway. It had the same input parameters as BENCH1.DAT except that the plant consumption rates were $0 \mathrm{~kg} / \mathrm{yr}$ for fruits, vegetables, 
TABLE A.2 Input Parameters Used in the Seitz et al. 1994

Benchmarking Report

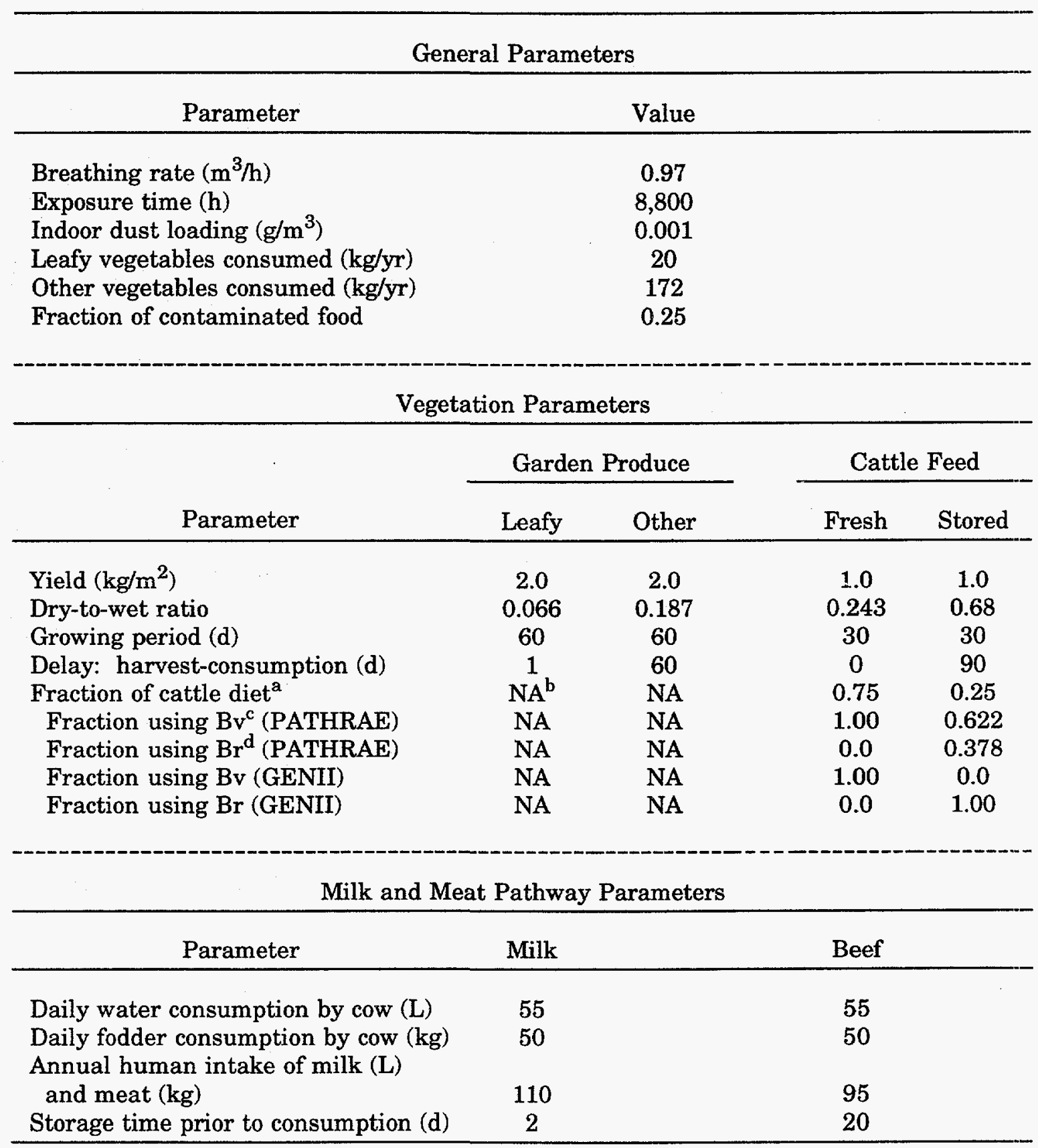

Source: Seitz et al. (1994).

a The cattle diet fractions are hardwired in the computer programs and cannot be changed by the user.

b $\mathrm{NA}=$ not applicable.

c $\mathrm{Bv}=$ soil-to-plant transfer factor for leafy vegetables (from PATHRAE).

d $\mathrm{Br}=$ soil-to-plant transfer factor for nonleafy vegetables (from PATHRAE). 
TABLE A.3 Input Parameters Used in BENCH1.DAT for RESRAD ${ }^{a}$

\begin{tabular}{|c|c|}
\hline Parameter & Value \\
\hline Area of contaminated zone $\left(\mathrm{m}^{2}\right)$ & 1,250 \\
\hline Thickness of contaminated zone (m) & 0.15 \\
\hline Time since placement of material (yr) & 300 \\
\hline $\begin{array}{l}\text { Initial principal radionuclide concentration (pCi/g) } \\
\text { for Co-60, Ni-59, Sr-90, Tc-99, I-129, Cs-137, Ra-226, } \\
\text { U-238, Np-237, Pu-239, and Am-241 }\end{array}$ & 666.667 \\
\hline $\begin{array}{l}\text { Concentration in groundwater (pCi/L) } \\
\text { for Co-60, Ni-59, Sr-90, Tc-99, I-129, Cs-137, Ra-226, } \\
\text { U-238, Np-237, Pu-239, and Am-241 }\end{array}$ & $1,000,000$ \\
\hline Cover depth $(\mathrm{m})$ & 0 \\
\hline Density of contaminated zone $\left(\mathrm{g} / \mathrm{cm}^{3}\right)$ & 1.5 \\
\hline Contaminated zone erosion rate $(\mathrm{m} / \mathrm{yr})$ & 0 \\
\hline Precipitation rate $(\mathrm{m} / \mathrm{yr})$ & 0.11 \\
\hline Irrigation rate $(\mathrm{m} / \mathrm{yr})$ & 0.941 \\
\hline Irrigation mode & Overhead \\
\hline Unsaturated zone thickness (m) & 0.1 \\
\hline \multicolumn{2}{|l|}{ Distribution coefficient $\left(\mathrm{cm}^{3} / \mathrm{g}\right)$} \\
\hline $\begin{array}{l}\text { for } \mathrm{Pb}-210, \text { Ac-227, Th-229, Th-230, Pa-231, U-233, } \\
\text { U-234, and U-235 }\end{array}$ & $1.0 \times 10^{9}$ \\
\hline Inhalation rate $\left(\mathrm{m}^{3} / \mathrm{yr}\right)$ & 8,500 \\
\hline Mass loading for inhalation $\left(\mathrm{g} / \mathrm{m}^{3}\right)$ & 0.0001 \\
\hline Fraction of time spent outdoors & 1.0 \\
\hline Fruit, vegetable, and grain consumption (kg/yr) & 172 \\
\hline Leafy vegetable consumption $(\mathrm{kg} / \mathrm{yr})$ & 0 \\
\hline Drinking water intake $(\mathrm{L} / \mathrm{yr})$ & 730 \\
\hline Contamination fraction of plant food & 0.25 \\
\hline Contamination fraction of drinking water & 1.0 \\
\hline Mass loading for foliar deposition $\left(\mathrm{g} / \mathrm{m}^{3}\right)$ & 0.0001 \\
\hline Depth of roots (m) & 0.15 \\
\hline \multicolumn{2}{|l|}{ Storage times of contaminated foodstuffs (d) } \\
\hline Fruits, nonleafy vegetables, and grain & 60 \\
\hline Leafy vegetables & 1 \\
\hline
\end{tabular}

a Default values were used for parameters not listed in this table.

and grain and $20 \mathrm{~kg} / \mathrm{yr}$ for leafy vegetables. The root uptake factors used in BENCH2.DAT were those for leafy vegetables in Seitz et al. (1994) multiplied by a dry-to-wet ratio of 0.066 . The plant ingestion doses for BENCH1.DAT and BENCH2.DAT were summed to give the total ingestion doses for the plant pathway and are given in Tables A.7 and A.8 for the water-independent and water-dependent components, respectively.

The radiation doses from ingestion of meat and milk were obtained from two separate runs. In the RESRAD input data files BENCH3.DAT and BENCH4.DAT, meat and milk ingestion were the only pathways considered. Most of the input parameters were the 
TABLE A.4 Comparison of External Radiation Doses (mrem/yr) from a Unit Soil Concentration $\left(1 \mathrm{Ci} / \mathrm{m}^{3}\right)$

\begin{tabular}{llllll}
\hline & & & & RESRAD/ & RESRAD/ \\
Radionuclide & RESRAD & GENII & PATHRAE & $\begin{array}{c}\text { GENII } \\
\text { PATHRAE }\end{array}$ \\
\hline Co-60 & $1.2 \times 10^{7}$ & $8.7 \times 10^{6}$ & $3.9 \times 10^{7}$ & 1.38 & 0.31 \\
Ni-59 & 3.7 & $1.5 \times 10^{2}$ & 0 & 0.02 & NC $^{\text {a }}$ \\
Sr-90 & 0 & $2.2 \times 10^{4}$ & 0 & 0 & NC \\
Tc-99 & 1.1 & $5.6 \times 10^{1}$ & 0 & 0.02 & NC \\
I-129 & $2.2 \times 10^{4}$ & $6.1 \times 10^{3}$ & $6.1 \times 10^{5}$ & 3.61 & 0.04 \\
Cs-137 & $2.9 \times 10^{6}$ & $2.1 \times 10^{6}$ & $1.1 \times 10^{7}$ & 1.38 & 0.26 \\
Ra-226 & $8.2 \times 10^{6}$ & $6.5 \times 10^{6}$ & $3.2 \times 10^{7}$ & 1.26 & 0.26 \\
U-238 & $7.3 \times 10^{4}$ & $8.3 \times 10^{4}$ & $1.3 \times 10^{6}$ & 0.88 & 0.06 \\
Np-237 & $9.8 \times 10^{5}$ & $8.1 \times 10^{5}$ & $1.3 \times 10^{7}$ & 1.21 & 0.08 \\
Pu-239 & $4.9 \times 10^{2}$ & $1.5 \times 10^{2}$ & $1.8 \times 10^{4}$ & 3.27 & 0.03 \\
Am-241 & $3.2 \times 10^{4}$ & $1.6 \times 10^{4}$ & $1.1 \times 10^{6}$ & 2.00 & 0.03 \\
\hline
\end{tabular}

a $\mathrm{NC}=$ not calculated.

TABLE A.5 Comparison of Inhalation Radiation Doses (mrem/yr) from a Unit Soil Concentration $\left(1 \mathrm{Ci} / \mathrm{m}^{3}\right)$

\begin{tabular}{llllll}
\hline Radionuclide & RESRAD & GENII & PATHRAE & $\begin{array}{c}\text { RESRAD/ } \\
\text { GENII }\end{array}$ & $\begin{array}{c}\text { RESRAD/ } \\
\text { PATHRAE }\end{array}$ \\
\hline Co-60 & $1.1 \times 10^{2}$ & $1.1 \times 10^{2}$ & $1.1 \times 10^{2}$ & 1.00 & 1.00 \\
Ni-59 & $6.7 \times 10^{-1}$ & $7.3 \times 10^{-1}$ & $7.1 \times 10^{-1}$ & 0.92 & 0.94 \\
Sr-90 & $1.1 \times 10^{2}$ & $1.2 \times 10^{2}$ & $1.2 \times 10^{2}$ & 0.92 & 0.92 \\
Tc-99 & 4.7 & $5.1 \times 10^{0}$ & $5.0 \times 10^{0}$ & 0.92 & 0.94 \\
I-129 & $7.9 \times 10^{1}$ & $8.6 \times 10^{1}$ & $8.4 \times 10^{1}$ & 0.92 & 0.94 \\
Cs-137 & $1.6 \times 10^{1}$ & $1.7 \times 10^{1}$ & $1.7 \times 10^{1}$ & 0.94 & 0.94 \\
Ra-226 & $4.3 \times 10^{3}$ & $4.7 \times 10^{3}$ & $4.6 \times 10^{3}$ & 0.91 & 0.93 \\
U-238 & $6.2 \times 10^{4}$ & $6.7 \times 10^{4}$ & $6.5 \times 10^{4}$ & 0.93 & 0.95 \\
Np-237 & $3.3 \times 10^{5}$ & $3.6 \times 10^{5}$ & $3.5 \times 10^{5}$ & 0.92 & 0.94 \\
Pu-239 & $2.3 \times 10^{5}$ & $2.5 \times 10^{5}$ & $2.4 \times 10^{5}$ & 0.92 & 0.96 \\
Am-241 & $2.3 \times 10^{5}$ & $2.5 \times 10^{5}$ & $2.5 \times 10^{5}$ & 0.92 & 0.92 \\
\hline
\end{tabular}

same as BENCH1.DAT except for a few parameters related to the meat and milk consumption. The annual milk consumption was $110 \mathrm{~L} / \mathrm{yr}$. The annual meat consumption was $95 \mathrm{~kg} / \mathrm{yr}$. Storage times were 2 days for milk and 20 days for meat. In BENCH3.DAT, the livestock fodder intake for meat and milk was $37.5 \mathrm{~kg} / \mathrm{d}$, and the livestock water intake for meat and milk was $55 \mathrm{~L} / \mathrm{d}$. Storage time for livestock fodder was not considered. The root uptake transfer factors were those for leafy vegetables in Seitz et al. (1994) multiplied by a dry-to-wet ratio of 0.243. In BENCH4.DAT, the livestock fodder intake for meat and milk was $12.5 \mathrm{~kg} / \mathrm{d}$, and the livestock water intake for meat and milk was $0 \mathrm{~L} / \mathrm{d}$. The storage time 
TABLE A.6 Comparison of Drinking Water Ingestion Doses (mrem/yr) from a Unit Water Concentration $(1 \mu \mathrm{Ci} / \mathrm{L})$

\begin{tabular}{lccccc}
\hline Radionuclide & RESRAD & GENII & PATHRAE & $\begin{array}{c}\text { RESRAD/ } \\
\text { GENII }\end{array}$ & $\begin{array}{c}\text { RESRAD/ } \\
\text { PATHRAE }\end{array}$ \\
\hline Co-60 & $2.0 \times 10^{4}$ & $1.9 \times 10^{4}$ & $1.9 \times 10^{4}$ & 1.00 & 1.00 \\
Ni-59 & $1.5 \times 10^{2}$ & $1.5 \times 10^{2}$ & $1.5 \times 10^{2}$ & 1.00 & 1.00 \\
Sr-90 & $9.9 \times 10^{4}$ & $9.7 \times 10^{4}$ & $9.6 \times 10^{4}$ & 1.02 & 1.03 \\
Tc-99 & $1.7 \times 10^{3}$ & $1.6 \times 10^{3}$ & $1.6 \times 10^{3}$ & 1.06 & 1.06 \\
I-129 & $1.9 \times 10^{5}$ & $1.8 \times 10^{5}$ & $1.8 \times 10^{5}$ & 1.06 & 1.06 \\
Cs-137 & $3.6 \times 10^{4}$ & $3.5 \times 10^{4}$ & $3.5 \times 10^{4}$ & 1.03 & 1.03 \\
Ra-226 & $7.2 \times 10^{5}$ & $7.0 \times 10^{5}$ & $7.0 \times 10^{5}$ & 1.03 & 1.03 \\
U-238 & $2.0 \times 10^{5}$ & $2.0 \times 10^{5}$ & $2.0 \times 10^{5}$ & 1.00 & 1.00 \\
Np-237 & $4.0 \times 10^{6}$ & $3.8 \times 10^{6}$ & $3.8 \times 10^{6}$ & 1.05 & 1.05 \\
Pu-239 & $2.7 \times 10^{6}$ & $2.6 \times 10^{6}$ & $2.6 \times 10^{6}$ & 1.04 & 1.04 \\
Am-241 & $2.7 \times 10^{6}$ & $2.7 \times 10^{6}$ & $2.7 \times 10^{6}$ & 1.00 & 1.00 \\
\hline
\end{tabular}

TABLE A.7 Comparison of Plant Ingestion Doses (mrem/yr) from a Unit Soil Concentration $\left(1 \mathrm{Ci} / \mathrm{m}^{3}\right)$

\begin{tabular}{lccccc}
\hline Radionuclide & RESRAD & GENII & PATHRAE & $\begin{array}{c}\text { RESRAD/ } \\
\text { GENII }\end{array}$ & $\begin{array}{c}\text { RESRAD/ } \\
\text { PATHRAE }\end{array}$ \\
\hline Co-60 & $1.1 \times 10^{3}$ & $1.1 \times 10^{3}$ & $1.1 \times 10^{3}$ & 1.00 & 1.00 \\
Ni-59 & $6.9 \times 10^{1}$ & $6.8 \times 10^{1}$ & $6.9 \times 10^{1}$ & 1.01 & 1.00 \\
Sr-90 & $2.5 \times 10^{5}$ & $2.4 \times 10^{5}$ & $2.5 \times 10^{5}$ & 1.04 & 1.00 \\
Tc-99 & $2.3 \times 10^{4}$ & $2.3 \times 10^{4}$ & $2.3 \times 10^{4}$ & 1.00 & 1.00 \\
I-129 & $7.6 \times 10^{4}$ & $7.6 \times 10^{4}$ & $7.5 \times 10^{4}$ & 1.00 & 1.01 \\
Cs-137 & $8.5 \times 10^{3}$ & $8.5 \times 10^{3}$ & $8.5 \times 10^{3}$ & 1.00 & 1.00 \\
Ra-226 & $1.1 \times 10^{4}$ & $1.1 \times 10^{4}$ & $1.1 \times 10^{4}$ & 1.00 & 1.00 \\
U-238 & $6.4 \times 10^{3}$ & $6.4 \times 10^{3}$ & $6.3 \times 10^{3}$ & 1.00 & 1.02 \\
Np-237 & $4.0 \times 10^{5}$ & $4.0 \times 10^{5}$ & $4.0 \times 10^{5}$ & 1.00 & 1.00 \\
Pu-239 & $2.0 \times 10^{3}$ & $1.2 \times 10^{3}$ & $1.2 \times 10^{3}$ & 1.67 & 1.67 \\
Am-241 & $1.0 \times 10^{4}$ & $9.1 \times 10^{3}$ & $9.3 \times 10^{3}$ & 1.10 & 1.08 \\
\hline
\end{tabular}

for fodder was 90 days. The root uptake transfer factors were those for nonleafy vegetables in Seitz et al. (1994) multiplied by a dry-to-wet ratio of 0.68. Results for BENCH3.DAT and BENCH4.DAT were summed to give the total doses (comparable to the GENII results) from meat and milk ingestion and are listed in Tables A.9 and A.10, respectively. The water-dependent components for the meat and milk pathways were compared with results from Seitz et al. (1994) since irrigation water was the only source for the meat and milk contamination. Another two input data files (BENCH5.DAT and BENCH6.DAT) were generated to obtain meat and milk ingestion doses comparable to the PATHRAE results. This was performed because in the PATHRAE code, different root uptake factors were used 
TABLE A.8 Comparison of Plant Ingestion Doses (mrem/yr) from a Unit Water Concentration ( $1 \mu \mathrm{Ci} / \mathrm{L})$

\begin{tabular}{lccccc}
\hline Radionuclide & RESRAD & GENII & PATHRAE & $\begin{array}{c}\text { RESRAD/ } \\
\text { GENII }\end{array}$ & $\begin{array}{c}\text { RESRAD/ } \\
\text { PATHRAE }\end{array}$ \\
\hline Co-60 & $2.8 \times 10^{3}$ & $2.9 \times 10^{3}$ & $2.9 \times 10^{3}$ & 0.97 & 0.97 \\
Ni-59 & $2.2 \times 10^{1}$ & $2.3 \times 10^{1}$ & $2.3 \times 10^{1}$ & 0.96 & 0.96 \\
Sr-90 & $1.4 \times 10^{4}$ & $1.6 \times 10^{4}$ & $1.6 \times 10^{4}$ & 0.88 & 0.88 \\
Tc-99 & $2.5 \times 10^{2}$ & $3.9 \times 10^{2}$ & $3.9 \times 10^{2}$ & 0.64 & 0.64 \\
I-129 & $2.6 \times 10^{4}$ & $2.8 \times 10^{4}$ & $2.8 \times 10^{4}$ & 0.93 & 0.93 \\
Cs-137 & $5.1 \times 10^{3}$ & $5.4 \times 10^{3}$ & $5.4 \times 10^{3}$ & 0.94 & 0.94 \\
Ra-226 & $1.0 \times 10^{5}$ & $1.1 \times 10^{5}$ & $1.1 \times 10^{5}$ & 0.91 & 0.91 \\
U-238 & $2.9 \times 10^{4}$ & $3.0 \times 10^{4}$ & $3.1 \times 10^{4}$ & 0.97 & 0.94 \\
Np-237 & $5.6 \times 10^{5}$ & $5.9 \times 10^{5}$ & $5.9 \times 10^{5}$ & 0.95 & 0.95 \\
Pu-239 & $3.8 \times 10^{5}$ & $4.0 \times 10^{5}$ & $4.0 \times 10^{5}$ & 0.95 & 0.95 \\
Am-241 & $3.8 \times 10^{5}$ & $4.1 \times 10^{5}$ & $4.1 \times 10^{5}$ & 0.93 & 0.93 \\
\hline
\end{tabular}

TABLE A.9 Comparison of Meat Ingestion Doses (mrem/yr) from a Unit Water Concentration $(1 \mathrm{\mu Ci} / \mathrm{L})$

\begin{tabular}{|c|c|c|c|c|c|c|}
\hline Radionuclide & RESRAD $^{a}$ & RESRAD $^{b}$ & GENII & PATHRAE & $\begin{array}{l}\text { RESRAD }^{\mathrm{a}} \\
\text { GENII }\end{array}$ & $\begin{array}{l}\text { RESRAD } / \\
\text { PATHRAE }\end{array}$ \\
\hline Co-60 & $2.3 \times 10^{4}$ & $2.3 \times 10^{4}$ & $4.0 \times 10^{4}$ & $4.1 \times 10^{4}$ & 0.58 & 0.56 \\
\hline $\mathrm{Ni}-59$ & $5.5 \times 10^{1}$ & $5.5 \times 10^{1}$ & $9.6 \times 10^{1}$ & $9.6 \times 10^{1}$ & 0.57 & 0.57 \\
\hline Sr-90 & $1.8 \times 10^{3}$ & $1.8 \times 10^{3}$ & $3.4 \times 10^{3}$ & $3.6 \times 10^{3}$ & 0.53 & 0.50 \\
\hline Tc-99 & $8.9 \times 10^{2}$ & $9.0 \times 10^{2}$ & $2.2 \times 10^{3}$ & $2.5 \times 10^{3}$ & 0.40 & 0.36 \\
\hline $\mathrm{I}-129$ & $7.8 \times 10^{4}$ & $7.8 \times 10^{4}$ & $1.4 \times 10^{5}$ & $1.4 \times 10^{5}$ & 0.56 & 0.56 \\
\hline $\mathrm{Cs}-137$ & $4.3 \times 10^{4}$ & $4.3 \times 10^{4}$ & $7.2 \times 10^{4}$ & $7.5 \times 10^{4}$ & 0.60 & 0.57 \\
\hline $\mathrm{Ra}-226$ & $1.1 \times 10^{4}$ & $1.1 \times 10^{4}$ & $1.8 \times 10^{4}$ & $1.9 \times 10^{4}$ & 0.61 & 0.58 \\
\hline U-238 & $2.4 \times 10^{3}$ & $2.4 \times 10^{3}$ & $4.0 \times 10^{3}$ & $4.2 \times 10^{3}$ & 0.60 & 0.57 \\
\hline $\mathrm{Np}-237$ & $1.3 \times 10^{4}$ & $1.3 \times 10^{4}$ & $2.3 \times 10^{4}$ & $2.3 \times 10^{4}$ & 0.57 & 0.57 \\
\hline Pu-239 & $8.0 \times 10^{1}$ & $8.0 \times 10^{1}$ & $1.4 \times 10^{2}$ & $1.4 \times 10^{2}$ & 0.57 & 0.57 \\
\hline $\mathrm{Am}-241$ & $5.7 \times 10^{2}$ & $5.7 \times 10^{2}$ & $9.8 \times 10^{2}$ & $9.8 \times 10^{2}$ & 0.58 & 0.58 \\
\hline
\end{tabular}

a RESRAD results were obtained by using leafy vegetable transfer factors for $100 \%$ fresh fodder and nonleafy vegetable transfer factors for $100 \%$ stored fodder.

b RESRAD results were obtained by using leafy vegetable transfer factors for $100 \%$ fresh fodder and $62.2 \%$ stored fodder and nonleafy vegetable transfer factors for $37.8 \%$ stored fodder. 
TABLE A.10 Comparison of Milk Ingestion Doses (mrem/yr) from a Unit Water Concentration (1 $\mathrm{\mu Ci} / \mathrm{L})$

\begin{tabular}{lcccccc}
\hline Radionuclide & RESRAD $^{\mathrm{a}}$ & RESRAD $^{\mathrm{b}}$ & GENII & PATHRAE & $\begin{array}{c}\text { RESRAD }^{\mathrm{a}} \text { / } \\
\text { GENII }\end{array}$ & $\begin{array}{c}\text { RESRAD }^{\mathrm{b}} \text { / } \\
\text { PATHRAE }\end{array}$ \\
\hline Co-60 & $2.7 \times 10^{3}$ & $2.7 \times 10^{3}$ & $4.8 \times 10^{3}$ & $4.7 \times 10^{3}$ & 0.56 & 0.57 \\
Ni-59 & $1.1 \times 10^{1}$ & $1.1 \times 10^{1}$ & $1.8 \times 10^{1}$ & $1.9 \times 10^{1}$ & 0.61 & 0.58 \\
Sr-90 & $1.0 \times 10^{4}$ & $1.0 \times 10^{4}$ & $1.9 \times 10^{4}$ & $2.1 \times 10^{4}$ & 0.53 & 0.48 \\
Tc-99 & $1.2 \times 10^{3}$ & $1.2 \times 10^{3}$ & $2.9 \times 10^{3}$ & $3.4 \times 10^{3}$ & 0.41 & 0.35 \\
I-129 & $1.3 \times 10^{5}$ & $1.3 \times 10^{5}$ & $2.2 \times 10^{5}$ & $2.3 \times 10^{5}$ & 0.59 & 0.57 \\
Cs-137 & $1.7 \times 10^{4}$ & $1.7 \times 10^{4}$ & $3.0 \times 10^{4}$ & $3.0 \times 10^{4}$ & 0.57 & 0.57 \\
Ra-226 & $2.3 \times 10^{4}$ & $2.3 \times 10^{4}$ & $3.8 \times 10^{4}$ & $3.9 \times 10^{4}$ & 0.61 & 0.59 \\
U-238 & $8.4 \times 10^{3}$ & $8.4 \times 10^{3}$ & $1.4 \times 10^{4}$ & $1.5 \times 10^{4}$ & 0.60 & 0.60 \\
Np-237 & $1.4 \times 10^{3}$ & $1.4 \times 10^{3}$ & $2.4 \times 10^{3}$ & $2.4 \times 10^{3}$ & 0.58 & 0.58 \\
Pu-239 & $1.8 \times 10^{1}$ & $1.8 \times 10^{1}$ & $3.2 \times 10^{1}$ & $3.2 \times 10^{1}$ & 0.56 & 0.56 \\
Am-241 & $7.5 \times 10^{1}$ & $7.5 \times 10^{1}$ & $1.3 \times 10^{2}$ & $1.3 \times 10^{2}$ & 0.58 & 0.58 \\
\hline
\end{tabular}

a RESRAD results were obtained by using leafy vegetable transfer factors for $100 \%$ fresh fodder and nonleafy vegetable transfer factors for $100 \%$ stored fodder.

b RESRAD results were obtained by using leafy vegetable transfer factors for $100 \%$ fresh fodder and $62.2 \%$ stored fodder and nonleafy vegetable transfer factors for $37.8 \%$ stored fodder.

for certain fractions of the stored fodder, and these diet fractions cannot be changed by the user. In BENCH5.DAT, the livestock fodder consumption rate was $4.725 \mathrm{~kg} / \mathrm{d}$, which was $37.8 \%$ of the consumed stored fodder; the water consumption rate was $0 \mathrm{~L} / \mathrm{d}$. The root uptake factors were the same as used in BENCH4.DAT. In BENCH6.DAT, the livestock fodder consumption rate was $7.775 \mathrm{~kg} / \mathrm{d}(62.2 \%$ of the consumed stored fodder), and the water consumption rate was also $0 \mathrm{~L} / \mathrm{d}$. The root uptake factors for leafy vegetables in Seitz et al. (1994) were multiplied by a dry-to-wet ratio of 0.68 and used in the RESRAD calculation. Results for BENCH3.DAT, BENCH5.DAT, and BENCH6.DAT were summed to give meat and milk (water-dependent component) doses comparable to the PATHRAE results. These results are given in Tables A.9 and A.10.

\section{A.3 RESULTS AND DISCUSSION}

Table A.4 compares the external radiation doses from the three computer codes. The GENII and PATHRAE codes took into account the ingrowth and decay of radionuclides within the one-year exposure period and calculated the accumulated doses. The RESRAD code also considered the ingrowth and decay of radionuclides and adjusted the soil concentrations at the calculation time periods. However, RESRAD does not integrate the radiation doses within the one-year exposure period; the radiation doses are assumed to be constant and to correspond to the soil concentrations at the beginning of the one-year period. To obtain the accumulated doses, decimal numbers can be entered at user-specified times, and then radiation doses at different times can be summed and averaged. The more time periods 
selected within the one-year duration, the better the average doses agree with the integrated doses. The RESRAD results listed in Table A.4 are averages of the radiation doses at $t=0 \mathrm{yr}$ and $t=1 \mathrm{yr}$. Radiation doses for $t=0 \mathrm{yr}$ and $t=1 \mathrm{yr}$ were about the same because all of the radionuclides considered have half-lives much greater than 1 yr except $\mathrm{Co}-60$, for which the radiation dose at $t=1 \mathrm{yr}$ was about $13 \%$ less than that at $t=0 \mathrm{yr}$. Because of the different methodologies used, the external doses from RESRAD, GENII, and PATHRAE, did not agree with each other; however, the RESRAD results were much closer to the GENII results than to the PATHRAE results.

The inhalation (Table A.5) and drinking water (Table A.6) doses compare very well among the three codes. The slightly smaller inhalation doses predicted by RESRAD were caused by the area factor, which with a value of 0.92 for an area of $1,250 \mathrm{~m}^{2}$ was used to adjust the radiation doses for the finite size of the contaminated area.

The plant ingestion doses (Table A.7) from a unit soil concentration agree very well among the three computer codes, except for Pu-239. The plant contamination comes from direct root uptake and foliar deposition of the airborne particulates. For all of the radionuclides excluding $\mathrm{Pu}-239$, the root uptake is the dominant source of contamination. For Pu-239, foliar deposition is more important since the root uptake transfer factors are small. The wet-weight crop yield, weathering removal constant, and growing period parameters used in the RESRAD foliar deposition model have hard-wired values and cannot be changed without modifying the source codes. These hard-wired parameters are different from those used by Seitz et al. (1994) and are the cause of discrepancies in the calculated doses, particularly for $\mathrm{Pu}-239$.

The plant food could become contaminated by irrigation water. This contamination is caused by direct deposition of radionuclides through overhead irrigation. The radionuclides are intercepted by plant leaves and then absorbed and transferred to the edible portion, or they are deposited in the soil phase with subsequent root uptake. These two components were taken into account by all three computer codes and, in fact, the models used by the three computer codes are very similar. For the soil deposition, the RESRAD methodology takes into account the leaching loss of the deposited radionuclides during the growing period and balances the soil deposition with the amount of radionuclides intercepted by foliage (Equation D.14, Yu et al. 1993). The effective surface density of soil and the growing period used for the soil deposition model are hard-wired in the RESRAD code. For the foliar deposition model, the growing period, weathering removal constant, and wet-weight crop yield are hard-wired numbers. Treatment of the irrigation rate differs among the three computer codes. In RESRAD, the annual irrigation water is assumed to be applied evenly throughout the year; however, in the GENII code, the irrigation water can be applied within the user-specified duration (six months was used by Seitz et al. [1994]). In this benchmarking study, the average annual irrigation rate of $36 \mathrm{in./yr}$ in Seitz et al. (1994) was used. For all of the radionuclides except Tc-99, foliar deposition is the dominant source for plant contamination. The radiation doses for plant ingestion (Table A.8) agree fairly well among the three codes. The close ratios between the RESRAD doses and the GENII (or PATHIRAE) doses for different radionuclides appear to be an aggregated effect of the hard-wired 
parameters and the irrigation rate. For Tc-99, which has large root uptake transfer factors, the root uptake contribution to the ingestion dose cannot be neglected. Therefore, the RESRAD/GENII (or RESRAD/PATHRAE) ratio also includes the effect from the effective surface density of soil.

Tables A.9 and A.10 compare the radiation doses of the meat and milk ingestion pathways resulting from a unit groundwater concentration $(1 \mu \mathrm{Ci} / \mathrm{L})$. The meat and milk cows ingest fodder irrigated by contaminated water and drink contaminated water directly. Therefore, except for the two sources (root uptake and foliar deposition) mentioned previously that contaminate fodder, the third source is the drinking water itself. The magnitude of influence on the radiation doses from the ingestion of drinking water was a little less than that from foliar deposition. Influence from the meat and milk transfer factors can be excluded since the RESRAD results were obtained by using the same numbers that Seitz et al. (1994) used. Using different root uptake factors rather than the same for all stored fodder does not significantly affect the results. The radiation doses predicted by RESRAD, as shown in the second and third columns of Tables A.9 and A.10, are almost identical. The close ratios for the different radionuclides are mainly an aggregated effect of the hard-wired parameters for the irrigation model.

\section{A.4 CONCLUSIONS}

The RESRAD results agreed very well with the GENII and PATHRAE results for inhalation and drinking water doses. The radiation doses for the plant, meat, and milk ingestion pathways also agreed favorably among the RESRAD, GENII, and PATHRAE codes. The differences were primarily caused by the hard-wired parameters in the RESRAD code (the values of which could not be changed unless the source code was modified) and the way the irrigation rate was treated among the three codes. Using the same values for the hard-wired parameters and the assumption that the irrigation water was evenly applied throughout the year, the RESRAD results should match those of GENII and PATHRAE even better. The comparisons confirmed that the food transfer models implemented in the RESRAD code are similar to those used in the GENII and PATHRAE codes. The major differences were observed in the external radiation doses because of the use of different methodologies. The RESRAD external doses agreed better with the GENII doses than with the PATHRAE doses.

Although the RESRAD code uses the same root uptake factors for different types of plants (leafy vegetables, nonleafy vegetables, and fodder) and considers only one type of fodder for meat and milk cows, more than one type of plant and fodder with different transfer factors can be simulated by RESRAD with multiple runs. The groundwater contamination at the beginning of the time period can be considered in the RESRAD code through the groundwater contamination input and the time since material placement parameter. However, caution should be taken to fine tune the time since material placement and the thickness of the unsaturated zone parameters to allow for derivation of a valid distribution coefficient while matching the assumed leaching condition. 


\section{A.5 REFERENCES}

Seitz, R.R., et al., 1994, Benchmarking of Computer Codes and Approaches for Modeling Exposure Scenarios, DOE/LLW-188, prepared by Idaho National Engineering Laboratory, EG\&G Idaho, Inc., Idaho Falls, Idaho, for U.S. Department of Energy, Washington, D.C.

Yu, C., et al., 1993, Manual for Implementing Residual Radioactive Material Guidelines Using RESRAD, Version 5.0, Working Draft, ANL/EAD/LD-2, Argonne National Laboratory, Argonne, $\mathrm{Ill}$. 